\title{
A LAND-BASED OIL SPILL MANAGEMENT PLANNING FRAMEWORK FOR THE PETROLEUM INDUSTRY
}

By: Natasha Michele Tang Kai,

Bachelor of Environmental Studies, York University, 1999

\author{
A Thesis
}

Presented to Ryerson University

In partial fulfillment of the requirement for the degree of

Master of Applied Science in the Program of

Environmental Applied Science and Management

TORONTO, ONTARIO, CANADA, 2005

(C) Natasha Michele Tang Kai 2005 
UMI Number: EC53585

\section{INFORMATION TO USERS}

The quality of this reproduction is dependent upon the quality of the copy submitted. Broken or indistinct print, colored or poor quality illustrations and photographs, print bleed-through, substandard margins, and improper alignment can adversely affect reproduction.

In the unlikely event that the author did not send a complete manuscript and there are missing pages, these will be noted. Also, if unauthorized copyright material had to be removed, a note will indicate the deletion.

\section{$\mathrm{UMI}$}

UMI Microform EC53585

Copyright 2009 by ProQuest LLC

All rights reserved. This microform edition is protected against unauthorized copying under Title 17, United States Code.

ProQuest LLC

789 East Eisenhower Parkway

P.O. Box 1346

Ann Arbor, Ml 48106-1346 
I hereby declare that I am the sole author of this thesis.

I authorize Ryerson University to lend this thesis to other institutions or individuals for the purpose of scholarly research.

I further authorize Ryerson University to reproduce this thesis by photocopying or by other means, in total or in part, at the request of other institutions or individualss for the purpose of scholarly research. 
Ryerson University requires the signatures of all persons using or photocopying this thesis. Please sign below, and give an address and date. 


\title{
ABSTRACT \\ A Land-Based Oil Spill Management Planning Framework For the Petroleum Industry
}

\author{
By: Natasha Michele Tang Kai
}

Environmental Applied Science and Management Master of Applied Science 2005, Ryerson University

Oil spill pollution efforts have historically focused on ocean-based oil spills and response has typically been reactive. Strategies to regulate and mitigate oil spills occur at all levels, internationally, nationally, and at the industry level. Absent is a strategy geared specifically to manage and mitigate land-based oil spills by the petroleum industry. To address this need, the objective of this study proposes a comprehensive oil spill management planning framework. It is comprised of five components, oil spill prevention, control, clean-up, and emphasis on the characterization and economic evaluation of oil spills. Land-based oil spills is a significant pollution problem largely due to a decaying pipeline infrastructure, which have escalated oil spill costs, volumes and frequencies. Using oil spill data collected at a petroleum company in Trinidad, statistical analyses and structural and non-structural concepts, adapted from Ontario's flood management approach, are applied to understand and mitigate oil spill events and costs. 


\section{ACKNOWLEDGEMENTS}

I would like acknowledge the following parties for their contributions.

- Ryerson University

- TTOil - Petroleum company used in case study

- Ministry of Energy and Energy Industries of Trinidad and Tobago

- Water Resources and Sewage Authority of Trinidad and Tobago

- Natural Science and Engineering Research Council (NSERC)

I would also like to thank my thesis supervisor Dr. James $\mathrm{Li}$ for his knowledgeable input and support in all phases of this project. The case study employed in this research, the following individual provided access to resources and expertise, Mr. Shyam Dyal, Ms. Marianne Hosein, Mr. Christopher Weeks, Mr. Jaipersad Roopchand and Mr. Carlisle De Bourg. 


\section{DEDICATION}

To my parents Glen and Angela, you always believe in everything I do or wish for, thanks for your loving support. To Nigel, thanks for your enduring commitment and support. 


\section{TABLE OF CONTENTS}

List of Figures

List of Tables. ...xii

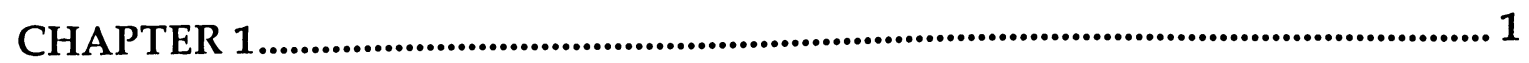

1.0 INTRODUCTION

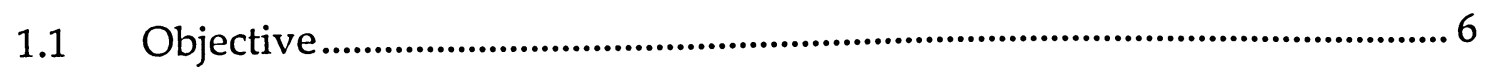

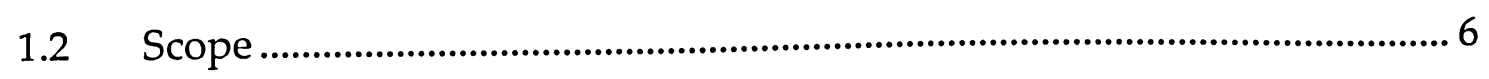

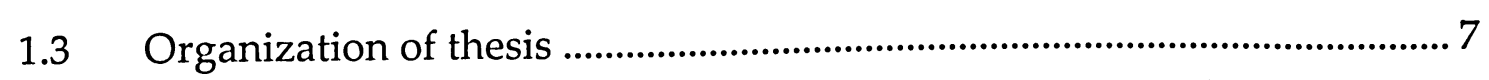

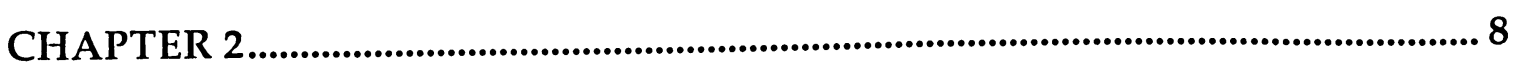

2.0 OIL SPILL MANAGEMENT PLANNING FRAMEWORK ........................... 8

$2.1 \quad$ Oil spill management planning framework ........................................... 12

CHAPTER 3 ........................................................................................................... 18

3.0 LITERATURE REVIEW ................................................................................. 18

3.1 Oil Spill Characterization......................................................................... 19

3.1.1 Spill reporting and reports ................................................................... 19

3.1.2 Magnitude of land-based oil spills ......................................................... 22

3.1.3 Oil spills from Exploration and Production............................................ 24

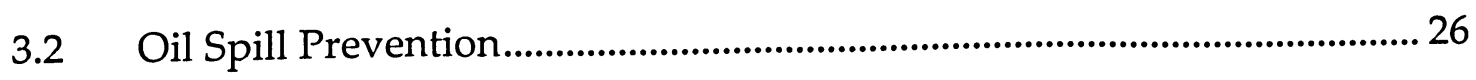

3.2.1 Oil spill regulations/conventions/protocols............................................. 27

3.2.2 Oil Spill Contingency planning ……………………………………...... 33

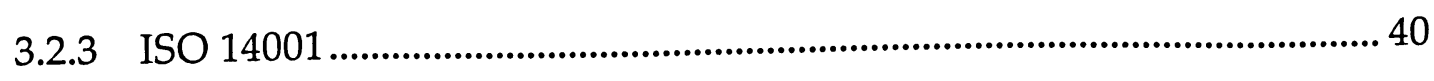

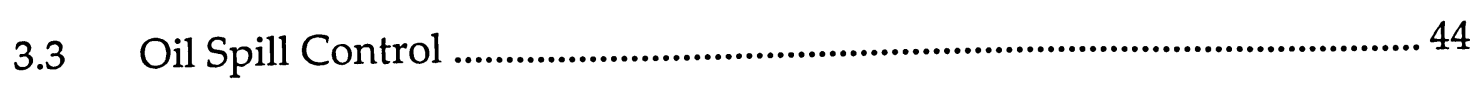

3.3.1 Oil spill containment before oil spill occurs (land-based oil spills).... 44

3.3.2 Oil Spill containment after a spill occurs (water-based oil spills)....... 49 


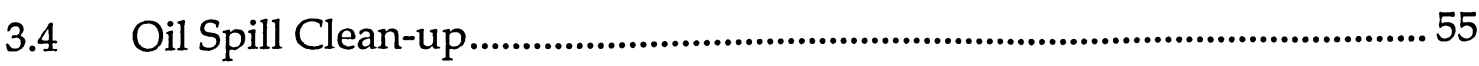

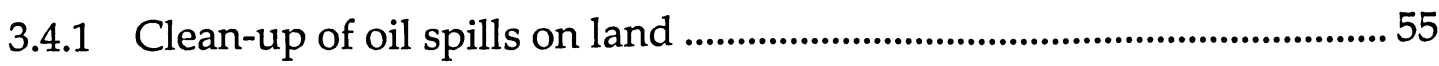

3.4.2 Clean-up of oil spills on water .................................................................... 59

3.5. Economic Evaluation ........................................................................................ 66

3.5.1 Factors that influence oil spill costs..........................................................6 67

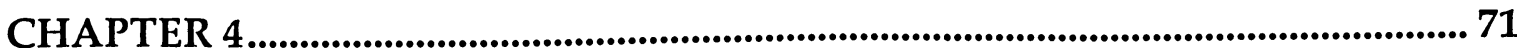

4.0 CASE STUDY: ANALYSIS OF OIL SPILLS AT TTOIL ............................ 71

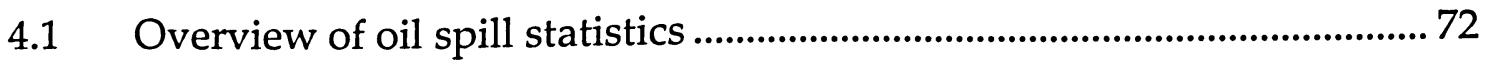

4.1.1 Oil Spill volume and frequency ................................................................. 72

4.1.2 Factors influencing oil spill volume and frequency.............................. 75

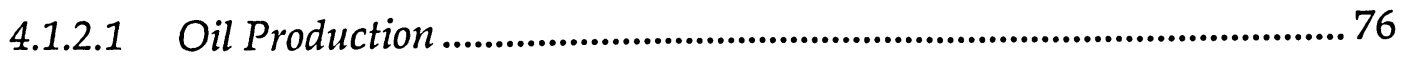

4.1.2.2 Oil Spill Causes and Reasons ................................................................... 77

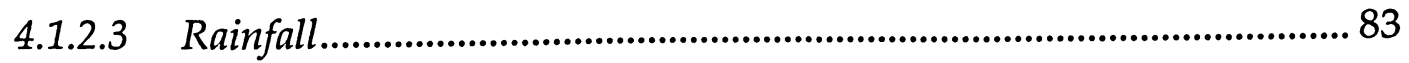

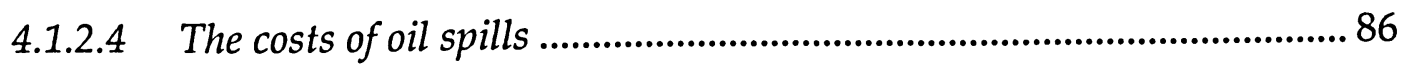

4.2 Analyses of oil spills at two oilfield districts ............................................... 91

4.2.1 Frequency of oil spill events..................................................................... 92

4.2.2 Frequency of oil spill events due to leaks and corrosion ...................... 94

4.2.3 Application of Ontario's "Flood Management Approach" .................. 97

4.2.4 Structural/non-structural controls suitable for petroleum industries 99

4.2.4.1 Application non-structural controls - District A................................. 100

4.2.4.2 Application structural controls -District A .......................................... 104

4.2.4.3 Application non-structural controls - District B ................................ 106

4.2.4.4 Application structural controls - District B ........................................ 107

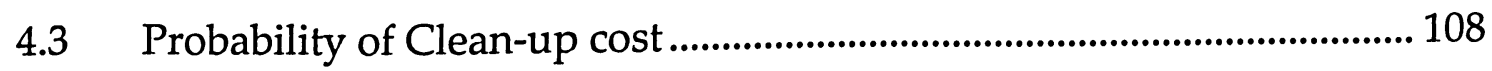

4.3.1 Probability of clean-up cost at district A ................................................ 108

4.3.2 Probability of clean-up cost at district B ................................................. 109 
CHAPTER 5

5.0 CONCLUSIONS AND RECOMMENDATIONS........................................ 110

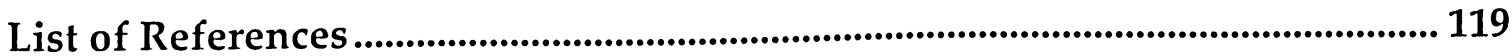

Appendix A: A detail description of the types of skimmers ..............................123

Appendix B: Types of habitats in Trinidad ...................................................... 126

Appendix C: Additional graphs and charts ........................................................ 128

Appendix D: Correlation results from 3 regression models.................................. 129

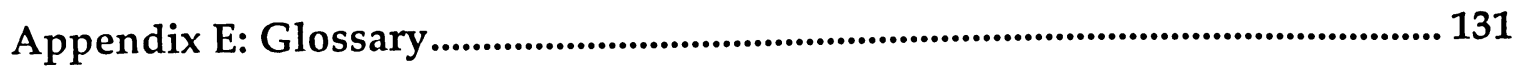

Appendix F: Description of oil spill data ........................................................... 134 


\section{List of Figures}

Figure 1: Map of Trinidad............................................................................................ 4

Figure 2: Oil Spill Management Framework.................................................................. 10

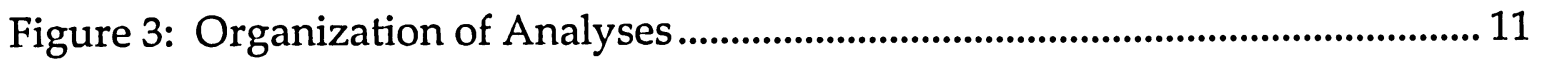

Figure 4: Worldwide total amount of oil spilled in decades .................................... 24

Figure 5: Worldwide annual oil spills from E \& P facilities ...................................... 25

Figure 6. Oil spill contingency plan framework.......................................................... 35

Figure 7. Tiered response in oil spill contingency planning...................................... 36

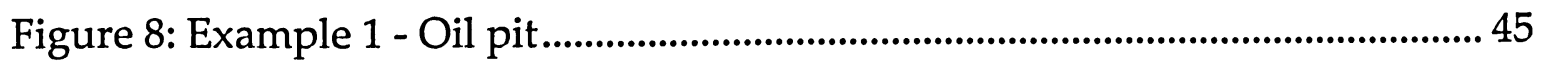

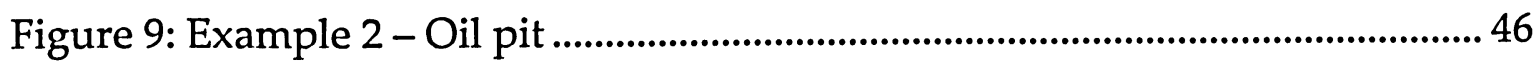

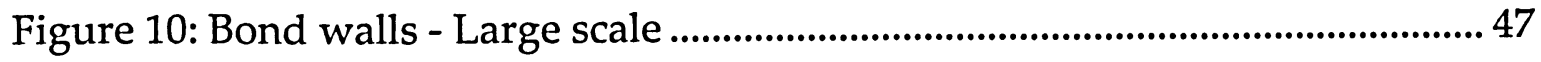

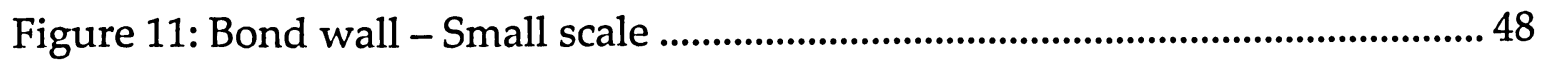

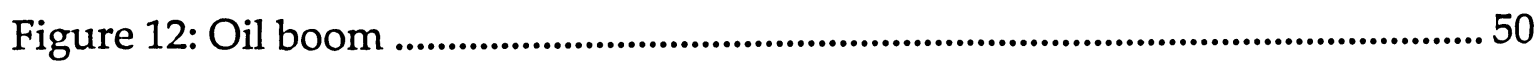

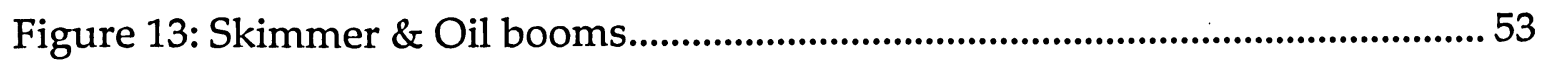

Figure 14: Distribution of oil spills (1995-2002) ......................................................... 73

Figure 15: Distribution of oil spills per year - District A ............................................. 74

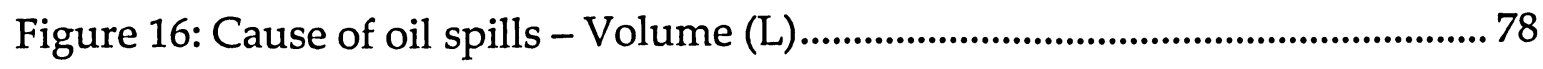

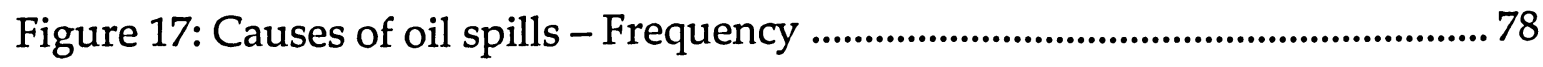

Figure 18: Reasons for oil spills - Volume (L) ............................................................... 81

Figure 19: Reason for oil spills - Frequency ..................................................................... 81

Figure 20: Average rainfall distribution at 5 rain gauge stations ............................ 84

Figure 21: Rainfall and oil spill frequency per month (1995-2002) .......................... 85

Figure 22: Distribution of oil spill costs (1995-2002) .................................................... 86

Figure 23: Average clean-up cost of the top 5 causes \& reasons of oil spills ......... 88

Figure 24: Correlation between average annual rainfall and clean-up cost........... 90

Figure 25: District A \& B: Frequency of oil spill event volume................................. 93

Figure 26: District A: Frequency of oil spill events - Corrosion \& Leaks................ 95 
Figure 27: District B: Frequency of oil spill events - Corrosion\& Leaks/Unknown

Figure 28. Implementation of non-structural measures to oil spills caused by human error - District A ......................................................................................... 103

Figure 29: Implementation of structural measures to oil spills occurring at well sites - District A..................................................................................................... 105

Figure 30. Probability of clean-up cost per year at districts A \& B - Damage Frequency 109 


\section{List of Tables}

Table 1: Typical annual oil spills to land and sea or navigable water in Canada... 2

Table 2: Number of Reported Spills in Seven Sectors in Canada.............................. 20

Table 3: Total quantity of reported spills in seven sectors in Canada (tonnes) .... 21

Table 4: Strategy and Operation Sections ......................................................................... 35

Table 5: Example of Environmental Management Programs within the EMS ..... 42

Table 6: Types of clean-up techniques/technologies for surface oil spills .............. 57

Table 7: Types of clean-up techniques/technologies for subsurface oil spills........ 58

Table 8: Typical Dispersant Effectiveness .......................................................................... 60

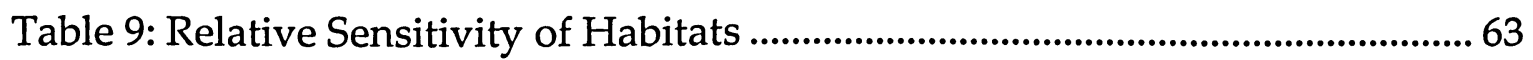

Table 10: Clean-up methods best suited for specific habitat types........................... 64

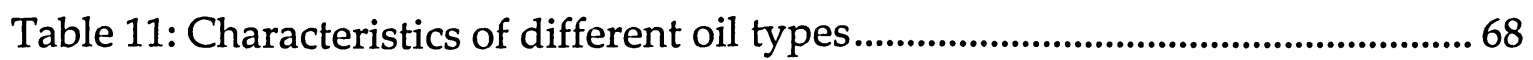

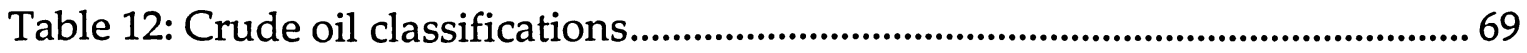




\subsection{INTRODUCTION}

Oil spills occur worldwide and their volume depends largely on the incidence of catastrophic spill events (Etkin 1999). Oil spills are typically accidental or from operational discharges. Accidental spills may occur in the transfer of oil at a local gas station or in a collision during the transport of oil either on land or at sea. Similarly, oil spills from operational discharges can occur from vessels during tank cleaning or oil contained in discharged ballast water (Lentz \& Felleman 2003). Other sources of oil spills include tankers, barges, land pipelines, fixed land facilities, storage tanks and oil exploration operations.

One of the major problems in oil spill management according to Lentz and Felleman, is that the focus of oil spills by the public, the media and many environmental organizations, occurs in response to major oil spill incidents, resulting in a largely reactive approach. Therefore, major initiatives to address oil spills with a few exceptions, have focused largely on spill clean-up and response measures, such as pre-booming and dispersant use (Lentz \& Felleman 2003). "Spill prevention", which refers to a proactive approach to prevent oil spills before they occur, is an essential component in oil spill management, one that has not received the attention it deserves (Lentz \& Felleman 2003).

Another issue in oil spill management is the fact that oil spills occurring in the marine environment have received much more media coverage and research efforts, when in reality, the amount of oil from vessels is often less than that spilled from pipelines, storage tanks, and other fixed facilities (Etkin 1999). Oil spill statistics worldwide suggest that oil spills from pipelines and other non- 
vessel sources, consistently spill oil more frequently than vessels, but usually in lower volumes per event (Etkin 1999). For example, in Canada more oil is spilled on land than sea or navigable waters. Table 1 illustrates these statistics.

Table 1: Typical annual oil spills to land and sea or navigable water in Canada

\begin{tabular}{|l|l|}
\hline Typical annual oil spills to Land & $80 \%$ by volume of oil spils \\
\hline Pipelines & $90 \%$ by actual number of oil spills \\
\hline Wells, batteries & $35 \%$ \\
\hline Storage depots, refineries & $24 \%$ \\
\hline Tank trucks & $17 \%$ \\
\hline Trains & $10 \%$ \\
\hline Industrial plants & $7 \%$ \\
\hline Other motor vehicles & $3 \%$ \\
\hline Service Stations & $2 \%$ \\
\hline Typicilannualo oil spills to Sea and & $2 \%$ \\
\hline Navigable waters & $20 \%$ by volume of oil spills \\
\hline Marine terminals / refineries & $10 \%$ by actual number of oil spills \\
\hline Bulk carriers & $32 \%$ \\
\hline Other watercraft & $26 \%$ \\
\hline Tankers & $23 \%$ \\
\hline
\end{tabular}

Source: Fingas, 2001

Table 1 indicates that significant oil spills occur from pipeline facilities; oil spill history further confirms that pipelines are a major source of oil spills. The reason is that nearly half of all pipeline oil spills are caused by structural problems such as corrosion, which can lead to consistent leaks or blowouts. The overall aging infrastructure, particularly pipelines, is a predominant problem for oil industries throughout the world. In most countries, this infrastructure was installed in the early to mid 1900s. Etkin states that part of this problem is that pipelines are subject to fewer regulations and inspections than vessels (1999). Hence, fewer actions are in place to replace damaged or old pipelines (Etkin 1999). In many 
developing nations such as Trinidad, the chronic problem of oil spill pollution is due in part, to an aging physical infrastructure, most notably the corrosion and decay of pipelines such as pumplines, flowlines, trunklines, testlines and gaslines. The definitions of these are provided in the glossary, Appendix E. The statistical oil spill data used in the case study are collected from a petroleum company in Trinidad called TTOil. The name TTOil is a pseudonym created for this study, the actual name of the petroleum company cannot be mentioned in any public document for confidentiality reasons.

Close to $90 \%$ of the world's oil production comes from the tropical zone, resulting in an increased potential for oil spill occurrences in this region (Nansingh \& Jurawan 1999). Oil spills here have a greater capacity to have disastrous impacts on the environment, as biological diversity is greater (NAS 1985). In the wider Caribbean region, Trinidad has been classified as a high-risk area for oil spills by the International Marine Organization (IMO) (Nansingh \& Jurawan, 1999). A threat to the environment from oil spill pollution exists for agricultural fields, rice fields, forested areas, freshwater ponds, wetlands, rivers and streams, mangrove forests, salt marshes, shorelines and freshwater swamps. The location of oilfields in close proximity to many of these environments poses an environmental threat in the event of an oil spill incident. Also, given the variability in sensitivity of each habitat, oil spilled in areas of high sensitivity such as mangrove forests, poses the greatest environmental threat, as reparation is slower or impossible in severe pollution circumstances.

Trinidad is the most southern island of the Caribbean, measuring $4,828 \mathrm{~km}^{2}$ and surrounded the Caribbean Sea to the north, the Atlantic Ocean to the east, the Caribbean Sea to the south and the Gulf-of-Paria to the west, as illustrated in 
Figure 1. It is also home to many oil and gas industries. One of the largest petroleum companies is TTOil, a company whose operations are largely landbased. Statistics indicate that on average, 345,000 liters of crude oil are spilled annually into the freshwaters, soil, diverse vegetation and urban areas.

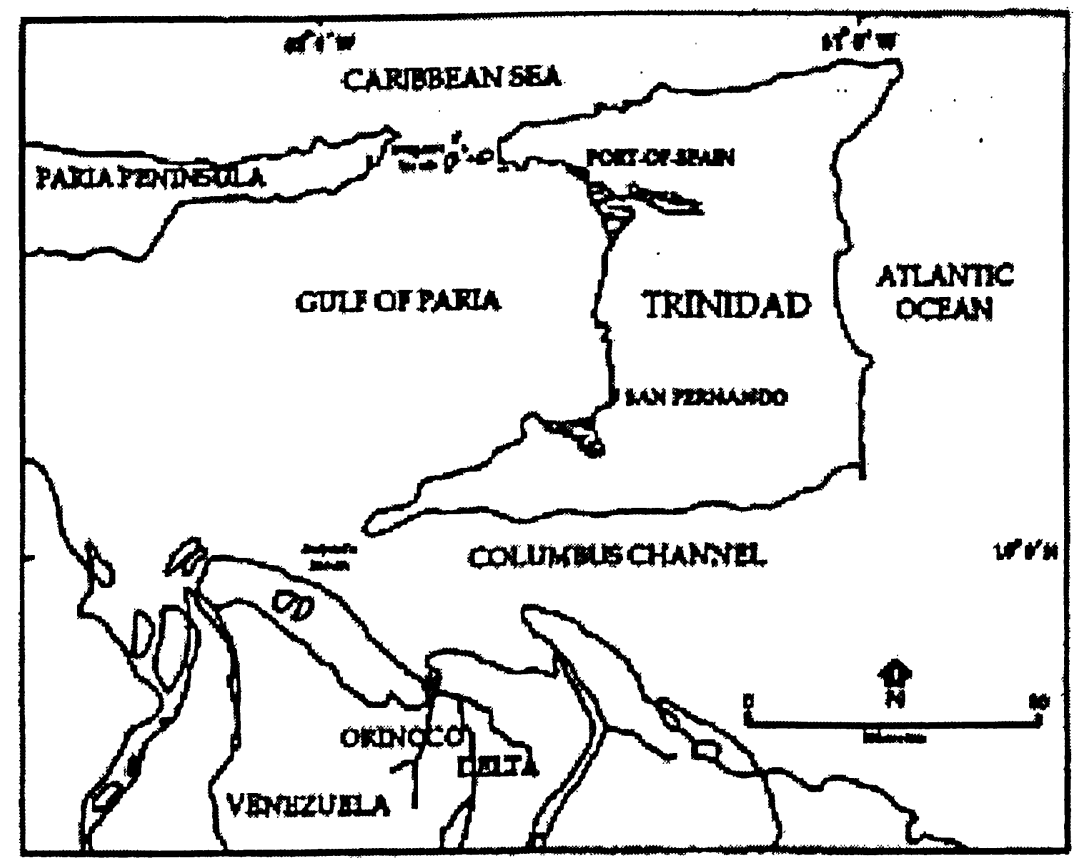

Figure 1: Map of Trinidad (Nansingh \& Jurawan, 1999)

TTOil is one of the oldest oil industries in the world, older than the industries in Venezuela and Saudi Arabia. Its exploratory drilling began in 1857, but commercial production started in 1908 with oilfields scattered throughout the southern portion of the island. Its refinery has a capacity to process 160,000 barrels of oil per day (bopd), of which approximately 70,000 come from local sources. This capacity is further satisfied with imports from Venezuela, Colombia, Brazil and West Africa. Local sources are expected to represent more than half of the refinery capacity in the near future. With a geographic advantage and proven reserves of 439.5 million barrels, oil production operations of TTOil will continue to thrive for many more years (TTOil, 2001). Oil spills from TTOil for the period 1995-2002 are used in the case study. 
The case study is one component of the study and its purpose is part of a larger research goal. The thesis proposes a comprehensive framework for oil spill management planning for petroleum industries, as no such framework has been formally developed for this sector. The framework establishes the components, through which oil spill dynamics can be understood, as well as the development of appropriate measures to mitigate or eliminate future oil spill frequency, volume, costs, and environmental impacts. Similar oil spill prevention tools or initiatives such as the ISO 14001. standard are available to industries who wish to improve their overall environmental management and performance. The proposed framework however, focuses on additional aspects of oil spill management, such as oil spill cost reduction, resulting in a more comprehensive oil spill management planning tool.

The proposed framework begins with a characterization of past oil spill data, followed by oil spill prevention initiatives, controls, clean-up efforts and an economic evaluation of the oil spill events. The oil spill characterization and economic evaluation incorporates oil spill statistics from TTOil and statistical analyses are performed to acquire knowledge about the factors that characterize and influence oil spill events and costs. Oil spill prevention, control and cleanup, the other three components of the framework, are addressed in the literature review.

This study promotes an informed approach to oil spill management planning, which can be used to improve environmental management and decision-making within the petroleum sector, in order to reduce and manage future oil spill events. The specific objective, scope and organization of the thesis are discussed in the next three sections of this chapter. 


\subsection{Objective}

The characteristics, economic impact and environmental impacts of land-based oil spills have received very little research effort and documentation has been inconsistent especially in the Caribbean. Studies conducted by Nansingh \& Jurawan for example, have focused on the characteristics and environmental impacts of oil spills to the coastal environment of Trinidad and Tobago, but none on the significance of land-based oil spills. In addition, there is no formal landbased oil spill management planning tool within the petroleum industry to specifically address oil spill pollution. To compensate for some of the gaps in oil spill research, the objectives of this study are:

- To propose a comprehensive land-based oil spill management framework for the petroleum industry

- To apply statistical analyses and concepts to quantify past oil spill data in order to derive useful information to improve oil spill management

\subsection{Scope}

The objective is a conceptual and quantitative approach to oil spill management. Based on these objectives, the scope of the study is:

- To describe the functions of each component of the proposed oil spill management planning framework

- To focus on two components of the oil spill management framework in detail through a case study, using oil spill data from TTOil to determine:

1. The factors that influence and characterize oil spill volume, frequency and cost.

2. The dynamics of oil spills at the oilfield level and apply flood management concepts to mitigate or eliminate future oil spill events 


\subsection{Organization of thesis}

The thesis is comprised of five chapters. Chapter 1 begins with an introduction of the research need, it provides and overview of the petroleum company used in the case study, and ends with the objective and scope of the study. The second chapter is typically the literature review, however, in this study, the focus of Chapter 2 is the oil spill management planning framework. It provides the structure of the thesis, in terms of the relevance and utility of each component in oil spill management plan. The literature reviews is addressed in Chapter 3. It describes the function of each component of the framework, using where applicable examples from TTOil. Chapter 4 is the case study. Oil spill data from TTOil are reviewed and statistically analyzed. This chapter is comprised of two sections, an overview of annual trends and factors that influence oil spill volume, frequency and costs during the period 1995-2002. The second section examines oil spill dynamics at the oilfield level. The return period for oil spill events and the probability of oil spill costs are discussed. Concepts derived from Canada's Flood Management Approach are applied to two oilfield districts, to demonstrate how oil spill cost can be reduced or eliminated. Finally, chapter 5 highlights the conclusions of the study, and ends with the recommendations based on the research findings. 


\subsection{OIL SPILL MANAGEMENT PLANNING FRAMEWORK}

In order to fulfill the objectives of the study, research was conducted on a macro and micro level. On the macro level, the research need identified that land-based oil spills had not been studied in depth as ocean-based oil spills, to allow for adequate oil spill management. To understand the actual dynamics of land-based oil spills, real data were required. Given the desire to pursue research in the Caribbean, a region where spill research is extremely limited, an opportunity was made available to study oil spills at a petroleum company in Trinidad and Tobago, a country rich in its capacity and utilization of petroleum reserves. A few months were spent at TTOil collecting oil spill data, conducting interviews with staff and related environmental agencies, and reviewing extensive in-house literature.

On a micro level, the research need was further refined to include a proposed oil spill management planning framework as it was discovered that no prior oil spill management system was available in the petroleum sector. Their resources typically focused on an operational framework, to include all pollution events. The proposed framework is specific to oil spills and incorporates five necessary elements to mitigate or eliminate the occurrence and impact of future oil spill events. The first is a characterization of oil spills followed by oil spill prevention, control and clean-up options, and an economic evaluation. Figure 2 illustrates the conceptual framework, and briefly defines how each component is addressed in this study. This framework forms the core of this study, as all subsequent chapters refer, and contribute to the knowledge required for the oil spill management plan. 
Given the comprehensiveness of the proposed oil spill management planning framework, every component of the framework could not be analyzed with the same level of detail. Two components, the oil spill characterization and economic evaluation are conducted in detail, using oil spill statistics collected from TTOil, this forms the case study. Figure 3 illustrates the organization of analyses used in the case study and how they relate to the oil spill management framework. The rest of this chapter provides an overview of the function of the oil spill management planning framework, and briefly describes the role and expectation of each component. 


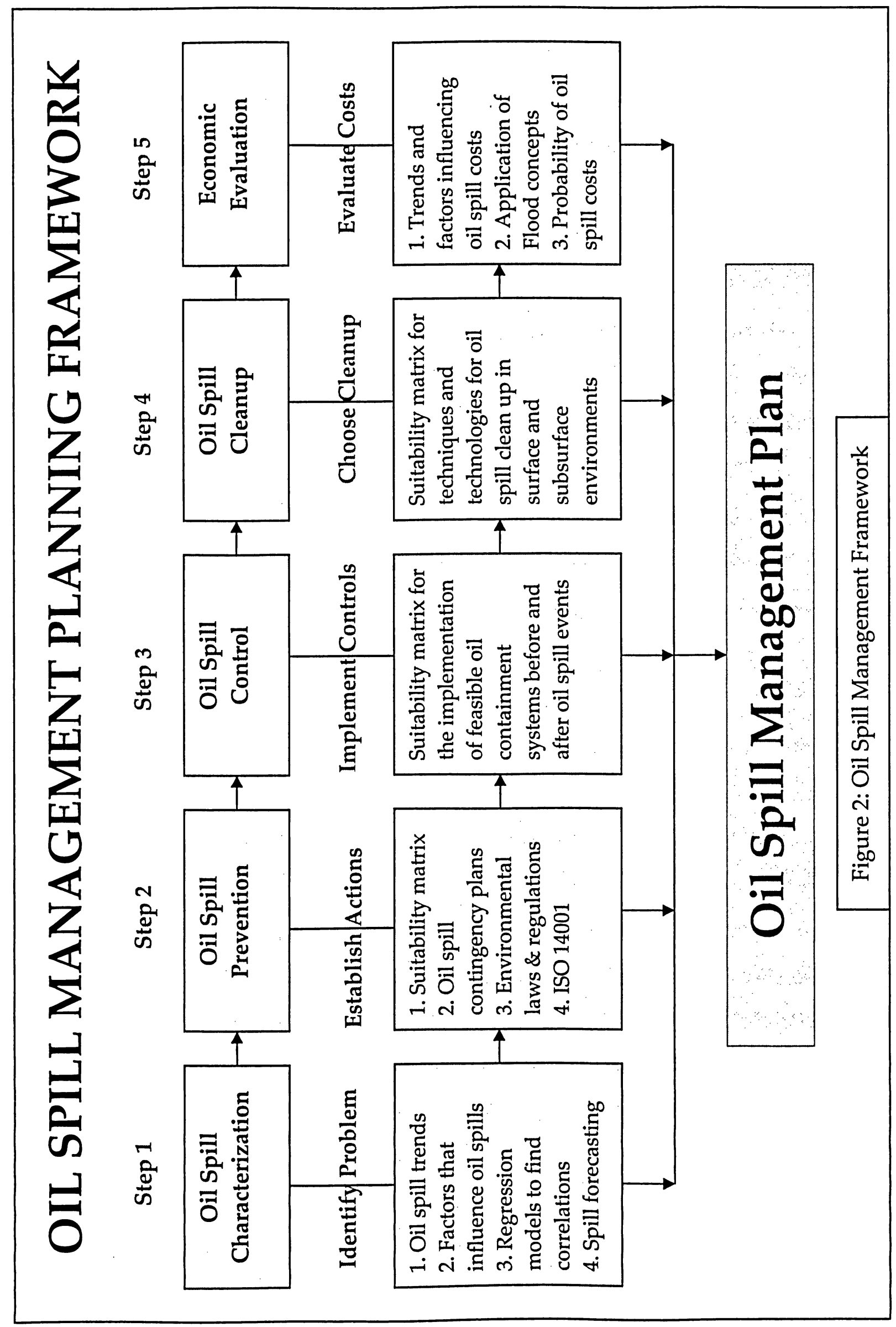




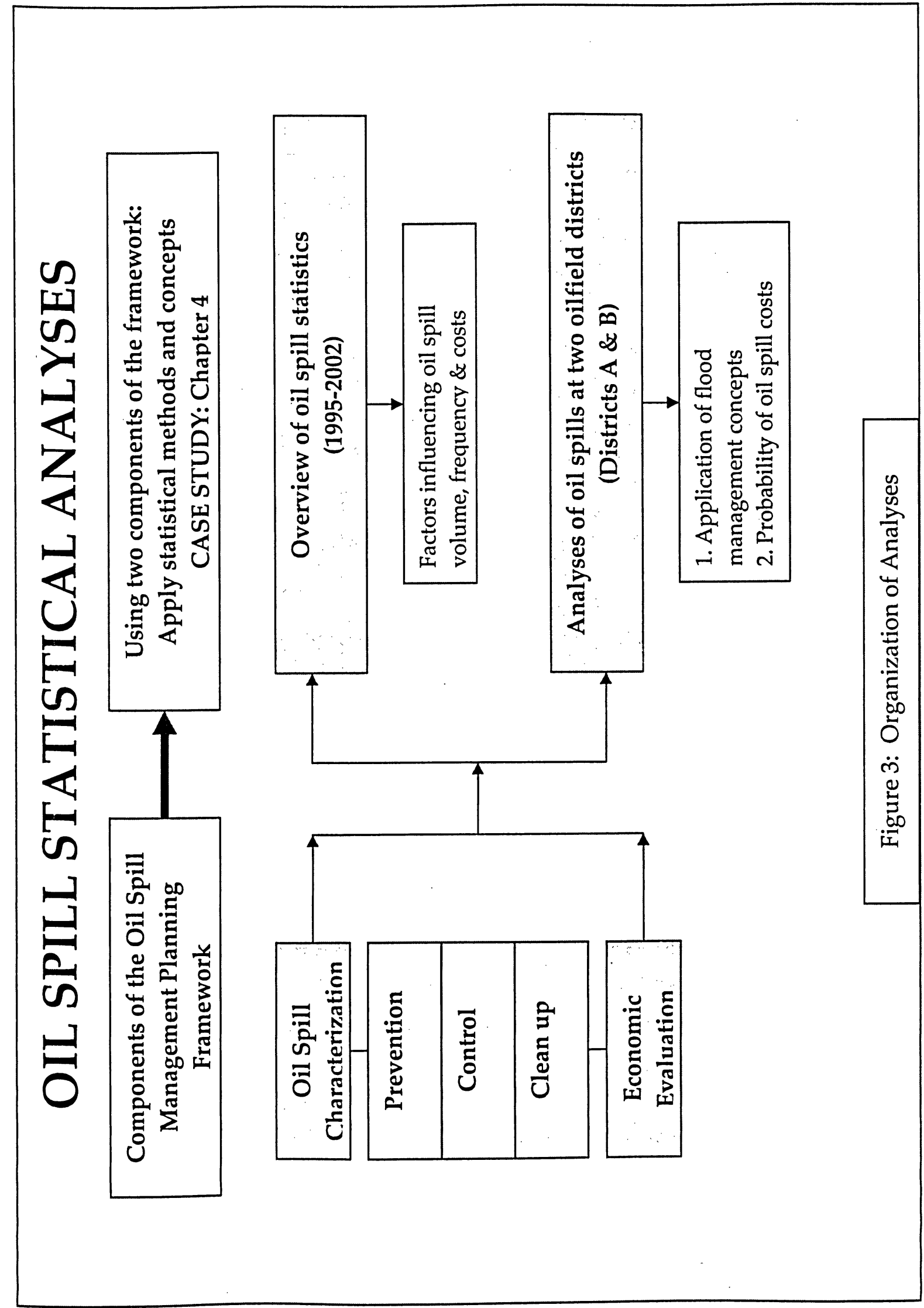




\subsection{Oil spill management planning framework}

Each component of the oil spill management framework is illustrated in the recommended sequence in which they should be considered. First, the oil spill characterization identifies the trends and the factors that influence oil spill events, this translates into the mobilization of appropriate oil spill prevention measures such as, the development of a suitability matrix to identify preferred prevention measures to target specific oil pollution sources. Other areas of oil spill prevention should include oil spill contingency planning, ISO 14001 certification, and adherence to applicable environmental laws. With or without preventative measures, oil spills are accidental in nature, oil spill controls are therefore necessary to contain the spilled oil into a predefined containment area. Depending on the capacity of the containment system, these controls oil from flowing into and contaminating adjacent environments. They can also reduce oil spill clean-up costs. This leads to the next component, oil spill clean-up. Clean-up measures are mobilized to reduce or eliminate harmful environmental impacts to the surface, subsurface and water environments. Unfortunately, cleaning a contaminated site does not always return the environment to its former ecological integrity, instead, remediation measures are required to rehabilitate the natural environment affected by oil pollution. Lastly, it is important to examine the cumulative cost of oil spills, which include the clean-up cost and compensation paid to external parties for damage to their property. Knowledge of the cumulative oil spill cost is an important consideration, and especially useful when encouraging polluters to develop comprehensive spill management plans.

The rest of this chapter provides and overview of the relevance and utility of each component of the oil spill management planning framework. 


\section{Oil Spill Characterization - Step 1}

The purpose of conducting this step is to determine the characteristics, the factors that influence, and the overall status of the oil spill pollution problem, in order to gain knowledge for future oil spill management planning. Some of the information that can be generated includes the identification of whether oil spill pollution is worsening or improving over time, the frequency and volume in which oil spills occur, the location of oil spill hot spots, and the factors that trigger oil spill events. This information can be determined using the following steps:

1. Examine oil spills from the entire data set to determine if any trends or patterns are apparent in daily, monthly and annual oil spill volume, frequency and costs.

2. Determine the primary causes and reasons for oil spills.

3. Establish the factors that influence oil spill volume, frequency and costs.

4. Using regression models, determine which variables exhibit strong correlations and are good predictors of oil spill volume, frequency and cost.

5. Oil spill volume, frequency and cost forecasting can be performed if good predictors of these variables are found. For example, if oil production significantly influences the frequency and volume of oil spills, based on known or anticipated future levels of production, future oil spill frequency and volume can be predetermined.

6. Calculate the return period of oil spill event volumes. This information is useful as it provides information about the likelihood of their re-occurrence, and oil spill volume expectancies.

7. Using the spatial and analytical capacity of a Geographic Information System (GIS), oil spill hot spots can be digitally mapped. This can be overlain with layers such as environmental sensitive habitats, land use and ecological layers, to establish possible treats to the environment. 
This is the first step in identifying the oil spill pollution problem in order to not only understand oil spill dynamics, but also to mobilize appropriate resources that target specific oil spill pollution problems. This leads to step 2-Oil Spill Prevention measures.

\section{Oil Spill Prevention - Step 2}

Oil spill prevention is probably the most important component of the oil spill management planning framework, as it encompasses the procedures, programs, standards, and policies of an environmental management system. "Prevention" measures as the name states, is focused on initiatives to prevent future oil spill events. The first step in oil spill prevention is the development of a suitability matrix listing oil pollution concerns. Paired with these concerns should be corresponding prevention efforts suitable and effective in mitigating, or eliminating specific pollution concerns. Oil spill prevention should also include oil spill contingency plans, which are guides for emergency procedures such as notifications and emergency equipment.

ISO 14001, an international environmental management standard, can also be a useful oil spill prevention tool; it encompasses comprehensive standards for environmental management. For example, it sets out the framework for policy development, to mobilizing operational programs and plans that define procedures such as, employee training, monitoring and reporting. It also incorporates a checking and corrective action component, and mandatory management review of operations and programs. This is done to ensure management intent is maintained, and continue to be effective in minimizing environmental impacts. Prevention measures should also heavily enforce required environmental laws and regulations into every component of oil spill management planning. With oil spill prevention measures in place, the development of oil spills control is the next step to mitigate or eliminate the oil spill pollution problem. This component is the third step of the framework. 


\section{Oil Spill Control - Step 3}

Oil spill controls are necessary measures designed to contain spilled oil, to reduce or eliminate potential environmental impacts, amount of oil lost, damages, and the costs associated with oil spills. A suitability matrix is useful as it prescribes the types of controls suitable for areas of pollution concern. Oil spill controls are available for spills both before and after they occur. Before an oil spill event occurs, pre-containment. involves the containment of spilled oil into built or confined areas. Post-containment measures contain oil using mechanical means or built environments such as berms. These controls most effective in reducing the cost of oil spills as all or a portion of discharged oil is contained. This reduces or alleviates all or part of oil spill costs, which can include clean-up costs, compensation costs and penalties. For oil spills that cannot be contained, several oil spill clean-up techniques and technologies are widely available. Oil spill clean-up is the next step in oil spill management planning; it is the forth step of the framework.

\section{Oil Spill Clean-up - Step 4}

Oil spill clean-up is a comprehensive topic, one that requires knowledge of environmental science and physical geography, in addition to oil spill clean-up methods. There are several oil spill clean-up techniques and technologies available for oil spills to water, surface and subsurface environments, each with their pros and cons. A suitability matrix is a useful tool, it prescribes the best technique or technology suited to the circumstances and environmental mediums affected by oil pollution. Each company should have a suitability matrix for each facility as different environmental mediums and circumstances may exist from one facility to the next. The key to selecting a clean-up method is one that yields maximum oil recovery with minimum negative impact to the environment. The cost of oil spill clean-up is dependant on a number of factors such as, the size of the oil spill, the type of oil, the amount of resources required, 
the environment affected, and the amount follow-up remediation measures needed. This cost combined with other associated costs of oil spills are addressed in step 5 - the economic evaluation.

\section{Economic Evaluation - Step 5}

There are three costs associated with oil spills. The first is the cost to clean-up and remediate an oil spill incident site, which includes expenditures on materials, equipment and labour. The second relates to the cost paid to external parties for damage to their property, which include assets such as livestock, crops and water systems. The third cost refers to legal entitlement owed to public agencies and/or international organizations, as a result of illegal pollution activities. These costs cumulatively can be significant. Since all industries have the same things in common to reduce expenditure, liability, increase profits, and improve environmental performance - the reduction of oil spills to minimize associated costs is an important goal of petroleum industries. Several steps can be taken to reduce or eliminate the cost of oil spills.

1. Establish the factors that influence oil spill costs such as, oil spill volume and weather conditions.

2. Determine the primary causes and reasons which inflate oil spill costs.

3. Using regression models, determine which variables are good predictors of oil spill costs.

4. Conduct oil spill cost forecasting if strong predictors of oil spill costs are found.

5. Apply the "Flood Management Approach", which make use of structural controls and non-structural measures to mitigate/eliminate oil spill costs.

6. Examine the probability oil spill costs, this information is useful for understanding the costs and extent of costs associated with oil spill volumes. 
The benefit of the oil spill management planning framework is that it is comprehensive; it targets a specific pollution issue, and addresses the various needs of that issue. The five steps can collectively improve oil spill management planning, as it provides specific information about oil spill pollution concerns and status. It highlights various prevention measures that can be integrated into an environmental management system. It describes oil spill controls, clean-up measures as well as the economic impacts, and attempts to find practical solutions to eliminate or mitigate oil spill costs. 


\section{CHAPTER 3}

\subsection{LITERATURE REVIEW}

The focus of this review is to explore literature and the company resources of TTOil related to the five components of the oil spill management planning framework. At the end of each section, the initiatives of TTOil are discussed to acquire an understanding of their current oil spill management practices. Firstly, aspects of the oil spill characteristics are addressed, to illustrate the status of oil spills from the petroleum sector in Canada and internationally. This is followed by an examination of the application of oil spill statistics to demonstrate their usefulness in oil spill management planning. Secondly, oil spill prevention measures are reviewed, and these include both oil spill national and international regulations/conventions/protocols, oil spill contingency planning and ISO 14001. Thirdly, oil spill controls are presented, these include oil spill containment before and after oil spills. Fourth, is the subject of oil spill clean-up measures, which examine various techniques and technologies available for oil spilled on surface and subsurface environments. Lastly, the factors that influence the costs of oil spills are explained. 


\subsection{Oil Spill Characterization}

Why is oil spill statistical analysis so important? According to one source, a spill of any size, regardless of its source can have significant adverse environmental impacts depending on seasonal timing, location, weather, and type of oil spilled; for this reason spill statistics should be used to form the basis for establishing the scope and magnitude of the problem (Lentz and Felleman 2003). The Canadian Petroleum Association (CPA) further states that spill statistics can help the petroleum industry identify potential spill sources and trends; programs can be implemented to prevent or mitigate the impacts of future spills and the potential for causing environmental damage (CPA, 1989).

In this study, the oil spill characterization makes use of past oil spill statistics to establish not only the scope and magnitude of the problem, but also to identify potential spill sources and trends, in the hope that the information can be used to implement future oil spill prevention programs and minimize the environmental impacts. Before the examination of oil spill data, the subject of data quality in oil spill reporting needs to be addressed, as well as the magnitude of the oil spill pollution problem from landbased upstream (E\&P) sources. Throughout this section, examples from TTOil will be provided.

\subsubsection{Spill reporting and reports}

Oil spill reporting is one of the most important components of an environmental management system; it provides useful information for a variety of purposes such as trend observations, policy formulation, and environmental enforcement and regulation. However, "spill statistics are only useful when spill reporting is mandatory and accurate" (CPA 1989). Spill statistics are commonly used by governing bodies and polluting organizations. Environment Canada for example, collects spill information 
through the National Pollution Release Inventory (NPRI) which receives reports from seven sectors - petroleum, chemical, government, metallurgy; mining, pulp \& paper, and the service sector. Environment Canada uses median oil spill values in their analyses. From their perspective, medians are a good measure of the central tendency of data sets that have very small values which are exceptions to the general situation; the median is one indicator of spill-reporting quality (Environment Canada 1998). If the median spill size is decreasing over time, a conclusion may be drawn that spill reporting is improving (Environment Canada 1998). Environment Canada statistics show that the petroleum and government sectors for the period 1984-1995 incurred the greatest number of reported spills. Table 2 illustrates the frequency of oil spills from the petroleum sector in juxtaposition to the six other sectors.

Table 2: Number of Reported Spills in Seven Sectors in Canada

\begin{tabular}{|c|c|c|c|c|c|c|c|}
\hline $\begin{array}{l}\text { YWe } \\
\text { Year } \\
y\end{array}$ & Chemical & $\begin{array}{l}\text { Why } \\
\text { Government } \\
\text { W }\end{array}$ & 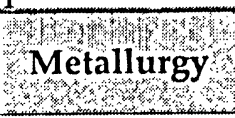 & Mining & 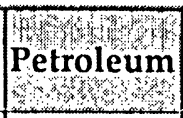 & $\begin{array}{l}\text { Pulp \& Paper } \\
\text { Pulp }\end{array}$ & $\begin{array}{l}\text { Service } \\
\text { Industry }\end{array}$ \\
\hline 1984 & 70 & 223 & 31 & 153 & 1831 & 38 & 94 \\
\hline 1985 & 130 & 200 & 58 & 83 & 2053 & 44 & 104 \\
\hline 1986 & 206 & 206 & 181 & 118 & 2398 & 73 & 157 \\
\hline 1987 & 179 & 228 & 139 & 124 & 2512 & 63 & 208 \\
\hline 1988 & 405 & 981 & 360 & 172 & 3021 & 148 & 281 \\
\hline 1989 & 582 & 1080 & 392 & 172 & 2971 & 224 & 346 \\
\hline 1990 & 588 & 1320 & 361 & 191 & 3157 & 312 & 408 \\
\hline 1991 & 552 & 1487 & 508 & 195 & 3139 & 291 & 434 \\
\hline 1992 & 667 & 1991 & 703 & 194 & 1144 & 340 & 427 \\
\hline 1993 & 754 & 1957 & 618 & 186 & 1531 & 371 & 456 \\
\hline 1994 & 784 & 2165 & 599 & 199 & 1577 & 458 & 464 \\
\hline 1995 & 534 & 2204 & 431 & 184 & 1642 & 353 & 484 \\
\hline Total & 5451 & 14042 & 4381 & 1971 & 26976 & 2715 & 3863 \\
\hline
\end{tabular}

Source: Found in Environment Canada, 1998 pp. 28.

The frequency of spills from the petroleum sector demonstrates a significantly higher number of spills than the other sectors. However, in comparison to its volume 
illustrated in table 3 , the petroleum sector only represents $6 \%$ of the total volume for all sectors over the 12-year period. In terms of spill volume consistency, next to the government sector, the petroleum spills demonstrate consistent, significant volumes each year, peaking once in 1989, beyond the consistent range of volumes. Other government agencies employ similar statistical analyses to understand oil spills, and in turn, use the information to enforce current environmental regulations, or update them as needed to reflect changes in levels of spills/emissions by the various sectors.

Table 3: Total quantity of reported spills in seven sectors in Canada (tonnes)

\begin{tabular}{|c|c|c|c|c|c|c|c|}
\hline 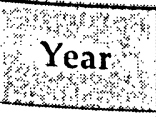 & Chemical & $\begin{array}{l}\text { Government } \\
\text { Govers }\end{array}$ & $\begin{array}{l}\text { Metalurgy } \\
\text { Mersurons }\end{array}$ & $\begin{array}{l}\text { Mining } \\
\text { Mong }\end{array}$ & Petroleum & $\begin{array}{l}\text { Pulp \& Paper } \\
\text { Pup }\end{array}$ & $\begin{array}{l}\text { Service } \\
\text { Industry }\end{array}$ \\
\hline 1984 & 1783 & 142556 & 4860 & 113078 & 72121 & 2948 & 433 \\
\hline 1985 & 12399 & 140820 & 314 & 16105 & 46029 & 35447 & 211 \\
\hline 1986 & 16160 & 11267 & 23923 & 29972 & 62232 & 28138 & 431886 \\
\hline 1987 & 17128 & 133863 & 87665 & 126939 & 89773 & 90608 & 616308 \\
\hline 1988 & 5498 & 58480 & 23497 & 6752 & $29 \leq 44$ & 26933 & 1115 \\
\hline 1989 & 7194 & 189169 & 51266 & 42899 & 120765 & 16322 & 228 \\
\hline 1990 & 6629 & 84194 & 79178 & 35247 & 50284 & 35845 & 310 \\
\hline 1991 & 1619 & 185449 & 32449 & 26172 & 43963 & 46491 & 5106 \\
\hline 1992 & 827 & 1386991 & 193435 & 58667 & 11164 & 25494 & 5625 \\
\hline 1993 & 1519 & 677529 & 1425753 & 12094 & 62725 & 35612 & 190 \\
\hline 1994 & 178 & 678622 & 27489 & 7262 & 18174 & 19751 & 197 \\
\hline 1995 & 325 & 1576576 & 11791 & 4783 & 18176 & 49224 & 763 \\
\hline Total & 71259 & 5265518 & 1961620 & 479969 & 624852 & 412814 & 1062374 \\
\hline
\end{tabular}

Source: Found in Environment Canada, pp.29, 1998

\section{Oil spill reporting TTOil}

Most oil spills events occur during exploration and production operations. These are field facilities where oil is drilled and pumped at its source and piped through extensive pipeline operations to various storage and testing facilities. Exploration and production operations do not include the oil refining processes. Oil spill statistics for TTOil have been collected for almost ten years; however oil spill reporting in the earlier years was 
inconsistent, resulting in huge gaps in observations. The most comprehensive data are available for the period 1995-2002. A detailed examination of these data have revealed inconsistencies in data reported for various oilfield districts, resulting in gaps in the data and subsequent deficiencies in analyses, some of which are discussed in Chapter 4. However, based on available information, best efforts are made to conduct statistical analyses. The results attained provide general clues about the factors that contribute to oil spill occurrences and probable oil spill expectations.

\subsubsection{Magnitude of land-based oil spills}

Two of the primary variables given consideration in oil spill analyses are the cause and reason. The cause of a spill answers the question, "What went wrong", while the reason for an oil spill explains "Why it went wrong" (Environment Canada, 1998). Oil spill statistics in Canada and in many countries worldwide indicate the three primary reasons for oil spills within the petroleum sector are corrosion, equipment failure and human error. Similarly, the three main causes for oil spills starting with the most common cause, are pipeline leaks, followed by unknown causes, indicating a need for better follow-up as the cause or reason for these spill are often not known until after the spill is reported (Environment Canada 1998). Lastly, valve fitting is the third largest cause of oil spills in the petroleum sector. Knowledge of these sources of statistical information is important, and according to the Canadian Petroleum Association, statistics on oil spill reasons and causes have helped industry to focus on preventative measures in specific areas (CPA 1989).

The two main causes and reasons for oil spill deserve greater attention as these two categories provide the impetus for improved current and future oil spill preventative measures. In the US for example, over nine million gallons of spilled oil are from landbased sources such as pipelines, storage facilities, fixed industrial facilities, air transport 
facilities, railways and motor vehicles (Etkin 2001). Etkins further elaborates that US pipeline oil spills in particular, in 1985 alone, spilled more oil than tankers and barges combined (the two largest sources of oil spills). She indicates that since 1991, pipeline spills have annually accounted for 37 times as much as tankers (Etkins 2001). Pipelines transport oil across several miles in the US, with- $69.3 \%$ of all oil transported by this medium (Etkins 2001). Several reports emphasize the cause for these pipeline leaks as a global aging pipeline infrastructure. With this aging pipeline infrastructure, pipelines become corroded, this translates into leaks if they are not replaced or maintained on a regular basis. This aging pipeline and facility infrastructure problem, as well as aging vessel fleets, may be "ticking time bombs" especially as they become subjected to increasing oil throughput and transport in future years (Etkin 2001).

\section{Causes and Reasons for oil spills at TTOil}

The typical reasons for oil spills at TTOil are similar to the findings from Environment Canada, where the top three reasons are corrosion, leaks and unknown reasons. The unknown reasons as mentioned are a result of improper oil spill follow-up reporting, as the reason for spills is often not known until after the spill is reported. The primary cause for oil spills from pipelines at TTOil consists of pumplines, trunklines, gaslines, testlines and flowlines (see Appendix E for definitions). Tanks and valves are the second and third most common causes of oil spills. The recognition of pipelines as the major source of oil spills has resulted in a recent plan to repair and replace some of the aging pipeline infrastructure. Given that this is a costly endeavor, a phased approach will occur over a period of approximately 20 years (TTOil, 2003). Details of this initiative and other preventative measures, are discussed in further detail in the oil spill prevention section. 


\subsubsection{Oil spills from Exploration and Production - (E\&P, Upstream processes)}

Pipeline oil spills fall into the category of E\&P as pipelines transport oil from an area of exploration to refinery facilities where they are fractioned into refined products such as gasoline and kerosene. Worldwide statistics reveal offshore oil and gas exploration, and production spills in particular, account for 27,000 and 111,000 tonnes of oil spilled each year (Lentz and Felleman 2003). Figure 4 illustrates the amount of oil from worldwide exploration and production activities per decade, while Figure 5 further elaborates on the amount of oil spilled per year from these facilities alone. Oil spills from TTOil's exploration and production land-based activities are addressed later in chapter 4.

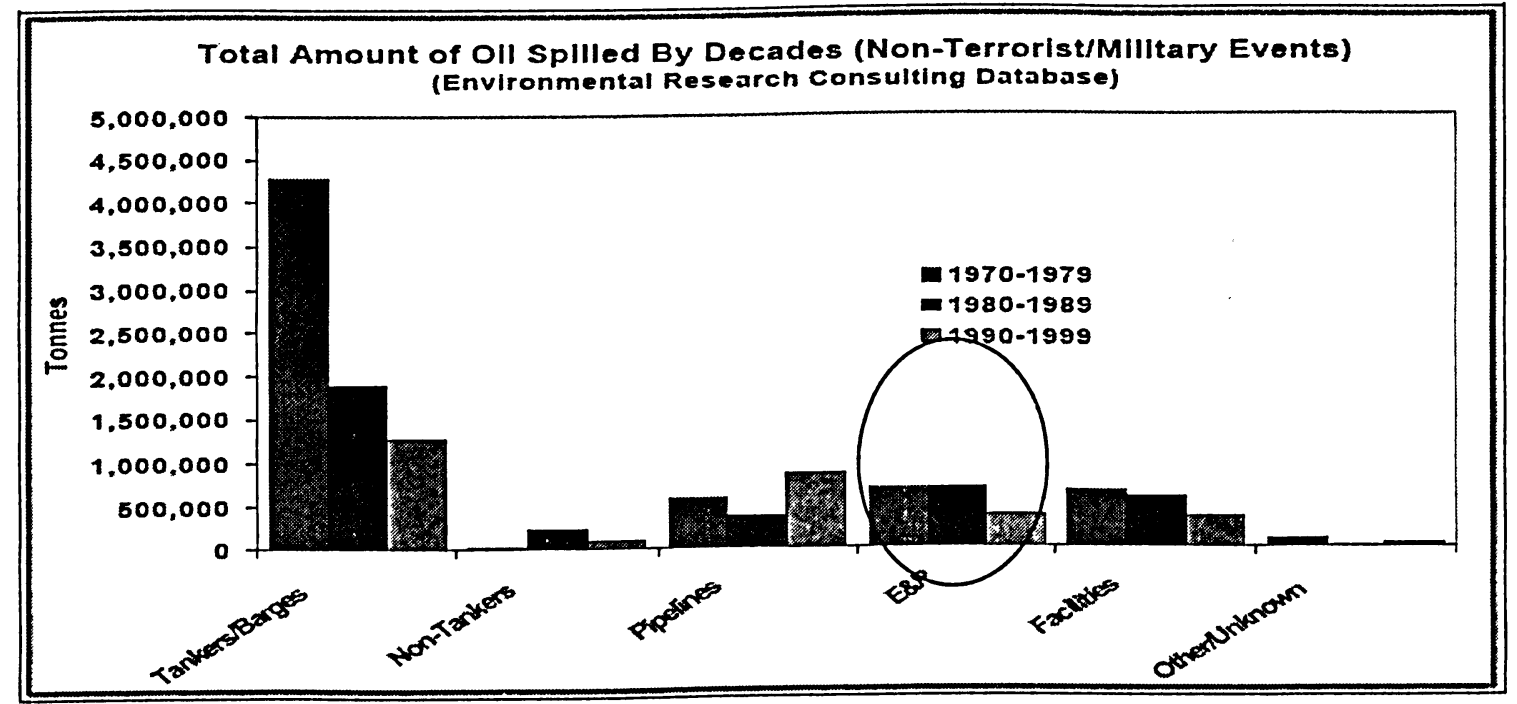

Figure 4: Worldwide total amount of oil spilled in decades (USCG 2001) 


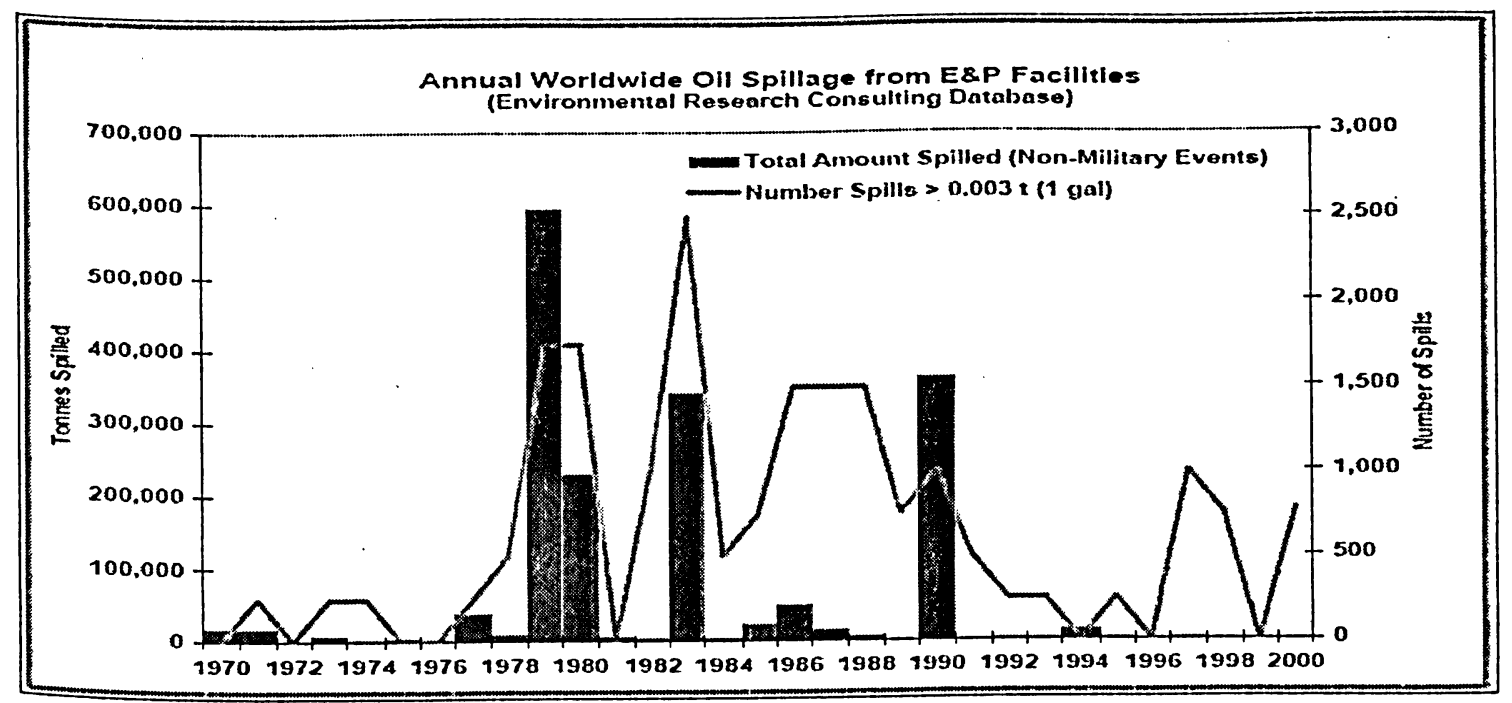

Figure 5: Worldwide annual oil spills from E \& P facilities (USCG 2001)

The general trend in Figure 5 demonstrates that in most recent decades, oil spills are decreasing. This could be attributed to a number of initiatives such as improved oil spill reporting, infrastructure improvements, including improved oil spill prevention through contingency planning and tighter regulations. Spills from E\&P sources still represent a significant worldwide frequency and volume, and greater efforts to reduce oil spills in this category are vital.

The literature thus far has revealed that oil spill statistics are useful for a number of reasons, but its best use is as a tool for understanding the scope and magnitude of the pollution problem. They are also used by many government agencies to establish and enforce environmental regulation, however, their use in the petroleum sector is not known. The task at hand therefore, is not only to use oil spill statistics as a tool for understanding oil spill dynamics, but also as a tool for implementing appropriate future spill prevention and control programs, which can minimize oil spill volume, frequency, costs and environmental impacts. 


\subsection{Oil Spill Prevention}

Given the worldwide magnitude of oil spills from offshore or onshore operations, oil spill prevention is a priority for petroleum industries. Oil spills are liabilities to petroleum companies which can result in significant costs, environmental impacts or even pose a risk to public health and safety. The petroleum industry in Canada for example, spends millions of dollars each year to ensure its drilling, production, operations and transportation systems are in compliance with existing regulations and facilities are operated as efficiently and safely as possible (CPA 1989). Oil industries must therefore be prepared to use proper construction and operational procedures along with adequate maintenance, inspection and training programs if prevention is to be attained (CPA 1989).

Some oil spill prevention efforts common to all petroleum industries include oil spill contingency planning, adoption and adherence to spill laws and regulations, as well as the implementation of ISO 14001. In this study, these will be discussed and examples of oil spill prevention methods and efforts at TTOil are discussed. 


\subsubsection{Oil spill regulations/conventions/protocols}

There are many levels of oil spill regulations, ocean spills for the most part follow international conventions/protocols. Oil spills on land generally follow national regulations governed by the country or state.

\subsubsection{Intemational Conventions/Protocols for oil spills}

The goal of international conventions is to foster international cooperation in constructing effective preparedness and response regimes both nationally and with bordering nations (Steen et. al 2003). Several agencies have conventions/protocols for the protection of marine resources in particular, from oil spill pollution, some of which include: The Institute of Marine Affairs (IMO), United Nations Environment Program (UNEP), the United Nations Industrial Development Organization (UNIDO), the International Petroleum Industry Environmental Conservation Association (IPIECA) and the International Tanker Owners Pollution Federation (ITOPF).

Some of the conventions overseen by the above governing agencies are:

1. International convention on Oil Pollution Preparedness, Response, and Cooperation (OPRC) is designed primarily to assist developing countries to prepare for, and respond to, major oil pollution incidents (not only from ships but also from offshore oil exploration and production platforms, sea ports and oil handling facilities)

2. The international Convention for the Prevention of Pollution from Ships (MARPOL). As the name states, this convention is aimed at preventing and minimizing pollution from ships, including both accidental pollution and release from routine operations.

3. 1992 Protocol to the International Convention on Civil Liability for Oil Pollution Damage, 1969 (CLC 92). This protocol provides information about compensation 
for pollution damage resulting from spills of persistent oil from laden and unladen tankers. The definition of pollution damage extends to preventative measures (this includes clean-up activities), property damage, economic loss and environmental restoration (IPIECA 2001)

4. Additionally, under the auspices of the United Nations Environment program (UNEP), the Convention for the Protection and Development of the Marine Environment of the Wider Caribbean Region, (Cartegena de Indias, 1983) addresses the problem of land-based sources of marine pollution (Lentz and Felleman 2003).

\subsubsection{Canadian Environmental Legislation and Regulations}

Given the tiered government structure of Canada, each level of government enforces regulations to maintain the integrity of the natural environment and to prevent any adverse effects by spills from toxic or hazardous substances (Li, 2002). The federal and provincial government enforces spill management through the Canadian Environmental Protection Act (CEPA), the Canada Shipping Act and the Emergency Plans Act. Spill management in Ontario exists through the Environmental Protection Act and the Ontario Water Resources Act, while the municipal government utilizes bylaws. The role of each level government in spill management is addressed in the following sections.

Municipal Spill Management: City of Toronto's Sewer Use By-Laws

Pollution prevention planning requirements are incorporated into the Sewer Use ByLaw as most of Toronto's spills enter municipal sewers before reaching rivers and lakes. This by-law requires pollution prevention planning by industries discharging subject pollutants. 
- Chapter 681-9 stipulates that the person responsible or the person having the charge, management, and control of the spill, immediately notify the Commissioner and provide any information with regard to the spill. The person shall do everything reasonably possible to contain the spill, protect the health and safety of citizens, minimize damage to property, protect the environment, clean up the spill and contaminated residue, and restore the affected area to its condition prior to the spill. The person shall provide a detailed report on the spill to the Commissioner within 5 days after the spill. Industries at whose premises a spill has occurred have to submit an updated plan and plan summary to the Commissioner within 30 days of the spill $(\mathrm{Li}, 2002)$

- Chapter 681-10 stipulates that every owner or operator of a restaurant, commercial, industrial or institutional premises, take all necessary measures to prevent oil and grease, motor oil and lubricating grease, and sediment from entering the drain or sewer. Additionally, the owner or operator shall install, operate, and properly maintain a grease interceptor or oil interceptor, in any piping system at its premises that connects directly or indirectly to a sewer ( $\mathrm{Li}$, 2002).

In addition, municipal teams such as the Industrial Waste and Enforcement Branch, the System and Services Branch, the Collection System Services Unit, all participate in spill containment and clean-up.

\section{Provincial Spill Management}

In Ontario it is illegal to discharge substances that will harm the natural environment. Provision such as the Environmental Protection Act, the Ontario Water Resources Act and the Emergency Plans Act, are enforced to monitor, manage and mitigate spill events. The primary role of the Environmental Protection Act (EPA): 
- Part II (General Provisions) s.14 (1) “No person shall, or shall allow the discharge of a contaminant into the natural environment that causes or is likely to cause adverse affects" (Li, 2005).

- Part X (Spills) section 92. Under section 18 (1), "for spill prevention, the Regional Director may issue orders requiring those with a potential for spills to: prepare contingency plans, to train staff, install monitoring, detection and spill alarm devices, and to construct spill prevention facilities." (Li, 2005)

- Under Part X (Spills) section 92 establishes prompt and broad notification requirements for the person who caused the spill, the person who had control of the material immediately prior to the spill, and for employees of all public authorities. It is mostly the discharger's responsibility for not only the notification of the spill (s.15) but also the clean up (s.93) and prevention of the spill (s.17). Severe penalties or jail terms are admissible to an individual or parties who commit this offence ( $\mathrm{Li}, 2005)$.

- According to the Water Resources Act section30 (1), "Any person that discharges any material that may cause impairment to the water supply any where, is guilty of an offence under this Act" (Li, 2005).

The integrity of the environment is the main priority of the Government of Ontario, who proposes that planning for a spill is the most effective way to minimize chances of negative effects of a substance when released into the natural environment, whether purposely or not. Industry and Municipal governments are encouraged to prepare plans that may be used in case of a spill or a spill emergency ( $\mathrm{Li}, 2005)$. Recently, the Ontario government created the "environmental SWAT team" to concentrate on compliance, inspection and enforcement of governing laws related to issues such as air and water quality, as well as hazardous wastes. The role of the Ministry of Environment is not limited to these activities and initiatives; they also focus on spill emergency 
response, such as spill assessment to ensure spills are responded to promptly, effectively and properly.

\section{Federal Spill Management}

The federal government is responsible for the protection of federally-owned lands and water. They also act as an advisor to any party in need of advice, provide information about chemicals, environmental impact, and countermeasures and monitor large spill clean-up efforts. Several legislations address spill management on either land or sea or both, some of which include the Canadian Environmental Protection Act (CEPA), the Canada Oil and Operations Act, the Canada Shipping Act, the Transportation of Dangerous Goods Act, the Fisheries Act and the Artic Water Pollution Prevention Act.

The Canadian Environmental Protection Act (CEPA) is designed to, among other things to: 1. Take remedial and preventative measures to protect, enhance and restore the natural environment. 2 . Recognize the necessity of protecting the environment. 3 . Work with other government to protect the environment. 4. Establish nation wide standards of environmental quality. Examples of restrictions imposed by CEPA include:

- The prohibition of unlawful discharge or spills of material that cause negative effects on the environment are under section 95 (1-8).

- Sections $95(1)(a, b, c)$ require quick notification of a spill to an official and the owner of the substance, doing everything reasonable to stop adverse effects and notifying any part that might be effected by the situation. The latter subsection applies to any person who owns, controls or manages the substance immediately before it was released into the natural environment, or anyone who caused or contributed to the release of the substance (s.95)(2).

- Under subsection (5) of section 95, an officer has the power to cause a party to take measures to stop or clean up a spill. An officer may enter any area and do 
anything reasonable under the circumstances to avoid negative effects to the natural environment (s.95)(7). The person who is responsible for a discharge is not liable if that party has done everything in his/her power and under the regulations required in case of such a situation.

- The Canada Oil and Operations Act also prohibits the release of substances (s.25) (1) and require prompt notification of a spill situation (s.25)(2), duty to take reasonable measures (s25)(3), personal liability (s.25)(9) and recovery of costs (s25)(7.1).

- Under the Canada Shipping Act, the owner of the ship is liable for oil pollution damage from the ship. Owners may limit their liability if the pollution incident occurred without their fault or involvement (s.25)(9).

Severe penalties or jail terms are admissible to an individual or parties who commit these offences. Fines can range from $\$ 20,000$ to several million dollars depending on the severity of the spill and the number of subsequent spills. In addition to these fines, jail terms up to 5 year are admissible according to Ontario's provincial and federal legislations.

\subsubsection{Environmental laws and regulations adopted by TTOil}

TTOil has currently ratified various (MARPOL conventions, MARPOL 73/78, Annex I/II, III, IV and V), the INTERVENTION Convention 69, OPRC Convention 90, CLC Protocol 92 and FUND Protocol 92 (compensations for pollution damage) in an attempt to acquire assistance for oil spill pollution occurring in the four surrounding water bodies: the Atlantic Ocean (East), the Caribbean Sea (North), the Gulf-of-Paria (West) and the Columbus Channel (South). In regions such as Canada, oil spills are dealt with by three levels of government depending on the severity of the oil spill and the location. In a small island such as Trinidad, the state governs and implements regulations for all 
land-based spills, while international conventions/protocols govern ocean based spills. The following list highlights the relevant regulations for oil spills applied on a national level in Trinidad which are adopted by TTOil. The primary environmental legislation is the Environmental Management Act.

- Environmental Management Act of 2000 (Section 26, 35-40)

This is the primary document used in environmental management by all industries likely to pollute. The national environmental policy of the EMA is aimed at the conservation and sustainable use of natural resources of Trinidad and Tobago, to ensure the growth of economic and social development (TTOil Legal Registry 2001). Among the policy objectives is the need to prevent, reduce or eliminate various forms of pollution, conserve biological diversity of the country, and the stability and resilience of the ecosystems, as well as to undertake retroactive analyses or evaluations to correct past development decisions that might be inimical to the continued environmental health of the country (TTOil Legal Registry 2001).

- Other acts which include spill management regulations include: The Petroleum Act Chapter 62:01 (rev 1980) S.29 (l)(j), 42 (2) (b,h,I,k,g), the Mineral Act No 61 of 2000 S.4, 22(c.d.f.g), 43, 44, the Planning and Development of Land Bill 2001 and the Certificate for Environmental Rules 2001 LN 104,91,103.

\subsubsection{Oil Spill Contingency planning}

According to Lentz and Felleman (2003), every oil spill regardless of its size or its source is worthy of prevention efforts at some level, since the size of an oil spill does not determine the degree of its resulting damage either environmentally or economically. One method to address oil spill prevention of all oil spills is the oil spill contingency plan. Oil spill contingency planning is essentially an action plan and guide for emergency procedures, notifications, responsibilities, emergency equipment locations, 
oil spill control points, safety, media and reporting requirements (CPA 1989). An oil industry may have several oil spill contingency plans for each refinery or production district. Whatever the area of operation, the same format for oil spill contingency planning is applied as described below.

Oil spill contingency plans are usually comprised of three parts:

1. A strategy section - to outline the scope of the plan, the geographic area, perceived risks, roles and responsibilities of those charged with implementing the plan and the proposed response strategy (IPIECA 2000).

2. An action and operations section - which outline emergency procedures that allow rapid assessment of the spill, and mobilization of appropriate response resources. (IPIECA 2000)

3. A data dictionary - which should contain all relevant maps, resources list and data sheets to support oil spill response effort, and conduct the response according to an agreed strategy. (IPIECA 2000)

The design specifications for oil spill contingency plans are standard as all oil spill contingency plans reviewed demonstrate similar criteria. The International Petroleum Industry Environmental Conservation Association (IPIECA 2000) graphically illustrates the three components of an oil spill contingency plan in Figure 6. 


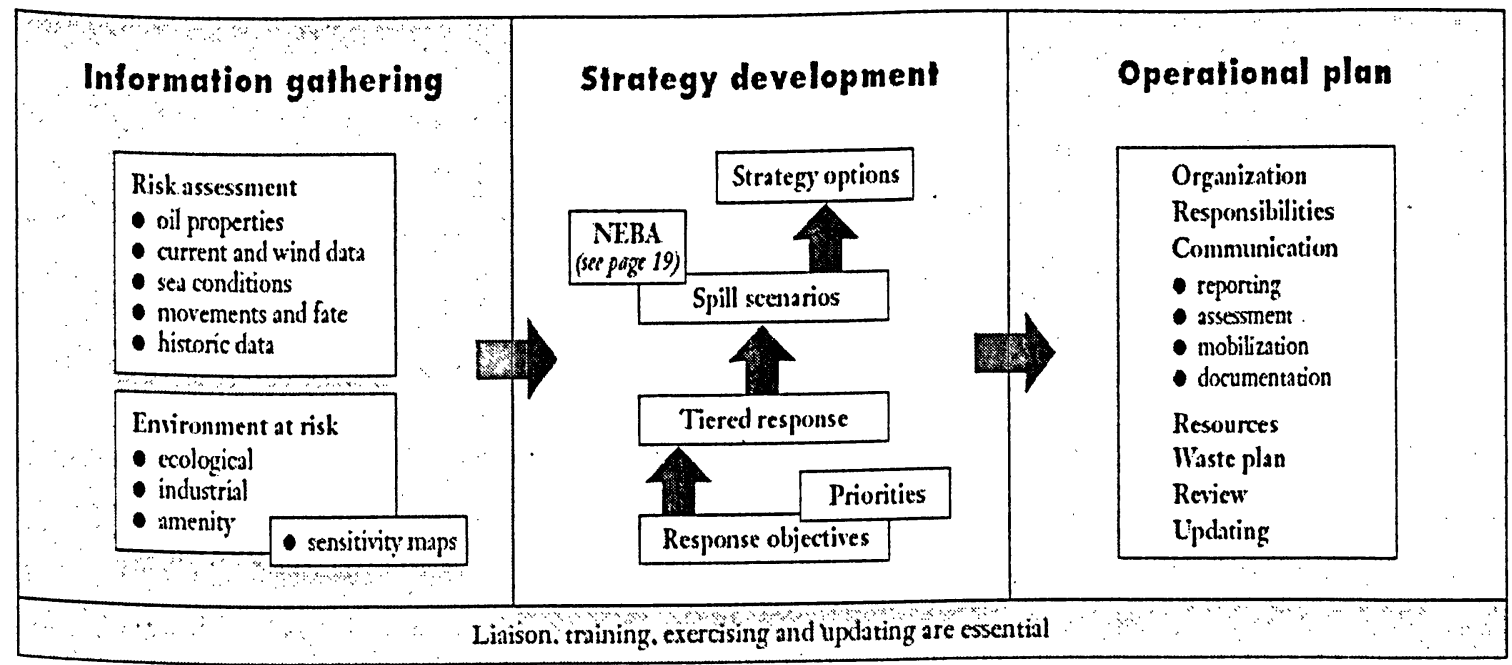

Figure 6. Oil spill contingency plan framework (IPIECA 2001)

The two most crucial sections are the strategy section, which entails a descriptive policy document and outlines the overall strategy, and the operational plan which is concerned with procedures to be followed when a spill occurs. Table 4 highlights the functions of these two sections.

Table 4: Strategy and Operation Sections

\begin{tabular}{l|l}
\hline Strategy Section & Operational Section \\
\hline Introduction & Notification \\
\hline Risk assessment & Evaluation \\
\hline Resources at risk and priorities for protection & Response \\
\hline Organization and management & Clean-Up \\
\hline Equipment, supplies services and manpower & Communication \\
\hline Communications \& control & Termination \\
\hline Training exercises and updating procedures & \\
\hline
\end{tabular}

Source: (ITOPF 2001)

Once an oil spill occurs, it is not necessary to mobilize all resources at one time, especially if the spill is small in size and not in an environmentally sensitive area. The tiered response system is usually based on the size of an oil spill, however, other factors such as the potential risks, location of the spill, oil type and environmental or socioeconomic sensitivities under threat are also considered when resources are mobilized. 


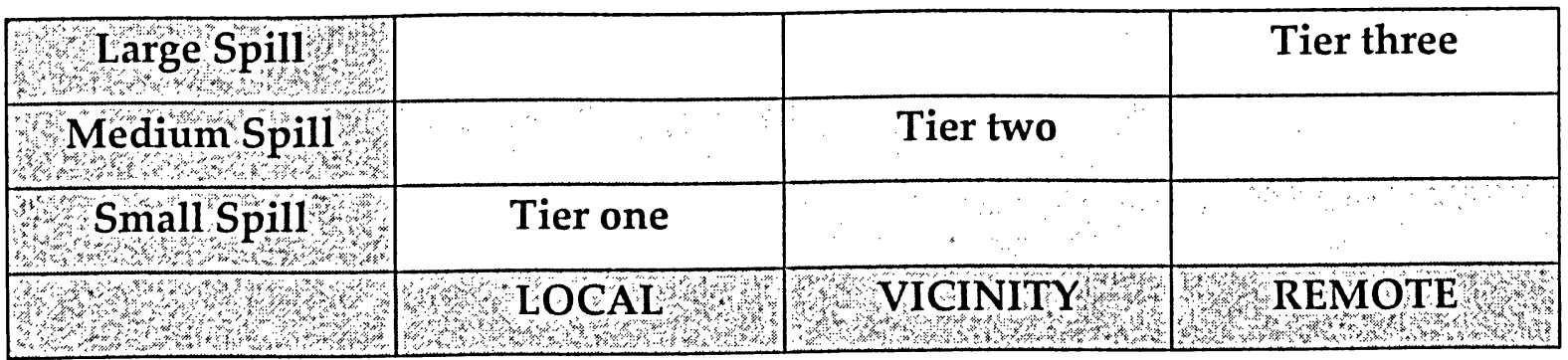

Figıre 7. Tiered response in oil spill contingency planning (IPIECA 2001)

Tiered responses are typically used in the following instances.

1. Tier 1: Small local spills

Are usually operational spills that may occur at or near company owned facilities as a consequence of their activities. An individual company would typically provide in-house resources to respond to this type of spill (IPIECA 2000).

2. Tier 2: Medium spills that may be local or some distance from operational areas Involve a larger spill in the vicinity of a company's facilities where resources from other companies, industries and possible government response agencies in the area can be called in on a mutual basis. The company may participate in a local cooperative where each member pool their Tier 1 resources and has access to any equipment that many have been jointly purchased (IPIECA 2000).

3. Tier 3: Large spills which may exceed national boundaries

Are large oil spills where substantial further resources will be required, and support from a national or international cooperative stockpile may be necessary (IPIECA 2000). 


\section{Oil spill contingency planning at TTOil}

At TTOil, oil spill contingency plans are available for each oilfield district within exploration and production operations. The plans are specific to the needs of each district and follow a similar oil spill contingency plan framework as discussed above. A national oil spill contingency plan is now available for additional support and resources; however, it only covers incidents in the marine environment, an initiative stimulated by the UN Convention of the Law of the Sea (UNCLOS).

Within the oil spill contingency plans for oilfield districts, a policy statement begins each document and follows with section I, "The Strategy", which includes an introduction about the scope of the plan, responsibilities of various groups and its connection with other oil spill contingency plans. Following the introduction is a list of activities liable to produce spills, and the respective resources at risk such as ecological, recreational, commercial and political. Human protection is the first priority followed by protection of the environment. The fate of spills or emissions is detailed for sensitive areas or regions prone to these pollution events. A spill response strategy is the third subject addressed, it summarizes the strategies for oil spills on land, sea zones, coastal zones, shoreline zones, watercourses, riverbanks, wetlands, mangrove and swamps and marshes. Other strategies for response include a strategy for the use of dispersants and chemicals, oil recovery, oils and water storage and disposal, transfer operations, VOCs and SVOCs, steam leaks, gas leaks, steam breakouts and finally planning and logistics. Equally important, and the fourth item in the plan is the set of equipment, supplies and services ready to be mobilized when an oil spill incident occurs. Attached to this section is an appendix listing the names of contractors, departments and storage sites containing these resources when required (TTOil, 2003). 
The fifth item in the contingency plan is Management, Manpower and Training section, which identifies through a crisis management team chart, the person/s or department responsible for various assignments in crisis management. The availability of manpower, routine training and emergency exercises are summarized. During field research at TTOil a full-scale emergency exercise drill was conducted and can be summarized as very comprehensive, with "good communication" as the primary lesson emphasized. It is a key component in crisis management to mobilize appropriate and necessary responses and resources. The final item contained in the strategy section is communication and control which focuses on the availability and requirements of field communication equipment, incident controls rooms, and report and log documents to dictate incident events (TTOil, 2003).

Another component of an oil spill contingency plan framework is the operational plan, which translates into section II known as "Action and Operations". There are three components of this section, the Initial procedures element sets the structure for notification when a pollution event occurs. A detailed notification chart is available for each district followed by the crisis management notification chart to inform assigned individuals depending on the tier level required, to their respective emergency duties. The evaluation procedures are defined by the crisis manager or On-Scene Commander who evaluates the situation, and assesses the threat posed by the oil to the resources at risk and the necessary data to be collected. The Operational Planning and Mobilization Procedures highlight the response decision, based on the initial report and evaluation, to mobilize the required manpower and equipment. The Response and Control of Operations involves the On-Scene Commander delegation of clean-up operations. An administrative assistant is also present to coordinate/advise on environment/ecological aspects of the spill, liaising with government agencies, ensuring clean-up strategies/techniques are in compliance with regulations, strategies and policies. Lastly, 
procedures are set up for the Termination of Operations when they become ineffective or when the desired level of clean-up has been achieved. In summary, based on the information presented above, oil spill contingency planning is not only comprehensive, but it is an exceptionally important and necessary process if carried out as prescribed (TTOil, 2003). 


\subsubsection{ISO 14001}

ISO 14001 is an international voluntary environmental management standard aimed at improving the management of environmental issues for any type of organization. It is commonly used by oil industries as a means by which to meet their goals for service delivery and to improve their environmental performance. The components of the standard include: The developments of an environmental policy, planning, implementation \& operation, checking \& corrective action and management review. ISO registration is achieved and maintained when all components of an industry can:

1. Establish an environmental policy endorsed by senior management.

2. Identify all of its actual and potential environmental impacts.

3. Identify areas with potential for significant impacts in order to concentrate on those that could most affect the environment.

4. Understand all of its legal obligations and requirements.

5. Set environmental objectives and targets for improved performance.

6. Develop programs, plans, and procedures to achieve the targets.

7. Ensure all staff are knowledgeable and trained for the role they play to protect the environment.

8. Monitor, measure and control emissions, discharges and other important aspects of the operation that could have environmental impacts.

9. Have a system in place for continuous improvement, which identifies records and corrects deficiencies.

10. Undertake a rigorous internal audit and management review program. (Shell Canada, 2002)

The benefits of an oil industry EMS that conforms to the ISO standard include

1. Compliance with all environmental legislation for the petroleum industry

2. Management of environmental issues for onshore oil and gas production 
3. Better anticipation and control over environmental incidents and accidents

4. Improved communication of environmental information with the public

5. Financial performance through improved environmental performance (TTOil, 2001)

\section{Application of ISO 14001 by TTOil}

In order to satisfy the requirements of the ISO 14001 standard, TTOil has developed:

1. An environmental policy that aims to prevent and control pollution and accidents, incorporate legislative compliance, audit Health, Safety and the Environment (HSE) performance, nurture an HSE culture throughout the workplace, and train and empower employee in HSE management.

2. Planning to ensure all facilities receive certification. For example, more than 266 environmental aspects have been documented of which more than 8 environmental objectives and more than 50 targets have been developed for these aspects. For example, the cleaning and disposal of oily basal sediment from tanks and oil saver pits at tanks for contamination of soil and waterways.

3. An Implementation $\mathcal{E}$ Operation phase to ensure all environmental management system roles and responsibilities are formalized and specified. Some of the work being delivered includes the development of operational controls to mitigate the significant environmental impacts which have been identified

4. A Checking and Corrective Action phase which houses an internal audit system to continuously monitor and measure performance of the system, and to ensure that they remain connected to the significant environmental aspects, objectives, targets, policy commitments, legal and other requirements

5. Lastly a Managentent Review to ensure that senior management reviews the progress of this project on a biannual basis (TTOil, 2003) 
Using a phased approach, one facility "District A", was able to secure certification as being in conformance with the requirements of the standard. Follow-up audit findings indicated that there was a $70 \%$ reduction in the number of non-conformances in its field facilities, such as well sites and tank batteries. Further checking and corrective action ensures that the status of completion of each environmental program is checked every two months to determine whether there are any deviations from what was intended. Table 5 provides an example of the phased approach of the process involved in the upgrade on an existing EMS to the standards employed by the ISO 14001 program

Table 5: Example of Environmental Management Programs within the EMS

\begin{tabular}{|c|c|c|}
\hline tis & Project & $\begin{array}{l}\text { Projected due } \\
\text { date. }\end{array}$ \\
\hline 1 & Replacement of ozone unfriendly refrigerants & January 2010 \\
\hline 2 & PCB oil disposal & September 2004 \\
\hline 3 & $\begin{array}{l}\text { Secondary containment of crude oil storage areas (Tank } \\
\text { Batteries) and chemical storage areas }\end{array}$ & December 2004 \\
\hline 4 & $\begin{array}{l}\text { Upgrading of production facilities to manage } \mathrm{H}_{2} \mathrm{~S} \\
\text { emissions at two thermal tank batteries }\end{array}$ & October 2005 \\
\hline
\end{tabular}

(Source: TTOil, 2003)

The intent at TTOil is to have all operations within the industry certified. Given the current rate of progress, it appears that may become a reality in the near future. The checking and corrective action phase is one of the most important components of the standard as it not only expects that a framework is created and policies made, but ensures that they are delivered, an important and required function of oil spill management at TTOil.

Given the comprehensiveness of the oil spill management framework, it was not feasible to investigate and analyze each component at the same level of detail, hence 
this section of the study uses the literature and research findings from TTOil to address the oil spill prevention component. The oil spill contingency plan at TTOil is effective and objectives are being met through the checking and corrective action phase. Currently, District A has been certified by the ISO 14001 standard, perhaps given the same level of environmental perseverance and resources, the entire operations of TTOil may one day achieve certification and operate at high levels of environmental performance. 


\subsection{Oil Spill Control}

Oil spill control refers to the containment of spilled oil which is the process of preventing its spread by confining the oil to the area in which it has been discharged (Fingas, 1979). Physical and mechanical methods are available for oil spill containment both before and after an oil spill event. The following section provides an overview of oil spill containment systems including examples from TTOil. The oil spill controls discussed in this section are not an exhaustive list however; they are examples of effective and typical oil spill containment systems used in the petroleum sector.

\subsubsection{Oil spill containment before oil spill occurs (land-based oil spills)}

Containment systems are built structures usually around or near fixed operations such as tanks and wells. They serve to capture spilled oil for easy recovery, to ensure spilled oil is not lost, and to protect the immediate environment from oil contamination by containing the spill in a confined area. The captured oil is then removed either physically or by mechanical means. Examples of pre-oil spill containment measures include pits and bond walls which are illustrated below. These controls are typically used by TTOil at many storage tanks and well sites. The capacity of bond walls built around tanks for example, have a capacity to contain 1.5 times the capacity of the tank. The plan is that contained oil spills would be removed and recycled; therefore little or no oil is lost. Oil spill pre-containment is an effective oil spill prevention tool as along as maintenance is regular, to ensure spilled oil does not present a risk to the adjacent natural environment, as most wells for example, are located in highly vegetated areas. Examples of pre-containment systems for land-based oil spills are illustrated in Figures 8-11. 


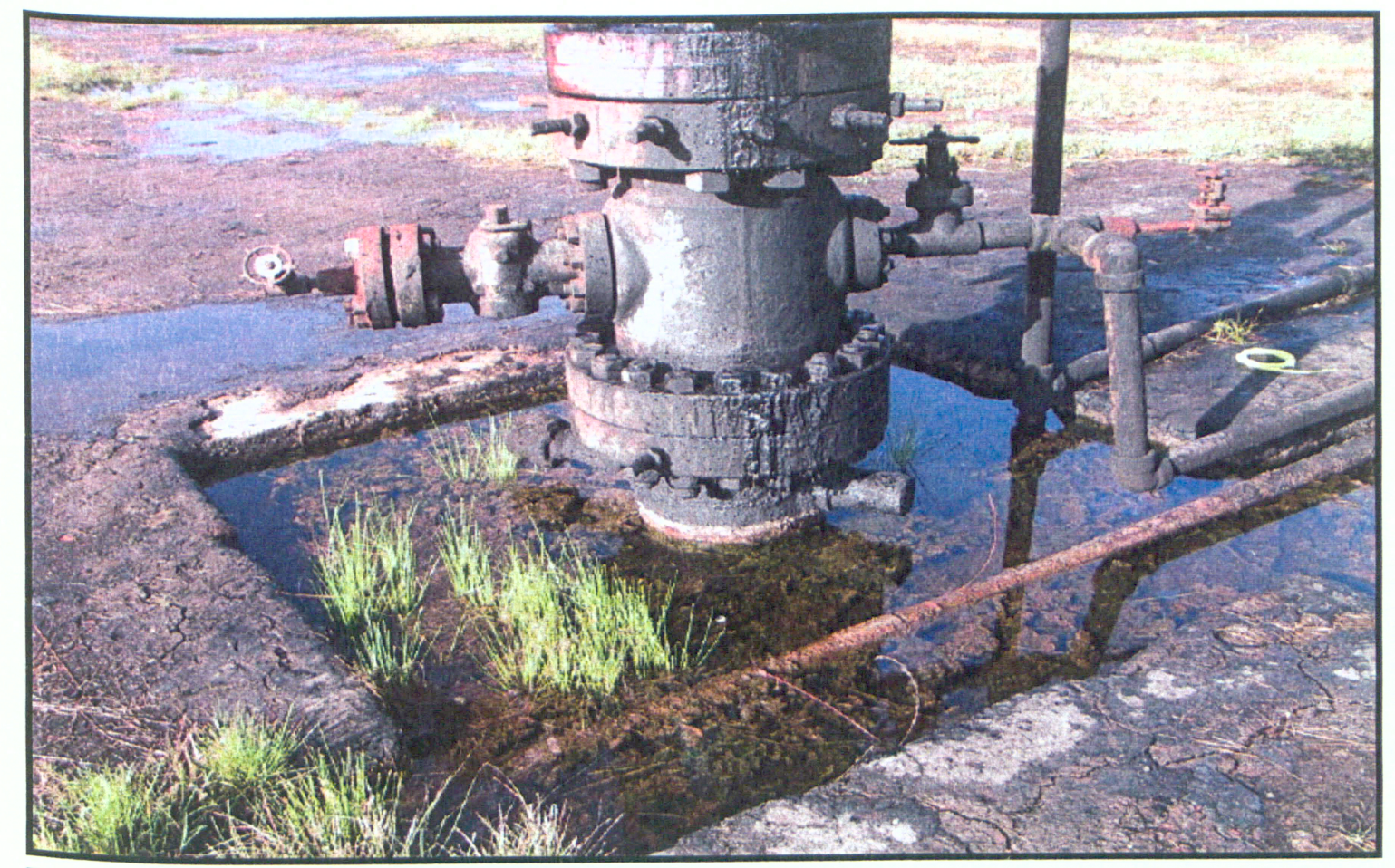

Figure 8: Example 1 - Oil pit (Source: Trinidad, 2003)

A pit (wall) is dug around the well to absorb any spillage of oil from the structure during the oil pumping process. Given the size of this pit, if oil is spilling out at a distance beyond the frame of the pit, it will obviously not be collected within the confines of the collection area. However, spills that leak downwards along the chassis of the well will be collected. The effectiveness of these measures is dependent on the volume spilled, the frequency of oil spill events, as well as weather conditions, whereby depending on the dimensions of the pit, significant precipitation may easily fill its existing capacity. 


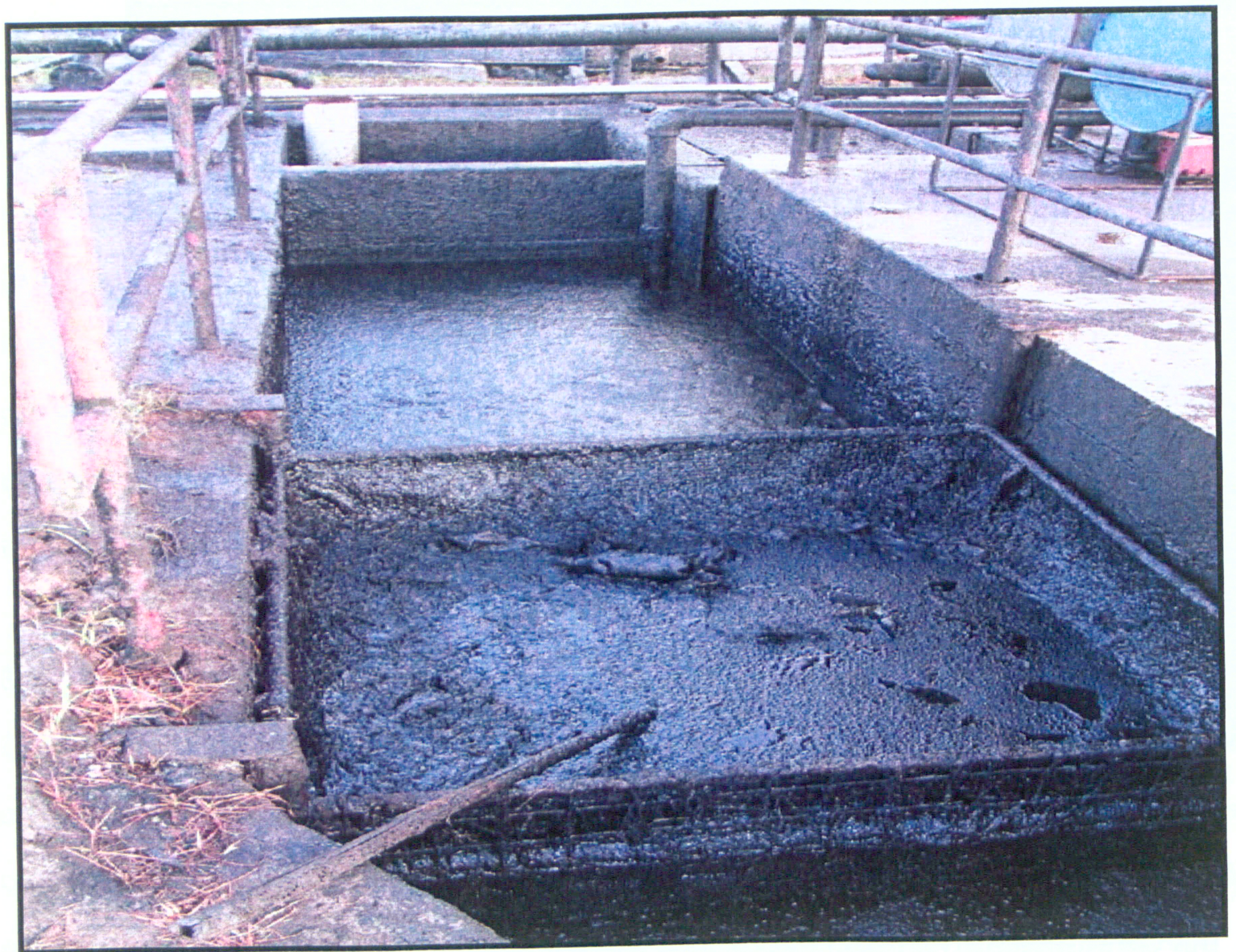

Figure 9: Example 2 - Oil pit (Trinidad, 2003)

Some pits can have two collection areas as shown in Figure 9. The oil collected is reused and not discarded. Maintenance is conducted as needed by field staff that visit field facilities daily. 


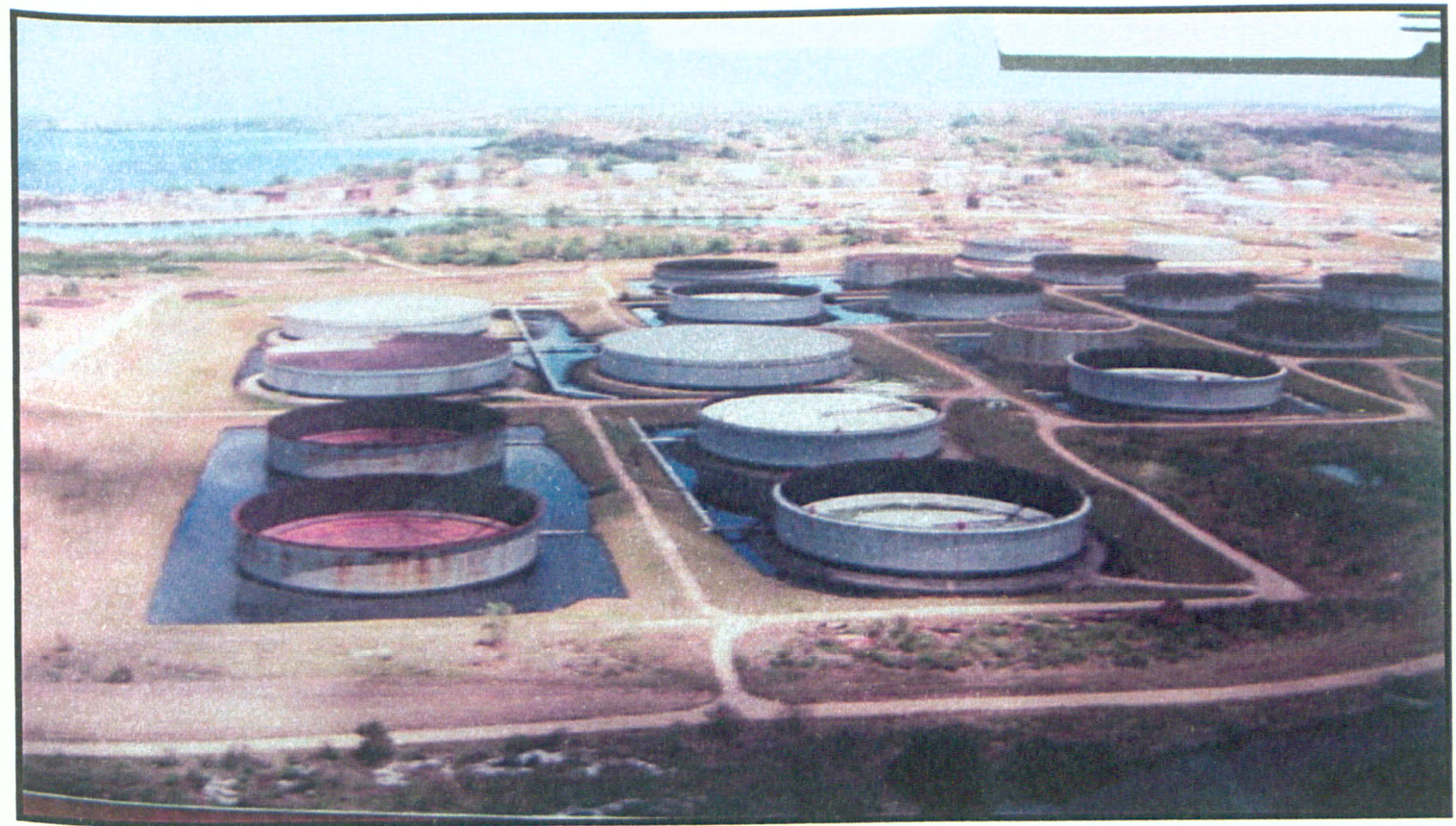

Figure 10: Bond walls - Large scale (Trinidad, 2001)

Given the aging infrastructure of many facilities, tanks also exhibit leaks over time. Bond walls are carved around the tanks to secure spilled oil from contaminating areas outside of the designated boundaries. This area is called a tank farm as it houses only storage tanks containing oil. 


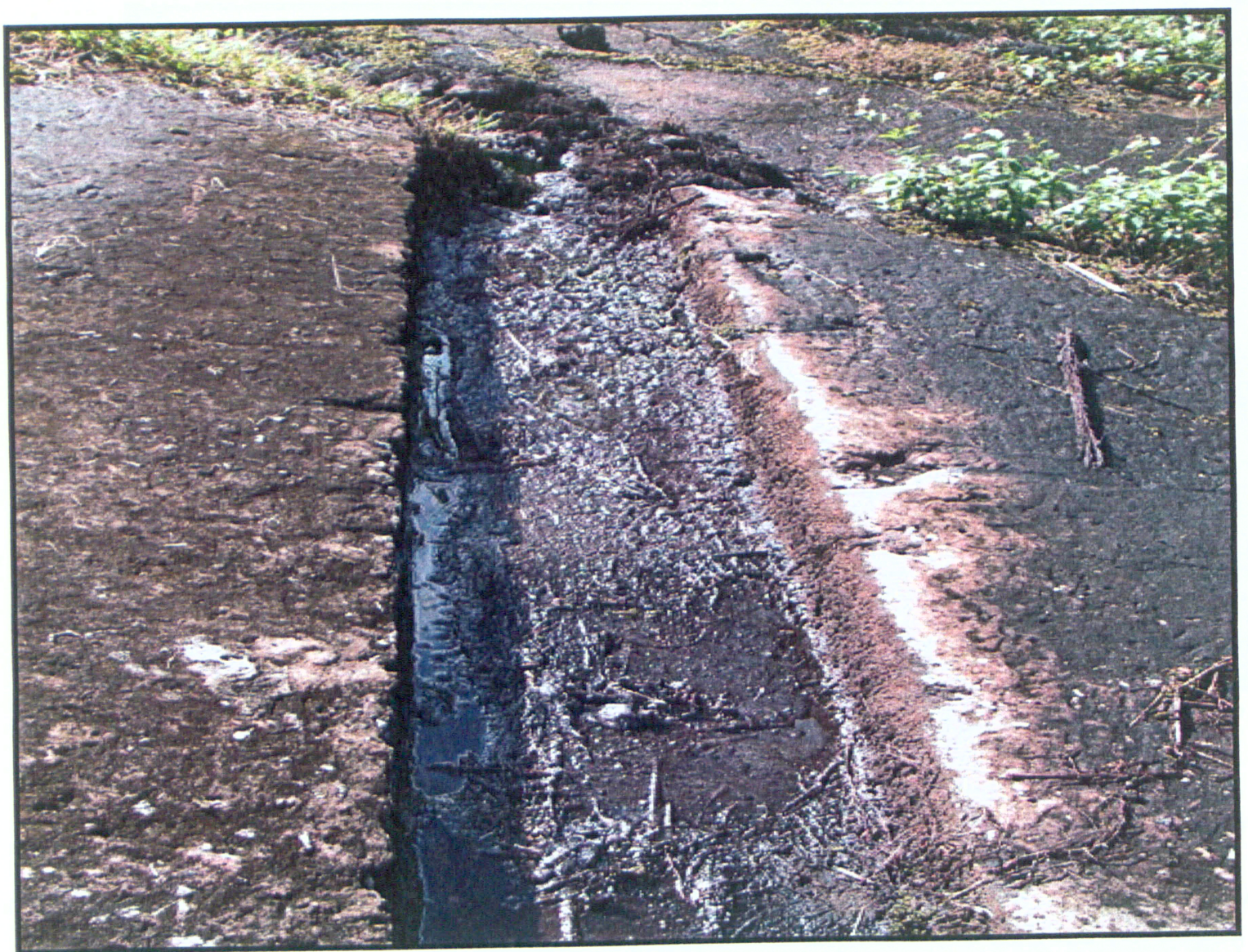

Figure 11: Bond wall - Small scale (Trinidad, 2003)

These containment systems allow for easy recovery of oil, and limit oil leakage into near by waterways, soils or vegetation. It looks like a drain but is actually a collection area for spilled oil. This is an example of the use of bond walls on a smaller scale. 


\subsubsection{Oil Spill containment after a spill occurs (water-based oil spills)}

For oil spills in water, physical containment systems such as booms are usually deployed to contain the oil within the boom, so that mechanical recovery measures such as skimmers can remove the lost oil. Several types of booms and skimmers are available today, each with their advantages and disadvantages. Skimmers are used in direct oil spill clean-up efforts and are usually paired with oil booms in most instances, therefore, both will be discussed in this section of the study.

\section{Oil Booms}

Booms are the most basic and most frequently used equipment for containing an oil spill on water. Booms are generally the first equipment mobilized at a spill and are often used throughout the operation. A boom is a floating mechanical barrier designed to stop or divert the movement of oil on water. It is designed to enclose the oil and prevent it from spreading, thus protecting shorelines, harbours, bays, and biologically sensitive areas. A boom can also divert the oil to areas where it can be recovered or treated, or concentrate the oil to maintain an even thickness so that skimmers and other clean-up techniques such as in sitı burning can be applied (Fingas, 2001).

Commercial booms are comprised of four parts. Floatation members or floats determine the buoyancy of the boom and keep it floating on the water's surface (Fingas, 2001). The freeboard member is the portion of the boom (height) above water, whose purpose is to contain the oil from spilling over the boom. The skirt is the portion of the boom below that floats to contain the oil. Attached to the end of the skirt are tension members made of steel cables or chains that run along the bottom of the boom to withstand the powerful forces to which the booms are subjected and contain the oil. Some booms are also constructed with ballast or weights which keep them in an upright position (Fingas 2001). Figure 12 is an example of an oil boom. 


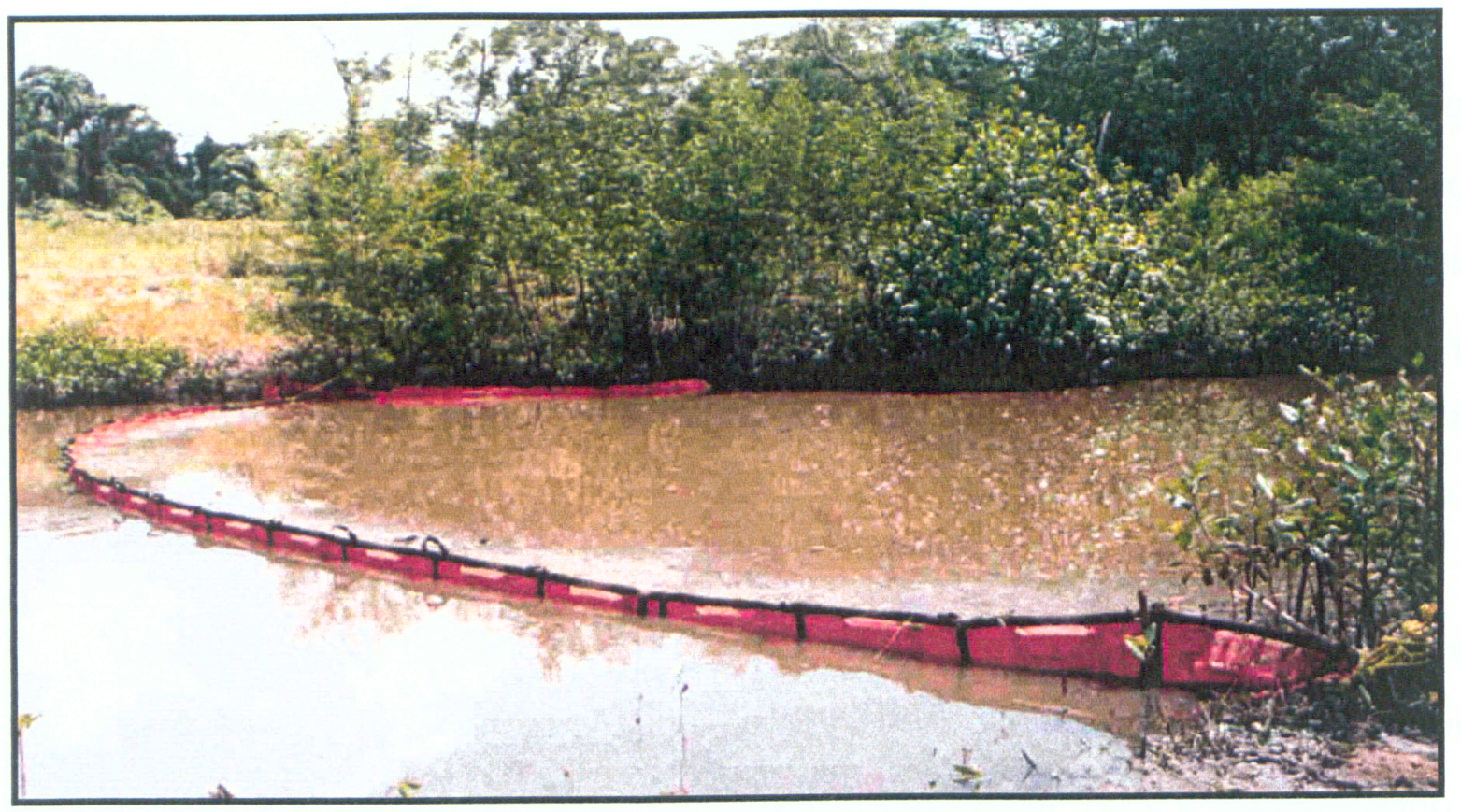

Figure 12: Oil boom (Trinidad, 2003)

Several types of booms are available. For example, a fence boom is constructed with a freeboard member above the float. Although relatively inexpensive, these booms are not recommended for use in high winds or strong water currents. A curtain boom is constructed with a skirt below the floats and no freeboard member above the float. Curtain booms are most suitable for use in strong water currents. The external tension member boom is constructed with a tension member outside the main structure and used in strong currents and in water containing ice or debris (Fingas, 2001). There are also several specialized booms suitable and only effective for certain types of water environments; these are briefly discussed next.

Specialized booms

1. A Tidal seal boom usually floats up or down but forms a seal against the bottom during low tide. These booms are often used to protect beaches or shorelines from oiling. 
2. An Ice boom is used to contain or divert oil in icy waters. The ice boom has slots at the waterline so that oil and water can pass through.

3. A Bubble Barrier is primarily used at fixed facilities such as harbours and loading platforms where the water is generally calm. A perforated pipe located on $f$ the ocean floor pumps air which creates a curtain of rising bubbles that deflect the oil. This mechanism demands a significant amount of energy. Therefore, it is predominantly used only to deflect oil in front of skimmers or fixed separator systems.

4. A Chemical Barrier makes use of chemicals to solidify the oil and prevent it from spreading; however, large amounts of chemical are usually needed and the potential for containment is low (Fingas, 2001).

\section{Disadvantages of booms}

Since booms are used in open waters, the effectiveness of a boom in containing oil spills is dependent on the natural processes that occur in that environment, such as water currents, waves, and wind conditions. Expertise is therefore need for deployment and monitoring of oil booms. Some of the disadvantages are:

1. Entrainment failure can occur in conditions of fast water currents. The boom acts like a dam, whereby it prevents oil from spilling over the boom. Under conditions of fast water currents, the currents break the oil and push droplets of oil under the boom and up to the water surface outside of the boom

2. Drainage Failure can occur via a similar process as entrainment failure, and is more likely to occur with lighter oils. The water current is the mechanism that affects the containment of the oil, in this case, the currents affect the oil directly at the boom. After critical velocity is reached, large amounts of oil contained directly at the boom can be swept under the boom by the current. 
3. Critical Accumulation can occur with heavier oils. Heavier oils tend to accumulate near the boom structure. Water currents at critical velocities can sweep these heavier oils underneath the boom

4. Splashover can occur in rough or high seas when the waves are higher than the boom's float. The oil splashes over the boom and therefore out of the boom containment area. This will also occur when there is excessive oil accumulation at the boom's structure.

5. Submergence Failure can occur when water goes over the boom if the boom is not buoyant enough. When the boom cannot conform to sharp waves, the boom can easily become submerged, this however, occurs very infrequently.

6. Planing occurs when the boom is moved from its vertical position to a horizontal position allowing oil to flow over or under the boom. This movement can occur when the tension members of the boom are poorly designed.

7. Structural failure commonly occurs when any boom's components fail and the"r boom allows oil to escape. Floating debris such as logs or ice can cause structural failures.

8. Shallow Water Blockage occurs when rapid currents form under a boom when used in shallow waters. In shallow conditions, smaller booms are generally more effective. (Fingas, 2001) 


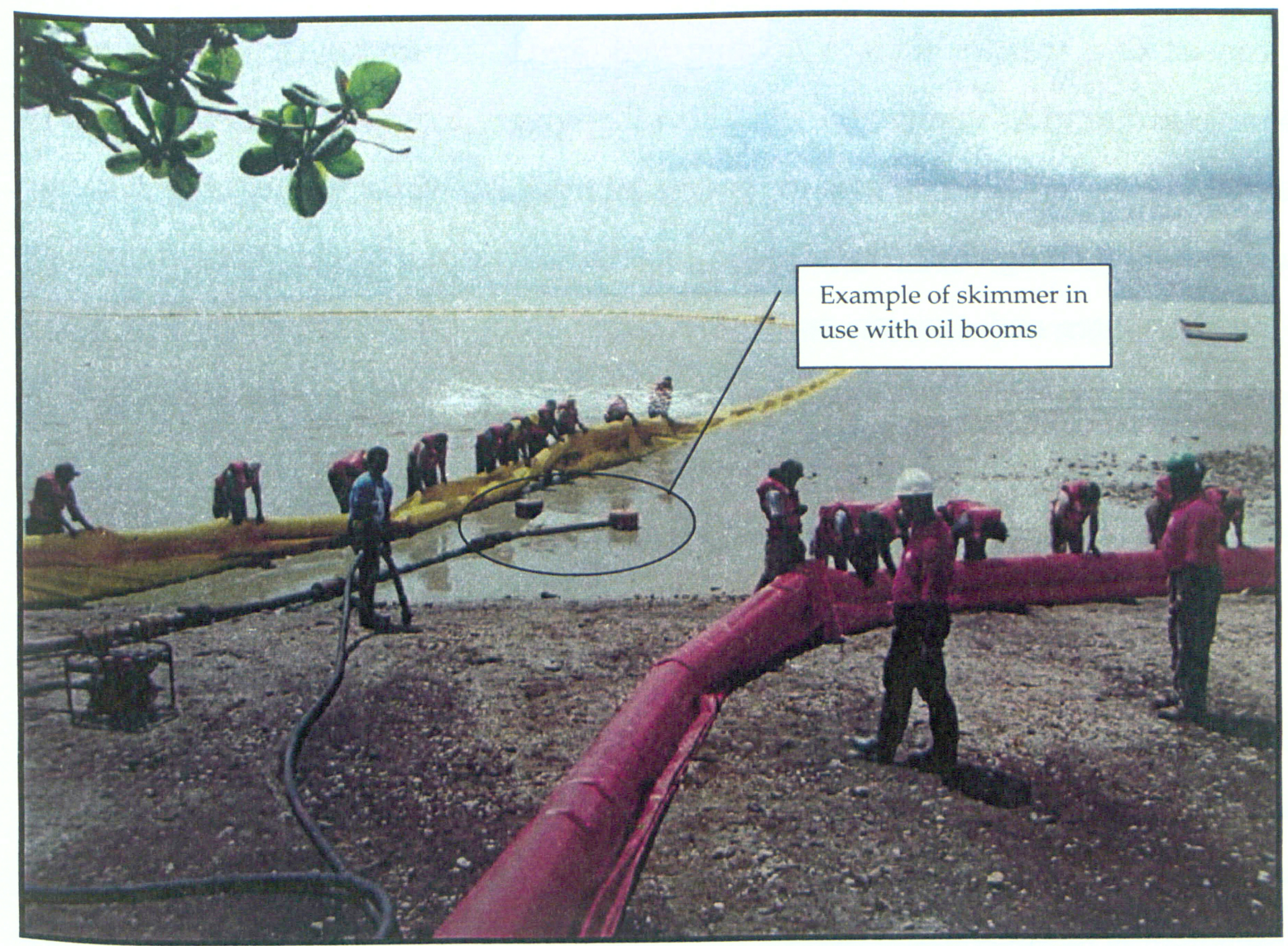

Figure 13: Skimmer \& Oil booms (Trinidad, 2001)

\section{Skimmers}

Skimmers are mechanical devices that recover spilled oil that has been contained by the oil boom. Figure 13 illustrates the use of a skimmer in shallow waters to recover spilled oil contained in the oil boom. The skimmer is attached to a suction hose which is connected to a tank to house the recovered oil. Several types of skimmer are available, a detailed description of each is provided in Appendix A. A summary is provided below:

1. Oleophilic Surface Skimmers: Also known as sorbent surface skimmers, these uses a surface such as a disc, drum, belt, brush or rope to which oil can adhere and be removed from the water surface.

2. Weir skimmers are a major group of skimmers that use gravity to drain the oil from the surface of the water into a submerged holding tank. Weir skimmers 
consist of a weir or dam, a holding tank and a connection to an external or internal pump to remove the oil. This oil recovery technique uses a vacuum or slight differential in pressure to remove oil from the water surface. The skimmer is a small floating head connected to an external vacuum truck. This skimmer sits on the water and uses an external vacuum truck for oil intake/suction into a holding tank. This system works best in calm waters with thick slicks and no debris.

3. Elevating skimmers use conveyors to lift oil from the water surface into a recovery area. A conveyor belt with ridges is adjusted to the top of the water layer and the oil is moved up the recovery device on a moving belt. The oil is removed from the conveyor by gravity.

4. Submersion skimmer uses a belt or inclined plate to force the oil beneath the surface. The belt or plane forces the oil downward toward a collection well where it is removed from the belt by a scraper or by gravity.

5. Vortex or Centrifugal skimmers make use of the density between the oil and water to separate them. This is followed by the removal of the oil. A water vortex is created to draw the oil into a collection area where it is rotated in a centrifuge, using either the force of the water itself or an external power source. The oil is therefore forced to the center by heavier water and pumped from the chamber (Fingas, 2001).

Given the comprehensiveness of the oil spill management framework, it was not feasible to investigate and analyze each component with the same level of detail, hence this section of the study uses the records and research findings from TTOil to provide the information required. 


\subsection{Oil Spill Clean-up}

Most oil spill events require some form of oil spill clean-up process unless they are very small spills. Many techniques and technologies available to clean-up oil spilled into various environmental media such as water, the land surface and subsurface environments. Oil spills in the ocean or on shorelines (oil slicks) in some ways are easier to clean-up than oil spilled unto land surface and subsurface environments, primarily because oil and water molecules do not mix resulting in oil forming a layer that floats on top of the water column. In this section oil spill clean-up measures on land and on water, not including skimmers, are discussed in detail.

One of the foremost writers on the subject of oil spill clean-up is Dr. Merv Fingas. He has worked more than 25 years in the field of oil spill technology at Environment Canada's Environmental Technology Center. As head of the Emergencies Science Division, he conducts and manages research, development projects in the sciences as they related to spill measurement, evaluation, and control. Given his level of expertise and experience, his work is heavily referenced in this section of the study, as field work in this component of the framework was not possible.

\subsubsection{Clean-up of oil spills on land}

Clean-up procedures on land appear to be far more complex than those on water as more variables have to be considered. For example, the movement of different types of oil in different habitats, the conditions at the spill site, such as specific soil type, moisture conditions in the soil, the slope of the land, and the level and flow rate of groundwater (TTOil 1993). Other variables include the presence of vegetation, the type and growth phase, the temperature, the presence of snow or ice, and the oil's ability to permeate soils and its adhesion properties are all important factors which further 
complicate the clean-up of oil spills on land (Fingas, 2001). Table 6 and 7 highlight the various clean-up technologies and techniques used to clean-up surface and subsurface oil spills. A clean-up technique according to TTOil, should be effective in removing a significant amount of oil, reducing contamination and the adverse impacts on the environment therefore, careful selection of clean-up techniques are crucial (TTOil 1993). 
Table 6: Types of clean-up techniques/technologies for surface oil spills

Clean-up of Surface spills

Berms or dikes

Makes use of soil in the area, sand bags or construction materials to build the berms which contains the oil spill and prevents it from spreading

Sorbents As discussed in section 3.3, sorbents can be used to recover some of the oil and prevent further spreading

Shallow trenches Shallow trenches dug into the soil are effective when water tables are high. Oil can readily be removed from or burned in the trenches

Natural Recovery

Is recommended for extremely sensitive environments that usually take many years to repair themselves such as tundra climates. The excess oil is usually removed using a technique that does not disturb or damage the surface.

Suction hoses, pumps, vacuum trucks, skimmers and sorbents

Manual removal

Mechanical recovery equipment As discussed in section 3.3, these technologies can be used to remove excess oil from the surface, ditches and lowlying areas. Sorbents are recommended for final traces of oil removal from water surfaces such as a wetland.

Makes use of shovels and other agricultural tools to remove oil from soil and vegetation followed by replanting measures.

Makes use of bulldozers, scrapers and front-end loaders. These methods can be damaging to the habitat so it is restricted to the clean-up of oil in urban areas, roadsides and perhaps agricultural lands. It is not recommended for sensitive environments.

Enhanced

biodegradation Certain portions of oil are biodegradable and can be enhanced with the use of fertilizers. The amount of nutrients needed is calculated using a carbon to nitrogen to phosphorous ratio. Some oils degrade better than others such as diesel fuel. This process tends to work best under ideal weather conditions. .

In-situ burning

Source: Fingas 2001 
Table 7: Types of clean-up techniques and technologies for subsurface oil spills

\begin{tabular}{|c|c|}
\hline Clean-up of Su & face spills \\
\hline $\begin{array}{l}\text { Interceptor } \\
\text { trench }\end{array}$ & $\begin{array}{l}\text { These are ditches or trenches dug down gradient from the spill } \\
\text { or in the direction of the spill flow to catch the flow of oil. The } \\
\text { trenches are placed below the depth of the groundwater to } \\
\text { ensure oil flowing on top of the groundwater will flow into the } \\
\text { trench. This is effective in reducing the horizontal spread of the } \\
\text { oil as containing the horizontal and downward movement of oil } \\
\text { is important in this type of environment. The trenches are } \\
\text { usually filled in after clean-up to restore the natural drainage } \\
\text { pattern of the land. }\end{array}$ \\
\hline $\begin{array}{l}\text { Hydraulic } \\
\text { measures }\end{array}$ & $\begin{array}{l}\text { Such as flooding, flushing, sumps, and French drain. These } \\
\text { methods work best in permeable soils and non-adhesive oils. } \\
\text { Flooding: Water is applied directly to the surface or to an } \\
\text { interceptor trench to allow the oil to float out. This method is } \\
\text { only advantageous when the oil has not been absorbed into the } \\
\text { soil. } \\
\text { Flushing: Water is used to flush oil into a sump, recovery well or } \\
\text { an interceptor trench } \\
\text { Sump: A sump or a deep hole is useful when light fuel is spilled } \\
\text { in permeable soil above an impermeable layer of soil. } \\
\text { French drain: A horizontal drain located under the oil spill, the } \\
\text { oil and perhaps water are pumped out. }\end{array}$ \\
\hline Soil venting & $\begin{array}{l}\text { This technique removes vapours from permeable soil above the } \\
\text { subsurface spill. It is only best suited for oils with high } \\
\text { evaporation rate. Air is sometimes blown through the soil and or } \\
\text { drawn out with a vacuum pump; the fuel vapours are then } \\
\text { removed from the air so as to prevent air pollution. }\end{array}$ \\
\hline Excavation & $\begin{array}{l}\text { Primarily used in urban area where human safety is an issue as } \\
\text { vapours from gasoline can travel through the soil and explode if } \\
\text { ignited. Therefore, contaminated soils are excavated and treated, } \\
\text { then sent to a landfill. }\end{array}$ \\
\hline Recovery wells & $\begin{array}{l}\text { A well is drilled or dug to the depth of the water table to catch } \\
\text { the oil flowing along the top of the water table. The oil is usually } \\
\text { recovered from the surface of the water with a pump or a } \\
\text { skimmer. }\end{array}$ \\
\hline
\end{tabular}

Source: Fingas, 2001 


\subsubsection{Clean-up of oil spills on water}

Various chemical and biological methods deliver oil spill remediation to deal with oil spill contamination on water. Chemical and biological methods often are used with mechanical methods; these include dispersants and gelling agents used primarily to keep oil from reaching shorelines and other sensitive habitats. Biological agents have more potential to assist recovery in sensitive areas such as shorelines, marshes, and wetlands. Dispersants are chemicals which have components of surface-active agents called surfactants, which aid in breaking up an oil slick into smaller droplets. Solidifiers or gelling agents change liquid oil to a solid compound that can be collected from the water surface with nets, or mechanical means (Fingas, 2001).

\section{Dispersants}

A "dispersant" is a common term used to label a chemical spill-treating agent that promotes the formation of small droplets of oil that "disperse" throughout the top layers of the water column (Fingas, 2001). They contain surfactants, molecules with both a water-soluble and oil-soluble component. Depending on the nature of these components, surfactants cause oil to behave in different ways in water. Surfactants or mixtures of surfactants used in dispersants have approximately the same solubility in oil and water, which stabilizes oil droplets in water so that the oil will disperse in the water column.

A measure of a dispersant's effectiveness is the amount of oil it puts into the water column compared to the amount of oil that remains on the water surface. A dispersant is at work when a white-to-coffee coloured plume of the dispersed oil appears in the water column. There are many factors that influence the effectiveness of dispersants:

1. The composition of the oil

2. The degree of weathering of the oil 
3. The amount and type of dispersant applied

4. Sea energy

5. The salinity of the water

6. Water temperature (Fingas, 2001)

Dispersants work best when the oil is at a certain thickness, for example, they will not work when the oil is spread into thin sheens as the dispersant will interact with the water rather than the oil. It is also equally important to have an understanding of the type of oil spilled as some oils, as per Table 8, disperse better than others. For example, some oils containing large amounts of saturates are susceptible to natural dispersion, such as diesel fuel, which disperses both naturally and when dispersants are added. Other types of oils containing resins, asphaltenes and larger aromatics are not prone to dispersion when dispersants are applied. As indicated above, sea energy also influences the effectiveness of dispersants and studies indicate that more dispersant is needed when sea energy is low to yield the same amount of dispersion when sea energy is high. Table 8 illustrates the typical effectiveness of dispersants based on sea energy.

Table 8: Typical Dispersant Effectiveness

\begin{tabular}{|c|c|c|}
\hline \multicolumn{3}{|c|}{ Why Wispersant Effectiveness } \\
\hline Oil & $\begin{array}{l}\text { At Low Sea Energy } \\
\text { (\% Of oil in the water } \\
\text { column) }\end{array}$ & $\begin{array}{l}\text { AtHigh Sea energy } \\
\text { (\% Of oil in the water } \\
\text { column) }\end{array}$ \\
\hline Diesel & 60 & 95 \\
\hline Light crude & 40 & 90 \\
\hline Medium crude & 10 & 70 \\
\hline Bunker C & 1 & 1 \\
\hline
\end{tabular}

Source: Fingas, 2001

"Dispersants are often applied either diluted or undiluted by aerial spraying from small or large aircrafts or helicopters or via spray systems available in boats. In order to determine the amount of dispersant required, a dispersant-to-oil ratio is applied which takes into account the size of area affected, the quantity and thickness of oil spilled" (Fingas, 2001). 


\section{Toxicity of Dispersants}

Dispersants today are much less toxic, often one hundredth as toxic as earlier products. The standard measure of toxicity of a dispersant is its acute toxicity to standard fish species. The dispersant's "Lethal Concentration to $50 \%$ of a test population (LC50) is used as given in $\mathrm{mg} / \mathrm{L}$, an approximate equivalent to $\mathrm{ppm}$. Oil appears to demonstrate more toxicity than dispersants with a LC 50 of diesel and light crude ranging from 20 to $50 \mathrm{mg} / \mathrm{L}$ whether the oil is chemically or naturally dispersed. Further studies indicate that oil does not increase in toxicity as a result of dispersants; however, the natural or chemical dispersion of oil in shallow waters can result in a greater concentration of oil in the sea that may be toxic to sea life. Although dispersants are widely discussed in many sources of literature related to oil spill clean-up, they are rarely used in North America and require special permission in Canada through the Regional Environmental Emergencies Team (REET). The use of dispersants is never $100 \%$ effective and concern for the protection of aquatic life, birds and shoreline species, remains a concern with the use of dispersants (Fingas, 2001).

\section{Solidifiers or gelling agents}

The purpose of solidifiers or gelling agents is to change liquid oil to a solid compound that can be collected from the water surface with nets or mechanical means. "Solidifiers consist of cross-linking chemicals that couple two molecules or more or polymerization catalysts that cause molecules to link to each other" (Fingas, 2001). Solidifiers consist of powders that immediately react and fuse with oil and depending on the agent, about 10 - $40 \%$ by weight of the agent are required to solidify the oil under ideal conditions. (Fingas, 2001) 


\section{Disadvantages of using Solidifiers}

Solidified oil is difficult to recover with skimming and other types of recovery equipment are normally designed for liquids. Significant amounts of agent are needed to solidify oil, therefore, for medium or larger spills, solidifiers may not be practical. As well, observations have indicated that the faster the solidifiers react with oil, the sooner it forms a barrier that prevents it from penetrating the remaining oil.

\section{Sorbent Booms}

Containment booms were discussed in section 3.3, however another type of boom is called the sorbent boom, a more specialized boom made up of porous sorbent material to absorb oil while it is contained. This sorbent technique is only effective in relatively thin oil slicks, to remove small traces of oil. Sorbents are usually placed along cleaned shorelines to absorb any oils that could potentially re-contaminate the area. Sorbent booms therefore act as secondary oil spill containment measure, to remove residual oils left behind from primary clean-up measures.

Like containment booms, strong wind currents may affect the performance of sorbent booms, and additional support or reinforcements may be necessary under these conditions. In order to maintain their position for effective absorption, flotation devices can be installed to insure the sorbent booms do not sink when saturated with oil and water. Recovery is the next phase of the oil spill clean-up process after containment. Recovery and containment of an oil spill normally occur simultaneously. When a spill occurs, booms are deployed to contain the spill and recovery equipment and personnel are on hand to recover and take advantage of the increased oil thickness, favourable weather and less weathered oil. The types of skimmer commonly used to recover spilled oil were discussed in section 3.3 and a more detail summary is available in Appendix A. 
Other oil spill control methods

Other types of control methods are In-Situ burning, which is the controlled burning of oil to remove an oil slick. Biodegradation is another process which occurs as a result of oxidation of certain components of spilled oil by microbes such as bacteria and fungi; this is a slow process and commonly adopted for residual oil after the major clean-up has occurred.

\section{Oil spill clean-up efforts at TTOil}

The selection of an oil spill clean-up method is a key decision as some habitats can be very sensitive in the tropics. Table 9 highlights the variable sensitivity of the tropical habitat of Trinidad. Appendix B provides a description of each habitat type in detail.

Table 9: Relative Sensitivity of Habitats

\begin{tabular}{lll}
\hline Sensitivity Ranking & Habitat & Mangrove Forests, Salt Marshes, \\
\hline High & Freshwater swamps, Tidal Flats \\
\hline Medium-High & Rivers/Streams, Forested areas, \\
& Freshwater ponds/dams, Sheltered \\
& rocky intertidal shore \\
\hline Medium & Agricultural fields \\
\hline Low-Medium & Gravel beaches, Sandy beaches \\
\hline & Exposed rocky intertidal shore, \\
& Roadways \\
\hline
\end{tabular}

Source: TTOil, 1993

At TTOil, for each of the twelve habitats the typical oil spill clean-up procedures that are applied in the order in which they occur are:

1. Containment of spills and control of source

2. Protection of more sensitive habitats

3. Removal of free oil

4. Use of sorbents for final clean-up

5. Rehabilitation (TTOil, 1993) 
Given these five steps, table 10 summarizes the specific clean-up method required for each habitat to allow for minimal impact to the individual habitat at risk.

Table 10: Clean-up methods best suited for specific habitat types

\begin{tabular}{|c|c|c|c|c|c|c|c|c|c|c|c|c|}
\hline 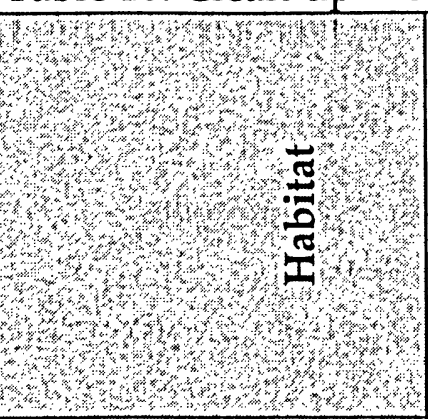 & 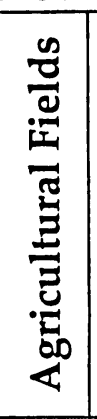 & 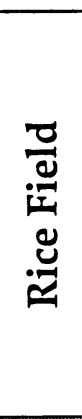 & 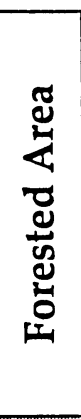 & 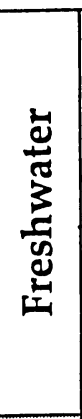 & 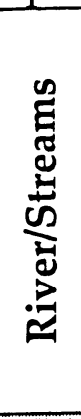 & 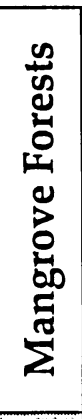 & 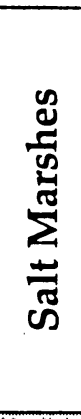 & 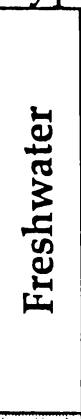 & 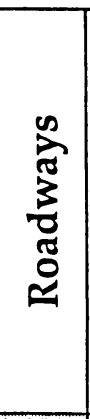 & 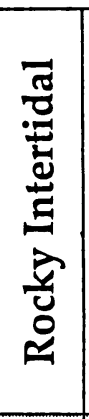 & 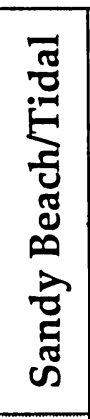 & 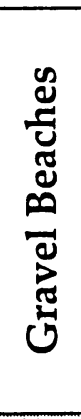 \\
\hline Wethod & 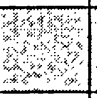 & 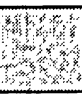 & 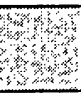 & 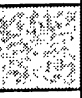 & 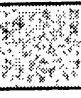 & & the & W & Whe & 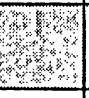 & 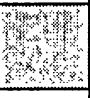 & ris \\
\hline Booms & - & $\mathrm{V}$ & - & $\mathrm{P}$ & $\mathrm{P}$ & $\mathrm{P}$ & $\mathrm{P}$ & $\mathrm{P}$ & - & $\mathrm{P}$ & $\mathrm{P}$ & - \\
\hline Burning & $\mathrm{V}$ & $\mathrm{N}$ & $\mathrm{N}$ & $\mathrm{N}$ & $\mathrm{N}$ & $\mathrm{A}$ & $\mathrm{A}$ & $\mathrm{A}$ & $\mathrm{A}$ & $\mathrm{N}$ & $\mathrm{A}$ & $\mathrm{A}$ \\
\hline Dispersants & - & $\mathrm{A}$ & - & A & A & $\mathrm{N}$ & $\mathrm{N}$ & $\mathrm{A}$ & - & $\mathrm{N}$ & $\mathrm{N}$ & $\mathrm{A}$ \\
\hline Earth Barriers & $P$ & $\mathrm{~V}$ & $\mathrm{P}$ & - & $\mathrm{V}$ & $\mathrm{V}$ & $\mathrm{V}$ & $P$ & $\mathrm{~V}$ & - & - & - \\
\hline Land farming on site & $\mathrm{P}$ & $\mathrm{N}$ & $\mathrm{V}$ & - & - & $\mathrm{A}$ & $\mathrm{A}$ & $\mathrm{A}$ & - & - & $\mathrm{A}$ & $\mathrm{A}$ \\
\hline $\begin{array}{l}\text { Low Pressure } \\
\text { Flushing }\end{array}$ & $\mathrm{P}$ & $\mathrm{P}$ & $\mathrm{V}$ & $\mathrm{P}$ & $P$ & $P$ & $P$ & $\mathrm{P}$ & $\mathrm{P}$ & $\mathrm{V}$ & $\mathrm{P}$ & $\mathrm{P}$ \\
\hline $\begin{array}{l}\text { Management of } \\
\text { Drainage }\end{array}$ & $\mathrm{V}$ & $\mathrm{P}$ & - & $\mathrm{V}$ & $\mathrm{V}$ & $\mathrm{P}$ & $\mathrm{P}$ & $\mathrm{P}$ & $\mathrm{P}$ & - & - & - \\
\hline Manual Removal & $\mathrm{V}$ & $\mathrm{V}$ & $\mathrm{V}$ & $\mathrm{V}$ & $\mathrm{V}$ & $\mathrm{V}$ & $\mathrm{V}$ & $\mathrm{V}$ & - & $\mathrm{V}$ & $\mathrm{P}$ & $\mathrm{V}$ \\
\hline Natural Cleansing & - & - & $\mathrm{P}$ & - & - & $\mathrm{V}$ & $\mathrm{P}$ & $\mathrm{P}$ & - & $\mathrm{P}$ & $P$ & $\mathrm{P}$ \\
\hline Skimmers & - & $\mathrm{P}$ & - & $\mathrm{P}$ & $P$ & $\mathrm{P}$ & $\mathrm{P}$ & $\mathrm{P}$ & - & $\mathrm{P}$ & $\mathrm{P}$ & - \\
\hline Sorbents & $P$ & $\mathrm{~V}$ & $\mathrm{~V}$ & $\mathrm{~V}$ & $\mathrm{~V}$ & $\mathrm{~V}$ & $\mathrm{~V}$ & $\mathrm{~V}$ & $\mathrm{P}$ & $\mathrm{N}$ & $\mathrm{V}$ & $\mathrm{V}$ \\
\hline Substrate Removal & $\mathrm{V}$ & $\mathrm{V}$ & $\mathrm{N}$ & - & $\mathrm{V}$ & $\mathrm{A}$ & $\mathrm{A}$ & $\mathrm{A}$ & $\mathrm{V}$ & $\mathrm{A}$ & $\mathrm{N}$ & $\mathrm{A}$ \\
\hline Vacuum Pumping & $\mathrm{P}$ & $\mathrm{P}$ & $\mathrm{P}$ & $P$ & $\mathrm{P}$ & $\mathrm{V}$ & $\mathrm{V}$ & $\mathrm{P}$ & $\mathrm{V}$ & $\mathrm{V}$ & $\mathrm{P}$ & $\mathrm{V}$ \\
\hline Vegetation Cropping & $P$ & $\mathrm{~V}$ & $\mathrm{~V}$ & - & - & $\mathrm{N}$ & $\mathrm{N}$ & $\mathrm{A}$ & $\mathrm{V}$ & $\mathrm{N}$ & $\mathrm{A}$ & - \\
\hline
\end{tabular}

Source: TTOil, 1993

P: Preferred - Cause the least habitat impact

V: Viable - Useful, but can cause some habitat damage

$\mathrm{N}$ : Not Advisable - Could be applicable, but may cause significant habitat impact A: Avoid - Unacceptable or ineffective method, use would always cause significant adverse habitat impact 
Details of the clean-up method for each habitat are itemized in a step-by-step guide. Follow up data about clean-up efforts were not available to account for the success or failure of these efforts, therefore the effectiveness of these clean-up measures or the impacts to the environment are unknown. They are not documented in the oil spill reports as these reports are typically submitted before clean-up efforts are finalized.

An entire thesis could have easily focused on clean-up activities using data from TTOil as a case study; however, this task was not feasible, largely because this part of oil spill management at TTOil is not documented. Moreover, documentation of the environmental impacts of oil spills is non-existent. Geographical Information Systems (GIS) were available to aid in understanding the potential environment impacts of oil spills to various regions and oilfields, however, the time and resources available to conduct that aspect of the study were beyond the defined scope of the research. It would be extremely beneficial to understand and possibly measure the environmental impacts of oil spills using the spatial analytical capacity of GIS; as it would be a new area of research not only for the petroleum company used in this study, but also useful for petroleum industries.

What were feasible however, are descriptions about the types of clean-up techniques and technologies available for various environmental mediums with specific reference to clean-up procedures employed at TTOil. The cost of oil spill clean-up is heavily used in chapter 4 of this study as it provides valuable information about the extent of this cost to the company. 


\subsection{Economic Evaluation}

The incidence of an oil spill event always has a cost; the size of the cost is what varies from one event to the next. Costs can start to accumulate from the moment an oil spill is reported. For example, it costs money to send someone out into the field to inspect and assess the impact of a spill. The cost increases when equipment and a contractor are mobilized to contain and clean-up the spill site. The cost further increases as the extent of the damage is realized to have affected a watercourse or nearby agricultural lands. If perhaps repairs are needed to fix the mechanism that caused the spill, the cost is further escalated, and finally, penalties have to be paid for oil spills in violation of the law. Although all these costs may not apply to all oil spill events, at least one cost will be incurred for every event because at a minimum, someone is always dispatched to observe the status of an oil spill site. Therefore, the oil spill cost, whether small or large is nonetheless an expense.

Previous studies by Dagmar Schmidt Etkin for example, have focused on the factors that contribute to oil spill costs rather than the factors that mitigate them. In this study, the economic evaluation focuses on the factors that mitigate or eliminate oil spill costs. This involves the application of concepts from the "flood management approach" and an investigation into the probability of oil spill clean-up costs. Using oil spill data from TTOil, the application of these concepts are discussed in chapter 4. However, for this section of the study, the focus turns to the factors that influence oil spill costs. 


\subsubsection{Factors that influence oil spill costs}

The primary factors that influence the cost of an oil spill are the physical characteristics of the spill site, the size or volume of the spill, the type of oil spilled and the rate of spillage (ITOPF 2001). These factors are described in this section of the study as they are commonly used to determine oil spill clean-up cost.

Physical characteristics of the spill site

The physical characteristics of an oil spill site can translate into significant costs based on a number of variables. The physical characteristics include prevailing winds, the weather, tidal range, currents, water depths and coastal topography for oil spills in water. For oil spills on land, the type of land-use is an important concern, the flora and fauna in the area, the type of soil, and again weather and water depth are concerns if the spill flows into nearby streams or rivers.

Size of oils spills (volume)

The general observation of oil spill data indicates that the larger the spill, the larger the clean-up cost. However, as indicated earlier there are many factors that influence the cost of oil spills, which translates into the observed variability in the cost for some oil spill events. For larger oil spills, however, the area exposed to contamination can be quite large especially during wet weather events, depending on the factors that influence oil spill costs.

Type of oil spilled

The type of oil spilled into the environment is one of the most important factors influencing cost of an oil spill, in particular the clean-up cost. The more viscous and persistent the oil, the more difficult and expensive it is to clean-up. Generally refined products such as gasoline and diesel fuels do not persist on the sea surface for a long 
time as they evaporate rapidly, but they may constitute a fire and explosion hazard (ITOPF 2001). On the other hand, heavy crude and fuels oils are highly persistent as they are very viscous, they travel long distances and have the capacity to contaminate a larger area which may include birds, other wildlife, sediments, and coastlines (ITOPF 2001). Their advantage is they have only a small portion of volatile components. The following table is taken from the International Petroleum Industry Environmental Conservation Association (IPIECA); it lists the characteristics the different types of oil that can be spilled into the environment.

Table 11: Characteristics of different oil types

\begin{tabular}{|c|c|c|c|c|}
\hline Oil Type & $\begin{array}{l}\text { Density }(\mathrm{kg} / \mathrm{l}) \\
\text { at } 15^{\circ} \mathrm{C}\end{array}$ & $\begin{array}{l}\text { Viscosity } \\
\text { mPAs at } 20^{\circ} \mathrm{C}\end{array}$ & $\begin{array}{l}\text { Pour Point } \\
\text { oc }\end{array}$ & $\begin{array}{l}\text { Flash Point } \\
\text { C }\end{array}$ \\
\hline Crude oil & $0.8-0.95$ & $1-100$ & +10 to -35 & Variable \\
\hline Gasoline & $0.70-0.78$ & 0.5 & $\mathrm{NA}$ & $<0$ \\
\hline Kerosene & 0.8 & 2 & $<-40$ & $38-60$ \\
\hline Jet Fuel & 0.8 & $1.5-2$ & $<-40$ & $38-60$ \\
\hline Diesel Fuel & 0.85 & 5 & -5 to -30 & $>55$ \\
\hline $\begin{array}{l}\text { Light Fuel } \\
\text { IFO } 60\end{array}$ & 0.9 & 60 at $50^{\circ} \mathrm{C}$ & +50 to -20 & $>60$ \\
\hline $\begin{array}{l}\text { Medium Fuel } \\
\text { IFO } 180\end{array}$ & 0.9 & 180 at $50^{\circ} \mathrm{C}$ & +30 to -20 & $>60$ \\
\hline $\begin{array}{l}\text { Heavy Fuel } \\
\text { IFO } 380\end{array}$ & 0.99 & 380 at $50^{\circ} \mathrm{C}$ & +30 to -20 & $>60$ \\
\hline
\end{tabular}

Source: IPIECA, 2000

In the Caribbean, various grades of crude oil are the predominant type of oil that is spilled. Table 12 lists the crude oil types and their associated physical/chemical properties. 
Table 12: Crude oil classifications

\begin{tabular}{|c|c|c|c|c|}
\hline Class & Type, & $\begin{array}{l}\text { Representative } \\
\text { Oils }\end{array}$ & 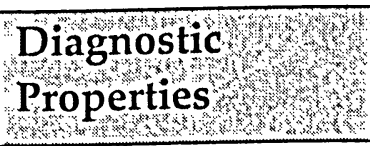 & Physical/Chemical Properties \\
\hline$\varangle$ & 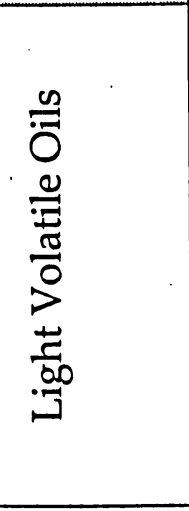 & $\begin{array}{l}\text { Diesel fuel and } \\
\text { light crude oils }\end{array}$ & $\begin{array}{l}\text { Highly fluid, } \\
\text { usually } \\
\text { transparent, can } \\
\text { be opaque, strong } \\
\text { odour, rapid } \\
\text { spreading, can be } \\
\text { rinsed from plant } \\
\text { by simple } \\
\text { agitation } \\
\end{array}$ & $\begin{array}{l}\text { May be flammable, high rate of } \\
\text { evaporative loss of volatile } \\
\text { components, assumed to be } \\
\text { highly toxic to marine or } \\
\text { aquatic biota when fresh. } \\
\text { Tends to form unstable } \\
\text { emulsions and may penetrate } \\
\text { substrates }\end{array}$ \\
\hline$\infty$ & 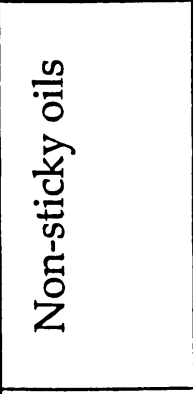 & $\begin{array}{l}\text { Medium to } \\
\text { heavy paraffin- } \\
\text { base refined to } \\
\text { crude oils }\end{array}$ & $\begin{array}{l}\text { Moderate to high } \\
\text { viscosity, waxy or } \\
\text { oily feel. Can be } \\
\text { rinsed from } \\
\text { surfaces by low } \\
\text { pressure water } \\
\text { flushing }\end{array}$ & $\begin{array}{l}\text { Generally removable from } \\
\text { surfaces, penetration of } \\
\text { substrates variable, toxicity } \\
\text { variable. Includes water on oil } \\
\text { emulsions }\end{array}$ \\
\hline$U$ & 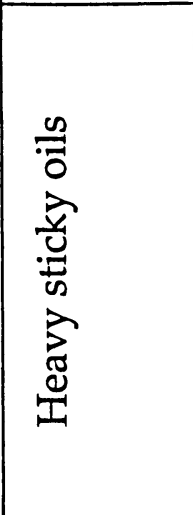 & $\begin{array}{l}\text { Residual fluid, } \\
\text { medium to } \\
\text { heavy asphalt } \\
\text { and mixed-base } \\
\text { crude }\end{array}$ & $\begin{array}{l}\text { Typically opaque } \\
\text { brown or black, } \\
\text { sticky or tarry, } \\
\text { viscous, cannot be } \\
\text { rinsed from plant } \\
\text { sample by } \\
\text { agitation }\end{array}$ & $\begin{array}{l}\text { High viscosity, hard to remove } \\
\text { from surfaces. Tend to form } \\
\text { emulsions and have high } \\
\text { specific gravity and potential } \\
\text { for sinking after weathering. } \\
\text { They have low substrate } \\
\text { penetration and low toxicity. } \\
\text { They will interfere with many } \\
\text { types of recovery equipment }\end{array}$ \\
\hline 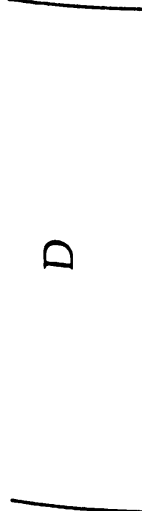 & 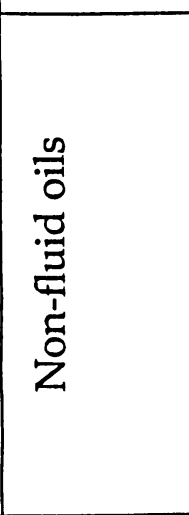 & $\begin{array}{l}\text { Residual and } \\
\text { heavy crude }\end{array}$ & $\begin{array}{l}\text { Tarry or waxy } \\
\text { lumps }\end{array}$ & $\begin{array}{l}\text { Non-spreading, cannot be } \\
\text { recovered from water surfaces } \\
\text { using most conventional clean- } \\
\text { up equipment. Cannot be } \\
\text { pumped with pre-heating or } \\
\text { slurrying. They are initially } \\
\text { relatively non-toxic and may } \\
\text { melt and flow when exposed to } \\
\text { the sun }\end{array}$ \\
\hline
\end{tabular}

Source: US EPA, 2001 


\section{Rate of spillage}

Rate of spillage also influences the cost of oil spills. For example, a single large oil spill may takes weeks to clean-up, but the same quantity of oil lost over several months from a damaged vessel close to the coast for instance, may require prolonged clean-up efforts as repeated efforts to clean the area may be required, and this instance may also result in prolonged effects on fishery resources and tourism (ITOPF 2001).

Financial evaluation of oil spill cost at TTOil

As mentioned earlier, there are many costs associated with oil spills; unfortunately a historical account of every cost per oil spill event was not available at TTOil. The costs that were available are clean-up cost for most events and the annual compensation paid to external parties (farmers/landowners). Based on the available oil spill cost data, chapter 4 explores trends in oil spill costs and factors that typically influence oil spill clean-up cost at TTOil. A flood management approach derived from Ontario's Flood Damage Reduction Program, provides structural and non-structural measures to arrive at probable new lower oil spill clean-up costs at two oilfield districts. The probability of oil spill clean-up cost is further detailed for these districts. 


\subsection{CASE STUDY: ANALYSIS OF OIL SPILLS AT TTOIL}

To illustrate the use and benefit of the oil spill characterization and economic evaluation components of the oil spill management framework, oil spill statistical data collected at TTOil are examined in this chapter. Eight years of daily oil spill data covering the period 1995-2002 are used. The statistical analysis is divided into two parts; the first is an overview of the characteristics and trends of oil spill events and the factors that influence oil spill event volume, frequency and costs. Microsoft Excel is the primary graphing tool used in this study, while Statistica, another data management tool, is used to perform basic statistical functions such as the calculation of correlation matrices and descriptive statistics.

The second part of this chapter examines oil spills at two oilfield districts at TTOil. Different oil spill management initiatives set the two districts apart, for example at district $A$, new and updated environmental initiatives to mitigate pollution problems are enforced. At District $B$, old environmental management practices and procedures still exist. Using oil spill data collected at these two oilfield districts, the return period of oil spill event volumes, and the primary causes and reasons for oil spills are discussed. The "Flood Management Approach", derived from Ontario's Flood Damage Reduction Program, is applied to oil spills at district A \& B. This approach uses structural controls to eliminate the cost of floods, while non-structural controls aid in the reduction of flood costs. These concepts are applied to the oil spill pollution problem at TTOil, in an effort to mitigate or eliminate the clean-up cost associated with oil spills. In addition, the probability of oil spill clean-up cost is graphed, to demonstrate and understand the extent of clean-up costs typically associated with oil spill event volumes. 


\subsection{Overview of oil spill statistics}

One method of understanding oil spill characteristics is through statistical analyses of oil spill data accumulated over a period of time. Many organizations and agencies that either pollute or regulate pollution activities collect similar types of pollution data. For example, government agencies in Canada collect pollution data at national and provincial levels. Environment Canada's NPRI collects daily pollution activities from seven sectors, similarly, the Ontario Ministry of Environment collect spill pollution data through the Spill Action Center 24-hour reporting line. These data and the quality of the data are important, as pollution reports collected consistently and comprehensively over a period of time, yields reliable statistics. According to Environment Canada (1998), good statistics are necessary as "better quality data allows for trends to be identified with increasing reliability, making them more effective indicators in the process of developing new strategies for pollution prevention, as well as in the measurement of performance of policies and programs". The goal of this section therefore, is to understand oil spill characteristics, trends and the factors that influence oil spill events, using oil spill data from TTOil. Some of this information will be used in this section in the hope that the results generated combined with the other components of the oil spill management framework, can promote improved oil spill management strategies, and be effective indicators for oil spill pollution prevention efforts.

\subsubsection{Oil Spill volume and frequency}

Studying trends in oil spill volume and frequency can reveal pertinent information about the extent of the oil pollution problem. It can also discern whether the pollution problem is improving or worsening over time and whether efforts to improve oil spill management are working. As indicated in Figure 14, general trends have revealed that just over half of all oil spills are medium in size, with an average event volume of 433 
liters. Large oil spills represent $23 \%$ of the total number of pollution incidents, with an average event volume of 3,200 liters. Small oil spills make up the third largest group of oil spill events. The general conclusion drawn from this graph is that most oil spill events at TTOil are medium in size. Enormous and catastrophic oil spills do occur, but are infrequent. The smallest range of less than 10 liters of oil is not graphed because these data are not available. It appears that oil spills less than 16 liters are not reported, therefore the frequency of these spills are unknown. The volume categories illustrated in Figure 14 are not based on assigned values by any authority; they are simply used to facilitate easier discussion of the numerical data.

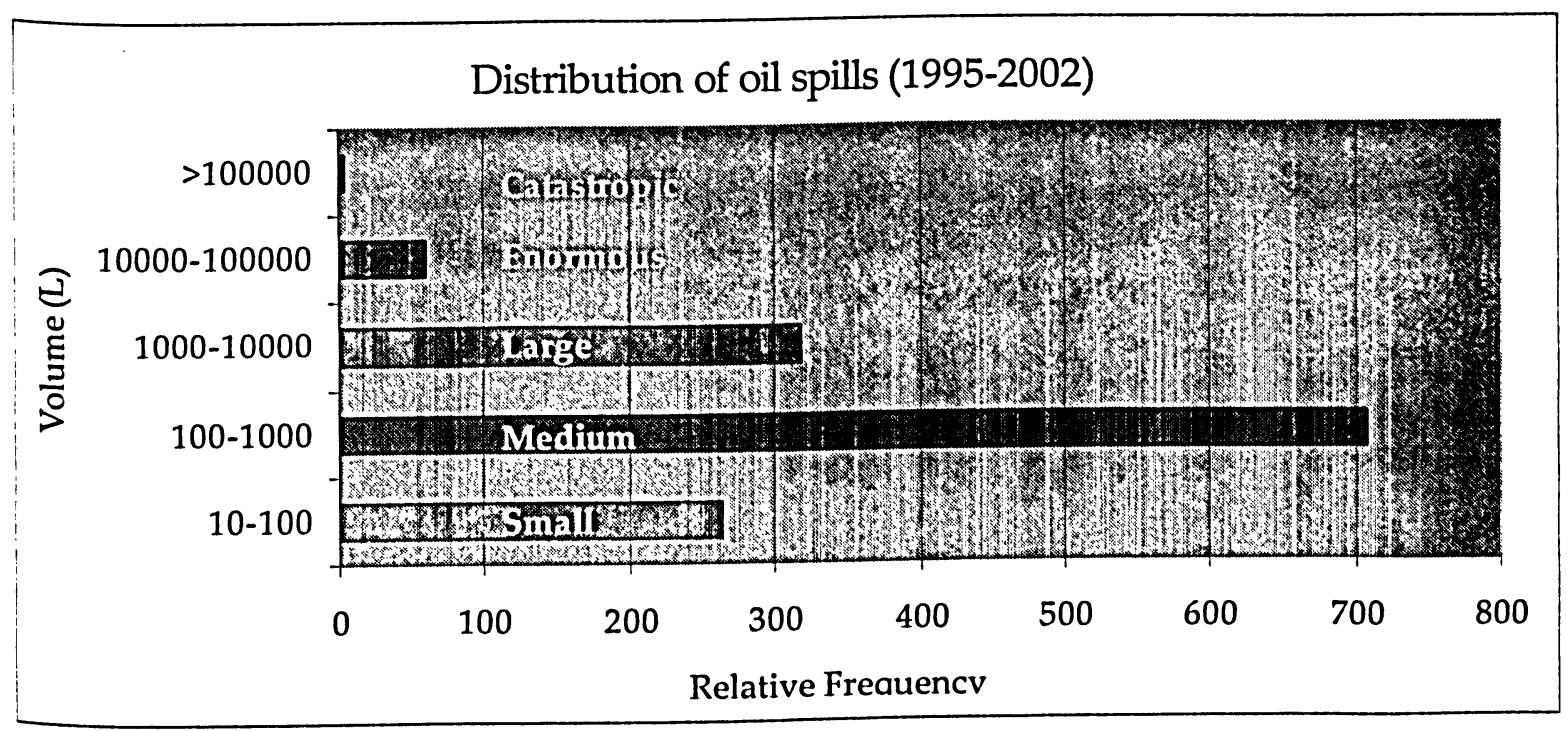

Figure 14: Distribution of oil spills (1995-2002)

In order to mitigate the pollution problem, TTOil has implemented many pollution prevention measures in recent years. For example, in October 1999, ISO 14001 initiatives were launched at District $A$ to encompass all the activities, products and services of its twenty departments such as drilling, transport, trunk pipelines and production operations to name a few. Certification was attained in September 2002. Some of the efforts conducted to attain certification were to incorporate relevant environmentally- 
conscious work practices and environmental legislation into its Exploration and Production operating system. All activities that negatively impacted the environment were identified, and operational controls were developed for impact minimization and prevention. To measure the impact of these initiatives, annual oil spill events from District A are graphed in Figure 15.

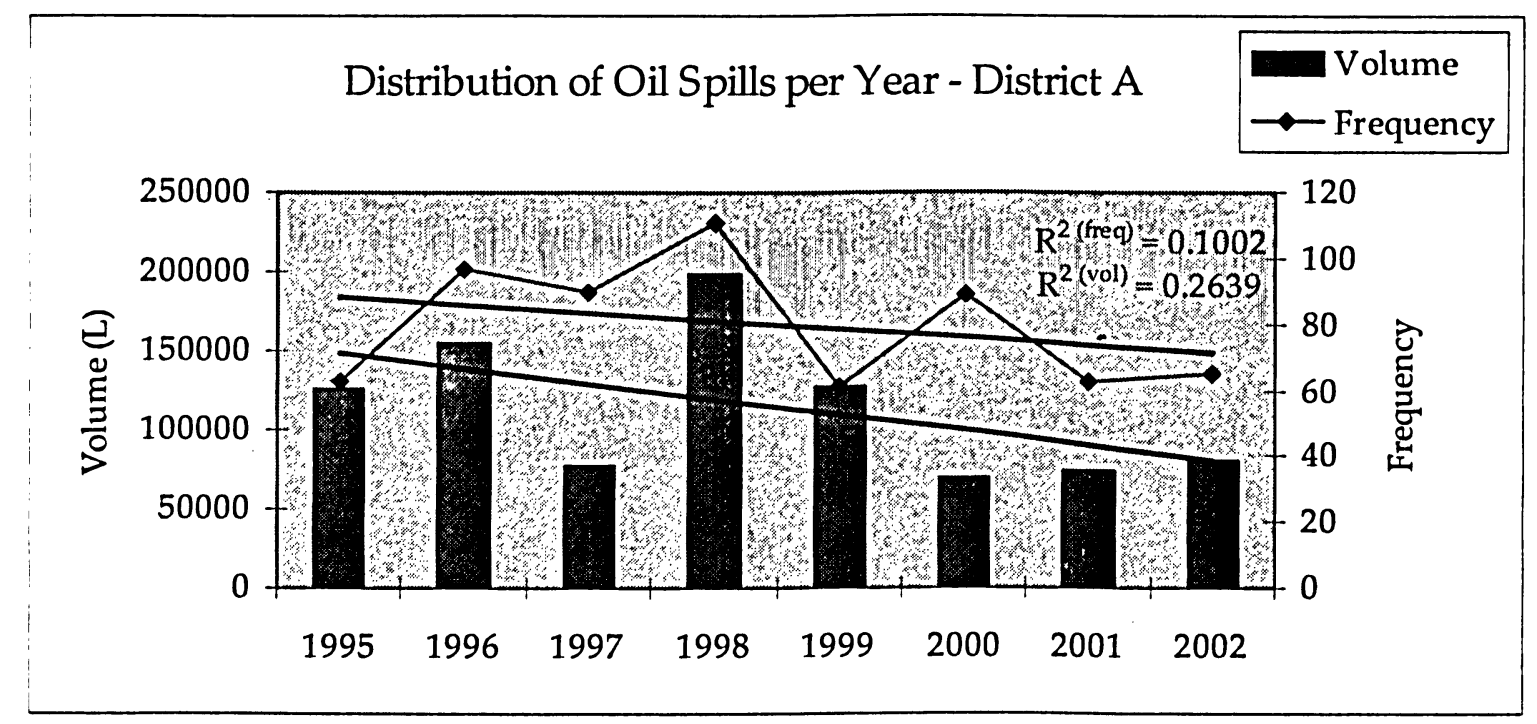

Figure 15: Distribution of oil spills per year-District A

Although the R-squared value derived from the volume and frequency is very low, the general trend from 1999-2002 indicates a reduction in oil spill volume and frequency compared to previous years. This decline may coincide with the ISO 14001 initiatives which began in 1999. Oil spill events did increase slightly in 2002, the year ISO 14001 certification was attained, however, given the novelty of the certification, fostering a new HSE culture throughout E\&P operations by all employees and operations, probably requires more time to fully adopt the new initiatives. In addition, since many infrastructure upgrades are phased in over time, this may result in a very gradual decrease in oil spill volume and frequency which may be apparent in future oil spill data. However, the general trend in oil spill volume and frequency of this district is 
that, oil spill events are significantly higher in the first four years with the exception of 1997 and steadily lower during 1999-2002.

A similar fluctuating pattern is also apparent when annual oil spill data for the entire dataset are graphed, see appendix C-1. One thing that was observed is that of the three lowest oil spill volumes, two occurred in the last two years (2001 \& 2002) of the eight year dataset. One can speculate that the decline is associated with the environmental improvements made at District A, a region formally prone to higher oil spill events. However, using the entire dataset, the average annual oil spill volume that can be expected each year at TTOil is approximately 345,433 liters, with an average oil spill frequency of 182 events. In a given month, the oil spill volume is averaged at 28,767 liters, with an expected frequency of 15 events. As environmental management initiatives progress in District $A$, and if similar efforts are implemented and maintained at Districts B and C, oil spill volume and frequency may subsequently decrease. Further future oil spill analyses based on 2003, 2004 and 2005 data for example, may be able to reveal the truer impacts of the environmental initiatives employed by TTOil to mitigate oil spills.

\subsubsection{Factors influencing oil spill volume and frequency}

Many factors can influence oil spill volume and frequency, for example, varying levels of production can stimulate oil spill occurrences in E\&P operations, whereby it can be assumed that the more oil pumped and produced, the higher the number and volume of oil spill events. Secondly, the value in knowing the common causes and reasons for oil spills can translate into prevention measures that target those needs directly. Thirdly, weather conditions can contribute to oil spill event occurrences and severity. The impact of rainfall, along with the influence of production activities, and the cause and reason for oil spills, are examined in this section. 


\subsubsection{Oil Production}

Given the fact that the physical infrastructure of TTOil is aging, one assumption made is that as more oil is pumped and produced, the greater the demand or pressure on the physical infrastructure, which results in higher oil spill frequeney and volumes. Three regression models are tested to determine if a significant correlation could be found when production is compared to oil spill volume and frequency. The results are conclusive as no correlation is apparent, see appendix $\mathrm{D}$ for results. If a correlation did exist, it may be used as an indicator in oil spill forecasting if the spill process is stationary, whereby, given expected levels of production for future time periods, an increase or decrease in oil spill volume or frequency could be detected. Knowledge of this information in advance could foster proactive oil spill planning and prevention efforts to prohibit not only the occurrence of an oil spill event, but its severity. Without this correlation, it is also difficult to conduct oil spill clean-up cost forecasting, as that cost is dependent on oil spill volume and frequency. This is further discussed in a section 4.1.2.4 of this chapter.

One thing for certain is oil production is decreasing each year at TTOil at a minimum of 300,000 barrels, or approximately 50 million liters per year. During the mid-to-late 1900s, oil production was higher, by 1999 production levels showed a steady but pronounced decline. Many of the oil fields still extracting oil have been in existence for several years. Perhaps their resources are slowly depleting while the development for new wells are not mobilized fast enough, to offset the decline experienced by existing wells. Conceivably more focus may have been placed on offshore operations, however, oil spills data from that sector are not considered in this study, as the focus is on landbased oil spills. Therefore, a probable conclusion that may be drawn from this analysis is that the inferior quality of the oil spill data, limits the application of oil spill volume and frequency forecasting using production data. 


\subsubsection{Oil Spill Causes and Reasons}

Two imperative variables for understanding oil spill characteristics are answers to the questions, what went wrong, and why did it go wrong. The answers are the causes and reasons for oil spills. What caused the oil spill is asking for answers about the factor/s that caused the incident to occur, for example, "a flowline broke due to corrosion". The cause is the breaking of the flowline, while the reason is the answer to the question, why did the flowline brake? It broke because that section of the flowline was corroded; corrosion therefore is the reason for the oil spill event. Fourteen oil spill causes and twelve reasons have been identified at TTOil. The definitions for oil spill causes and reasons at TTOil are listed in the glossary, see Appendix E.

\section{Cause of oil spills}

In terms of oil spill volume, the most significant cause of oil spills is from pipelines, such as pumplines, flowlines and trunklines, and to a lesser extent from tanks and valves, as is illustrated in Figure 16. In most pipeline incidents, the most frequent reason for oil spills are corrosion, unknown, or leaks if the line develops a crack or hole. Spills from tanks are mainly a result of overflows, equipment failure/defect, or reasons that are unknown. Spills from valves are largely related to human error, whereby a valve may be left open in error or from equipment failure or defect. Many oilfields are located in areas accessible to the public, thus, vandalism is a problem as pipelines and other materials are subject to theft or damage. Oil spill frequency and its relation to the cause of oil spills are illustrated in Figure 17. This graph indicates that oil spills from pipelines such as pumplines and flowlines occur in larger numbers, while valves, tanks and other causes occur in smaller numbers. 


\section{Cause of Oil Spills - Volume (liters)}

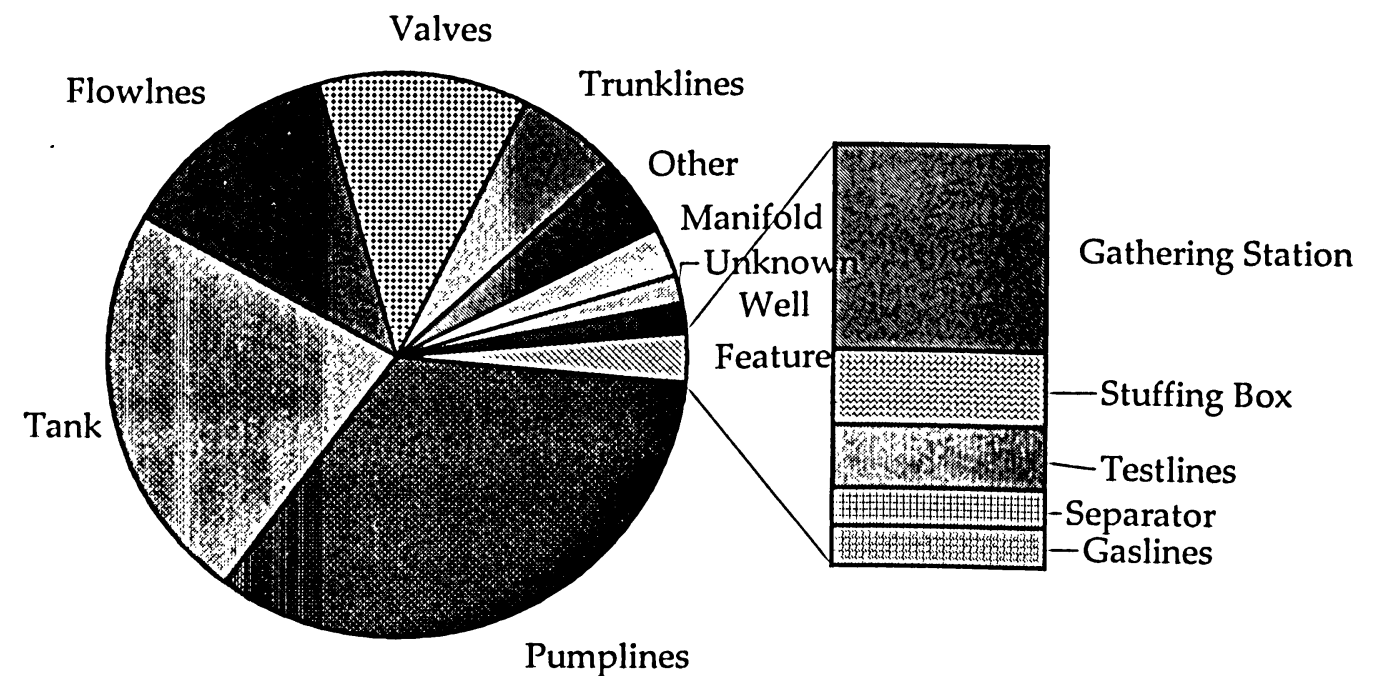

Figure 16: Cause of oil spills - Volume (L)

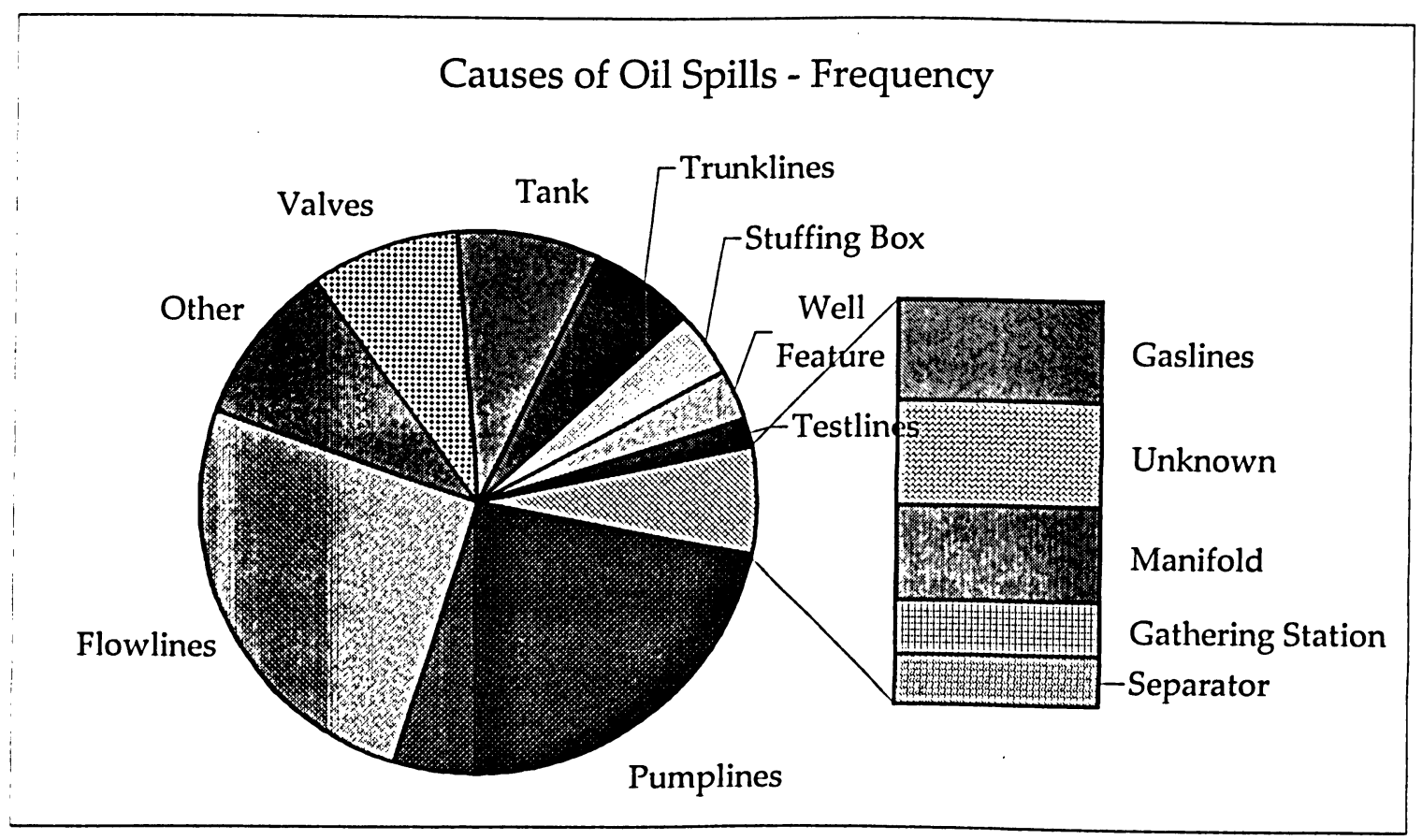

Figure 17: Causes of oil spills - Frequency

Common to both pie charts (Figures 16 and 17), is that significant volumes and frequencies exist for pipeline oil spills, in particular, flowlines and pumplines. This is followed by oil spills from valves and trunklines. Since both pie chart distributions are 
similar for these causes of oil spills, it is an indication that these spills, apart from a few isolated incidents, are generally not individually large oil spill events. For example, for pumpline spills, the median size is 636 liters with a mean of 2,700 liters. The median for flowlines is 318 with a mean of 4,061 liters. Valves and trunklines have a median of 318 and 477 liters respectively, and means of 2,733 and 7947 liters. For tank spills, where a higher volume is combined with a lower frequency (Figure 16-17), the individual spills events may be larger in volume. This is evident given that the median of tank spills is 954 with a mean of 19,627 liters. The median is fairly significant and just bordering the category of "large" oil spills. The mean is within the group entitled "Enormous". A spill of this magnitude can have very significant impacts on the environment, especially if it occurs near environmentally sensitive environments. Typically at TTOil, many tanks are constructed with an individual containment system described earlier in section 3.3 as a bond wall. The walls are built around the tanks, allowing spilled oil to be collected within the confines of the containment system. Large tanks as mentioned earlier, are typically built to contain 1.5 times the capacity of the tank contents. Oil traps may be used, these are mechanisms that exist below the surface and connected to the containment system, to trap oil for easier removal. The spilled oil is simply recycled. The impacts on the environment from these types of oil spills are unknown, as details of environmental impacts are not reported at TTOil.

\section{Ideas for pollution prevention derived from statistical analyses of oil spill causes}

Pollution prevention efforts are required for pipeline spills, particularly flowlines and pumplines, in the form of repairs or replacement of sections of damaged pipeline. Mechanisms such as valves, stuffing boxes, manifolds or separators, are susceptible to equipment failure or defect, and therefore require regular preventative maintenance to mitigate future oil spills. If oil spill pollution prevention efforts are to be addressed in phases, as is common in industrial settings, oil spill statistics have revealed that pipeline 
oil spills are the most problematic pollution issue, both in terms of volume and frequency. Therefore they should be given priority followed by oil spills caused by mechanisms' failures.

\section{Reasons for Oil Spills}

In order to fully comprehend the characteristics of oil spill events, it is necessary to understand the reasons why they occur. When physical infrastructures are aging, as is the case of TTOil, problems such as corroded and leaking pipes or the malfunction of equipment are common. The common reasons for oil spills based on oil spill event data from 1995-2002 are illustrated in Figures 18 and 19. As discussed in the previous section, pipeline spills are the most common cause of oil spills, as result, it is not surprising that corrosion and leaks of the pipelines that pump, transport or contain oil, are the top two reasons for oil spill occurrences. Together (corrosion/leaks), contribute $37 \%$ of total oil spill volume and $53 \%$ of the total oil spill frequency. Unknown reasons also make up a significant portion of the total oil spill volume (23\%) and frequency (18\%). This missing information is problematic as much vital information that could be used in oil spill prevention is not available. Overflows, human error and equipment failure also collectively represent about $20 \%$ of the total volume and frequency, also a significant percentage. 


\section{Reasons for Oil Spills - Volume (L)}

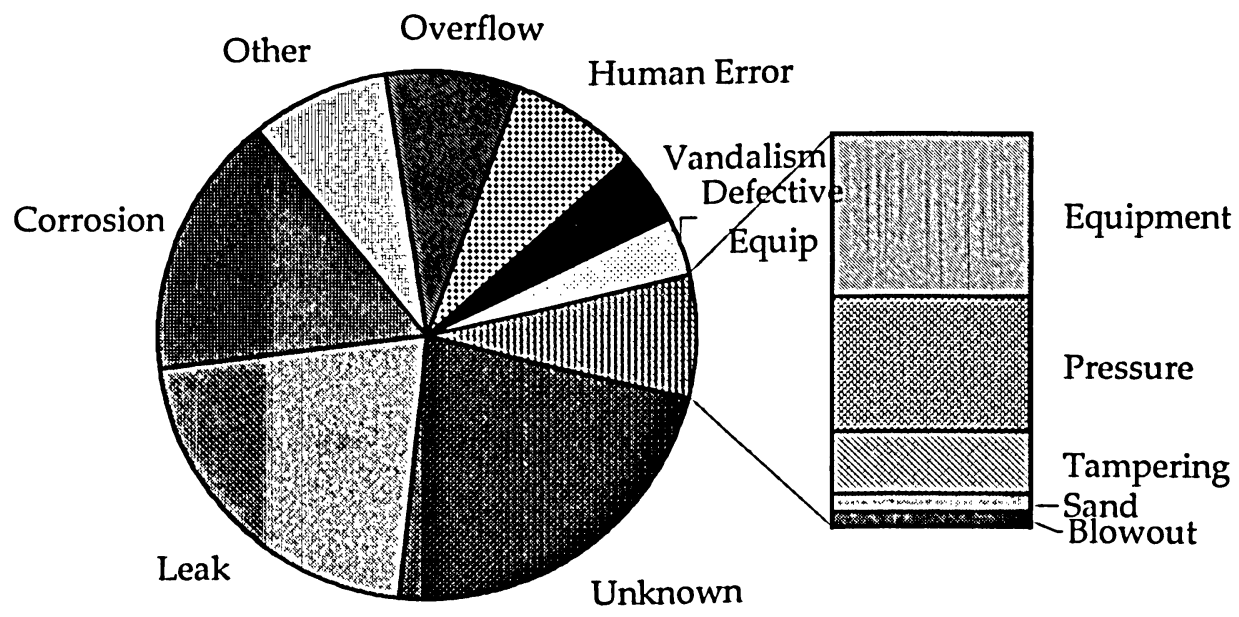

Figure 18: Reasons for oil spills - Volume (L)

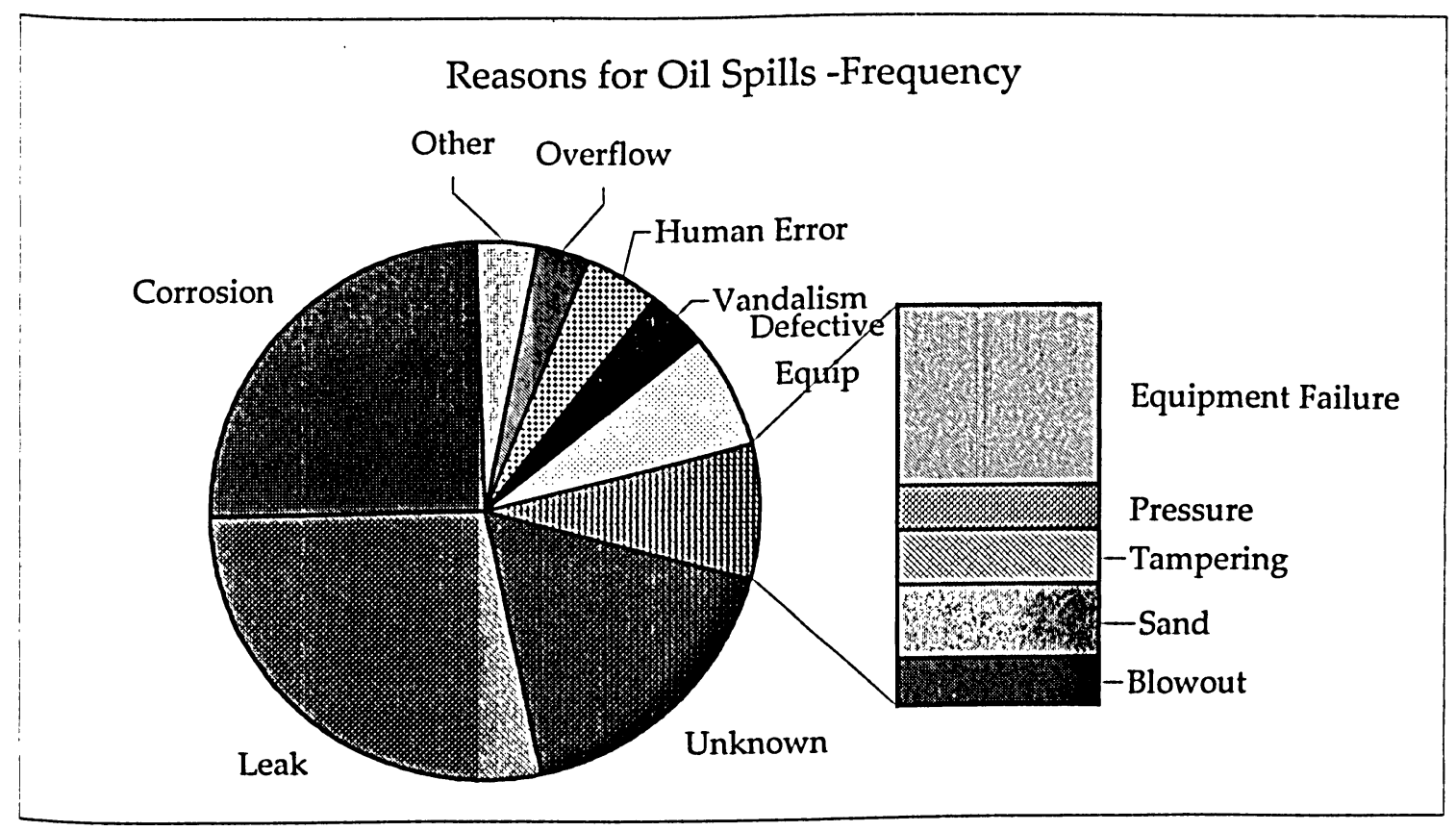

Figure 19: Reason for oil spills - Frequency 
Oil spills from Leaks and Corrosion

Oil spill event volume from corrosion and leaks both have a median of 318 liters and means of 1,471 and 5,322 liters respectively. The mean of oil spills from leaks is higher as it includes one of two extremely large oil spills, measuring over 1 million liters. Apart from these extreme events, it appears leaks are typically medium sized in volume, as almost half of its spills (49\%), are within that range. The other half of oil spills from leaks are from large spills (21\%), and small spills (27\%). Spills from corrosion exhibit a similar trend whereby, $56 \%$ of all spills are medium, and $21 \%$ are less than 100 liters. In terms of enormous spills from leaks and corrosion together, only a marginal number of spills (2\%) exist within this range. As result, their occurrences are infrequent and are not representative of typical oil spill expectations from these two categories. Overall, the majority of spills from leaks and corrosion are largely medium in size, $29 \%$ are large and $10 \%$ are enormous. Two of three catastrophic oil spill events were from leaks.

Ideas for pollution prevention derived from statistical analyses of oil spill reasons

Corrosion and leaks are closely related to spills from pipelines, as they collectively represent $69 \%$ of oil spill frequency and $75 \%$ oil spill volume from pipeline operations. Preventative measures should include structural changes such as the maintenance of the physical infrastructure, through replacement or repairs of corroded and leaking pipelines. Priority should be given to pipelines prone to reoccurring oil spill reports. Clamping the lines when spillage occurs (a common practice at TTOil) should be a temporary fix that results in permanent changes within a reasonable time frame.

To a lesser extent, oil spills from human error and equipment defects or failures are accountable for $15 \%$ of the total oil spill frequency, and $9 \%$ of the volume. This can be translated into non-structural and structural changes. In regards to non-structural changes, employees could be re-trained in the use and maintenance of the physical 
mechanisms within E\&P operations, in order to reduce future oil spills events. Concepts of environmental integrity could be also instilled in the values of not only HSE staff but also field and operations staff within E\&P, to foster improved environmental performance. Thereby, simple mistakes can be fixed, such as valves left open or closed when they shouldn't, or failure to recognize that the stuffing box rubbers require replacements when worn down. The volume capacity of storage or temporary holding tanks requires a better monitoring system, to ensure tanks do not exceed their capacities. If it does occur, containment systems should be implemented at all storage tanks whether temporary, transitory or long-term, as it was observed in the field, that not all storage systems were outfitted with appropriate oil spill containment/trap systems.

\subsubsection{Rainfall}

Rainfall may influence the frequency and volume of oil spills as severe rainfall can cause power outages, the destruction of vegetative material, the flooding on containment systems, all of which may contribute to varied levels of oil spill pollution. The relationship between oil spills and rainfall are explored in this section.

Trinidad and Tobago has a tropical climate therefore has two seasons, the rainy/wet season and the dry season. The dry season occurs from January to May and the wet season from June to December (TIDCO, 2001). Annual rainfall is about $200 \mathrm{~cm}$ over most of the country (TIDCO, 2001). It's location as the most southern isle in the Caribbean places it just south of the Atlantic hurricane belt, therefore not in the usual path of the storms. Figure 20 illustrates the annual rainfall at 5 rainfall stations in Trinidad, all of which are located within the oilfield operations of TTOil. 
The graph demonstrates a lower rainfall volume during the first few months of the year as it is the dry season; the wet season begins in June. A drastic increase in rainfall is observed then and this continues until November. In September the rainfall volume decreases slightly, then increases again until November, and begins to taper off by December just before the beginning of the dry season in January. The negative rainfall value observed in March is an indication of a rainfall station failure for that month.

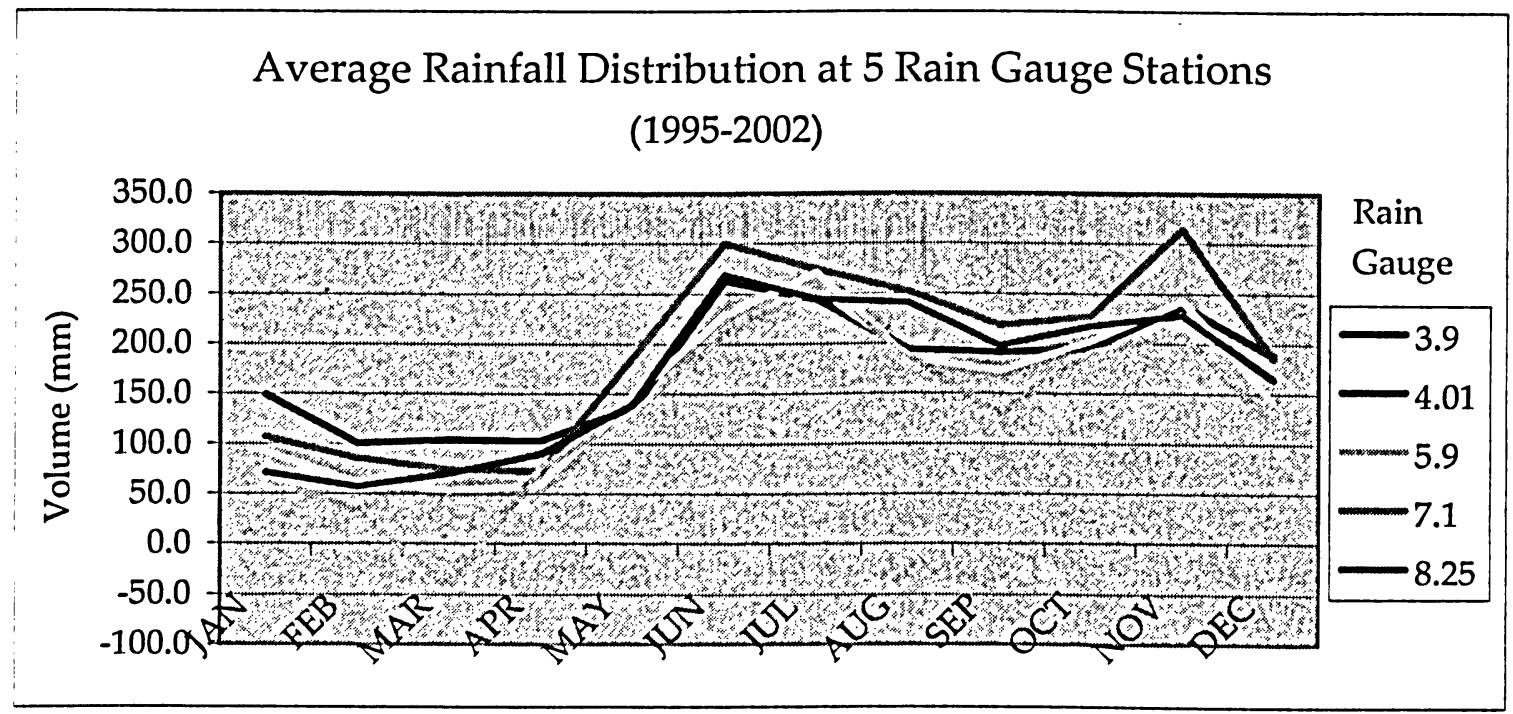

Figure 20: Average rainfall distribution at 5 rain gauge stations (Water and Sewage Authority, 2004)

Weather conditions may influence oil spill events whereby heavy and/or consistent rainfall events may increase the frequency, volume or cost of oil spills as water transports oil to greater distances and to different environmental media. The environmental impact of oil spills are not known as this information is not reported. However, what is reported are the environmental mediums affected, such as soils, vegetation and watercourses; the extent of the environmental impacts from oil spill events is unknown. Appendix C-2 illustrates the distribution of environmental mediums affected by oil spill events in terms of oil spill frequency. The graphs shows 
that $66 \%$ the environmental mediums are not even reported. If the environmental impacts were recorded for each spill event, it would be interesting to compare that variable with rainfall data, to determine if environmental consequences are worsen by weather conditions.

As indicated in Figure 20, the period of lowest rainfall is between December and May, and the highest period of rainfall is between June and November. More than half of the total oil spill frequency occurs in the wet season. According to Appendix D, a strong correlation exists between oil spill frequency and rainfall. A Pearson r-squared value of 0.80 is attained. Figure 21 which illustrate oil spill frequency versus rainfall, a distinct similarity in the pattern of the each line graph exists. Oil spill frequency is highest during the wet season and lowest in the dry season, a strong indication that the two variables have a relationship. Therefore, it is fair to conclude that oil spill frequency is influenced by rainfall. The field staff at TTOil has to be more assertive in enforcing spill prevention during wet seasons.

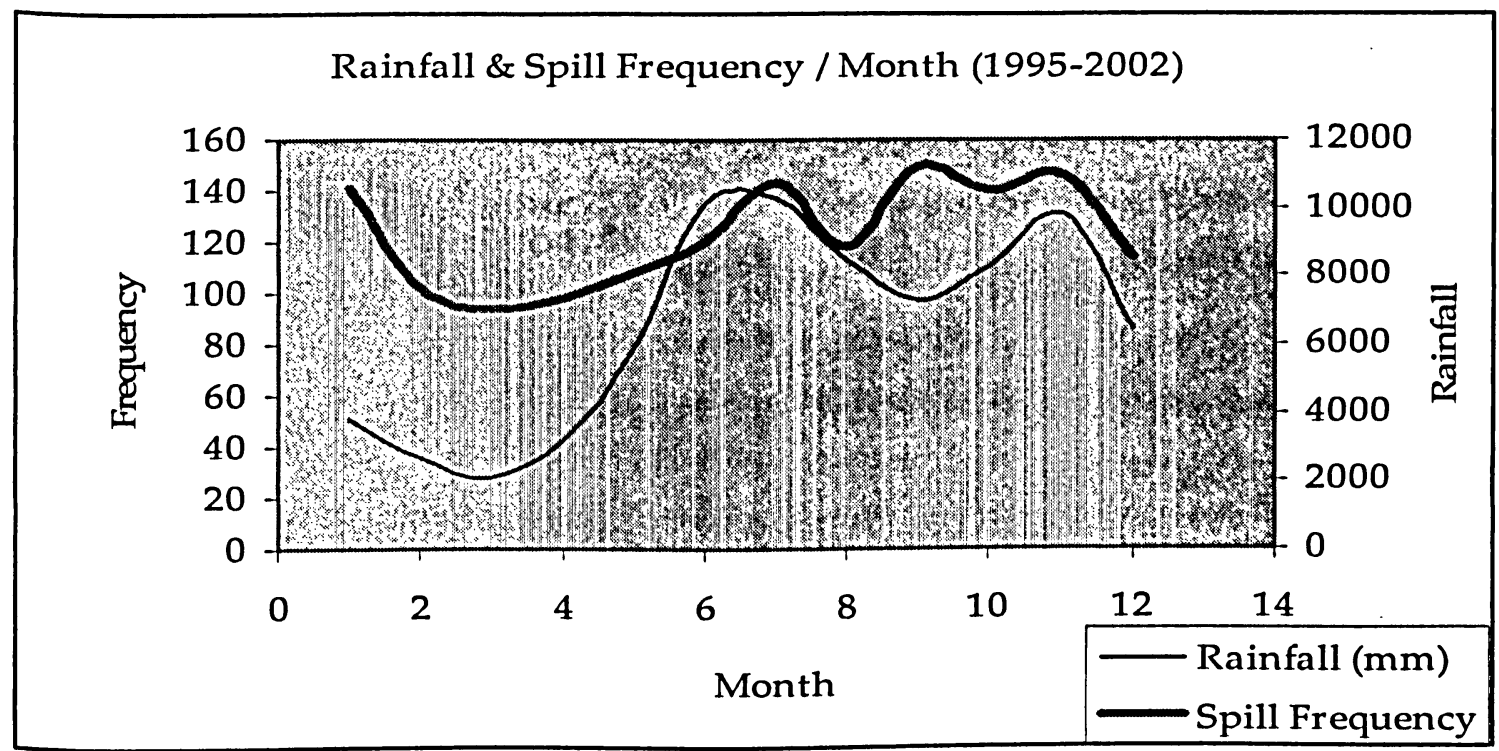

Figure 21: Rainfall and oil spill frequency per month (1995-2002) 


\subsubsection{The costs of oil spills}

The oil spill costs used in this study include the cost to clean-up an oil spill event, and the cost incurred to compensate external parties for damages to their property. Section 4.2 addresses the costs of oil spills in greater depth however, this section will provide an overview of the trends in oil spill costs. Factors that influence costs are examined, such as oil spill volume and frequency, the causes and reasons for oil spills and weather.

\section{Distribution of oil spill costs}

General trends in oil spill cost have revealed that clean-up costs are $9 \%$ higher than compensation costs. As indicated in Figure 22, compensation costs over the eight-year period are fairly steady with the exception of 1996, while clean-up costs fluctuate dramatically over the years, with a very high peak in 1998. One interesting observation is, during the first four years, the total cost of oil spills was much higher than the last four. It appears that the clean-up cost began decreasing in 1999, perhaps due to the improved efforts to prevent oil spill pollution which began that year at District A.

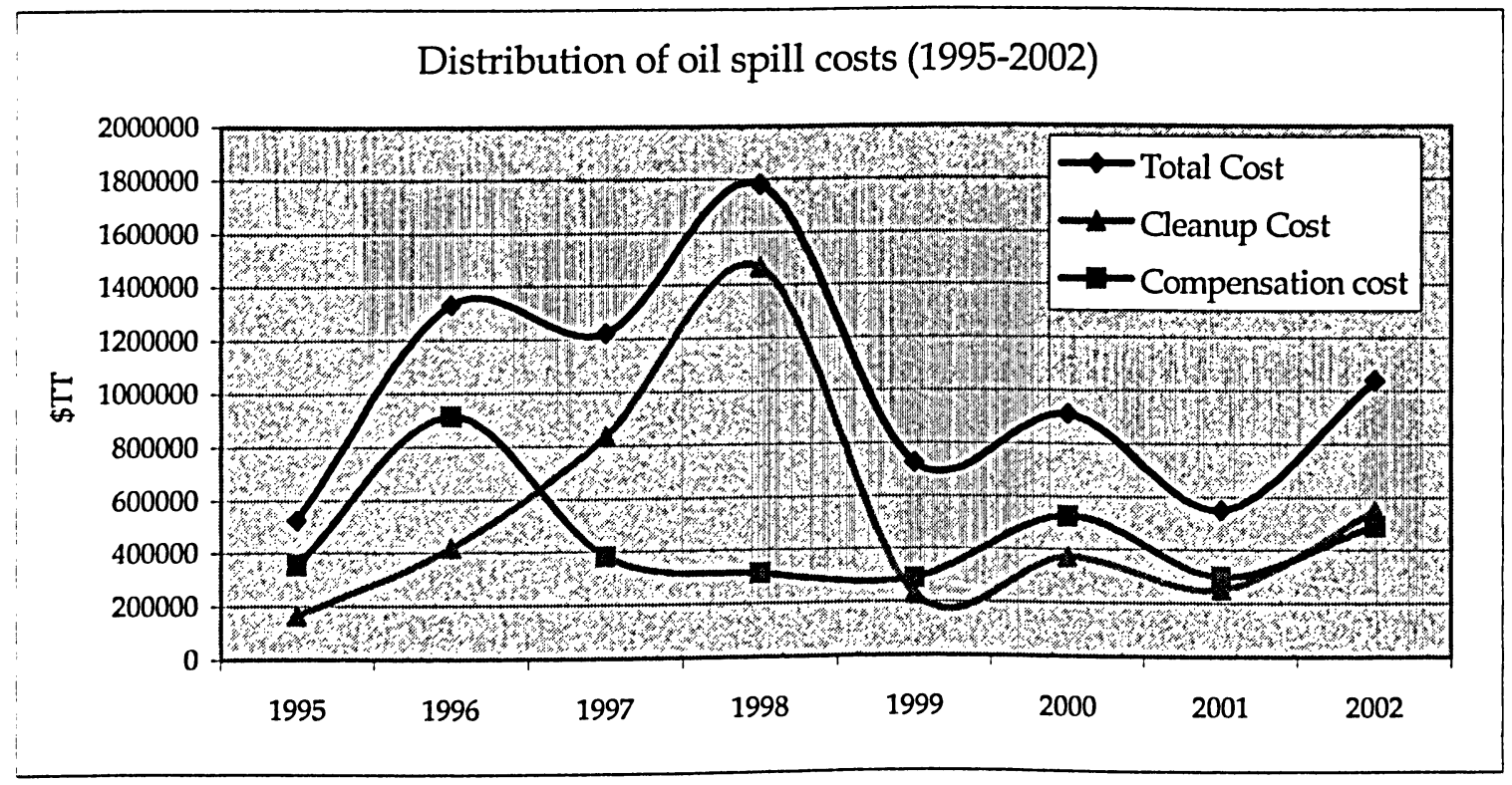

Figure 22: Distribution of oil spill costs (1995-2002) 
Factors that influence oil spill costs

The total cost of oil spills in this study refers to the cost to clean-up an oil spill and compensation paid to external parties for damages. Information about legal penalties is not available, therefore not considered in this study. The total cost of oil spills is significantly influenced by oil spill frequency and to a lesser extent by oil spill volume. See appendix $D$, for results of correlation matrices from three regression models. For example, using the linear regression model, the Pearson r-value for annual total cost versus frequency is 0.85 , while total cost versus volume is 0.50 . Total cost is therefore, influenced by oil spill frequency. Clean-up cost is also influenced by oil spill frequency; a strong Pearson r-value of 0.75 is derived. There is no correlation between the clean-up cost and oil spill volume.

For compensation to external parties, a weak correlation exists with oil spill frequency. However, a very strong correlation with oil spill volume is apparent; the Pearson rvalue is 0.88 . The most effective variable therefore for predicting the annual total cost and clean-up cost of oil spills is frequency, while oil spill annual volume is a better predictor for compensation costs. Unfortunately, the desired predictor variable for oil spill volume and frequency, the "production" variable, does not correlate significantly; the Pearson r-values are very low at 0.06 for frequency, and 0.39 for oil spill volume. Thus, without the ability to predict oil spill volume or frequency, it is not possible to predict realistic future costs. Predicting future costs is another aspect of analysis that would be interesting to calculate if there were no limitations in the production versus oil spill frequency and production data, however, either the data are inferior or given the fact that this is real data, no correlation is apparent. 
The clean-up cost of oil spill causes and reasons

The cost for oil spill clean-up can vary depending on the cause or reason of the oil spill event as illustrated in Figure 23. Oil spills from pumplines rank the highest clean-up cost on average, however, in terms of oil spill frequency, it is the second largest cause of oil spills. Oil spills from flowlines have the highest frequency of events and cost much less than pumplines. Their average spill is approximately TT $\$ 2000$. In terms of oil spill reason, oil spills from corrosion costs the most, the average cost is TT\$7771 per event. Oil spills from corrosion are also a common occurrence. They represent $23 \%$ of the total oil spill frequency. Spills from leaks contribute the highest frequency of oil spill events but the average cost is lower at TT $\$ 4893$.

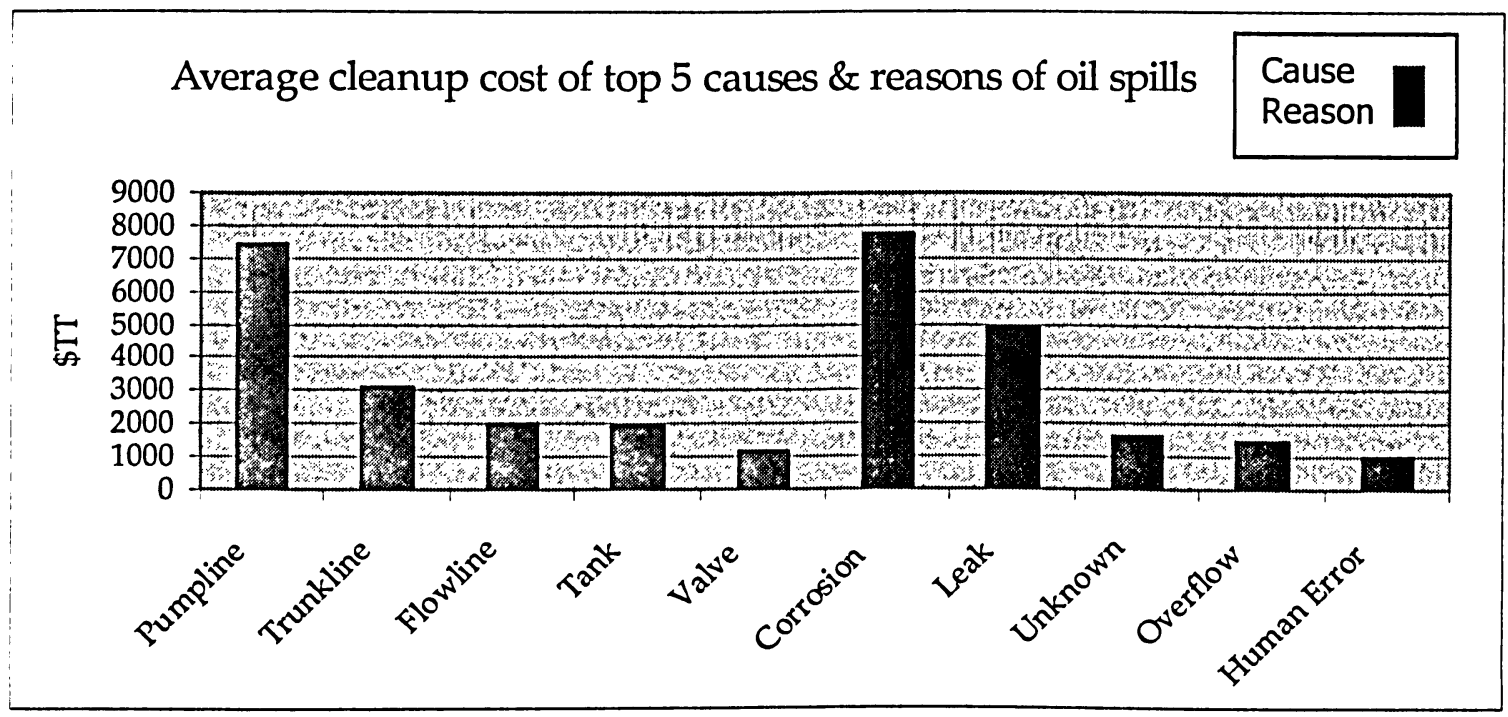

Figure 23: Average clean-up cost of the top 5 causes \& reasons of oil spills

One of the most important characteristics that can be discerned and reinforced from Figure 23, is that oil spill occurrences related to the physical infrastructure such as corroded and leaking pipelines, are costing the company a significant amount of money. This cost only represents the clean-up cost, other costs such as compensation to external parties and regulatory penalties can significantly increase the costs of oil spills 
caused by pipelines. Pollution prevention efforts to remedy infrastructure problems would not only save the company money by reducing oil spills, but also simultaneously reduce oil spill volume and frequency and likely environmental impacts. Structural and non-structural applications are used in section 4.2, to illustrate how oil spill clean-up cost can be reduced.

The impact of weather conditions

The correlation between the total cost of oil spills and average annual rainfall is illustrated in Figure 24. It was assumed that the cost paid to external parties would increase during the wet season as rainfall transports oil to larger areas, which can potentially damage more crops, livestock or pollute local water courses and downstream habitats. Since compensation cost is only available on an annual basis, it is paired with the average annual rainfall from the five rain gauge stations and a strong correlation was not derived. Perhaps if the compensation data was available in smaller units, such as daily or monthly data, it would be possible to attain a stronger correlation. The clean-up cost of oil spills however did demonstrate a correlation by the three regression models. Figure 21 illustrates a Pearson r-value of 0.57873 with many data points in close proximity to the $95 \%$ confidence interval. The graph indicates that during the years of significant rainfall, oil spill clean-up costs consequently increases. 


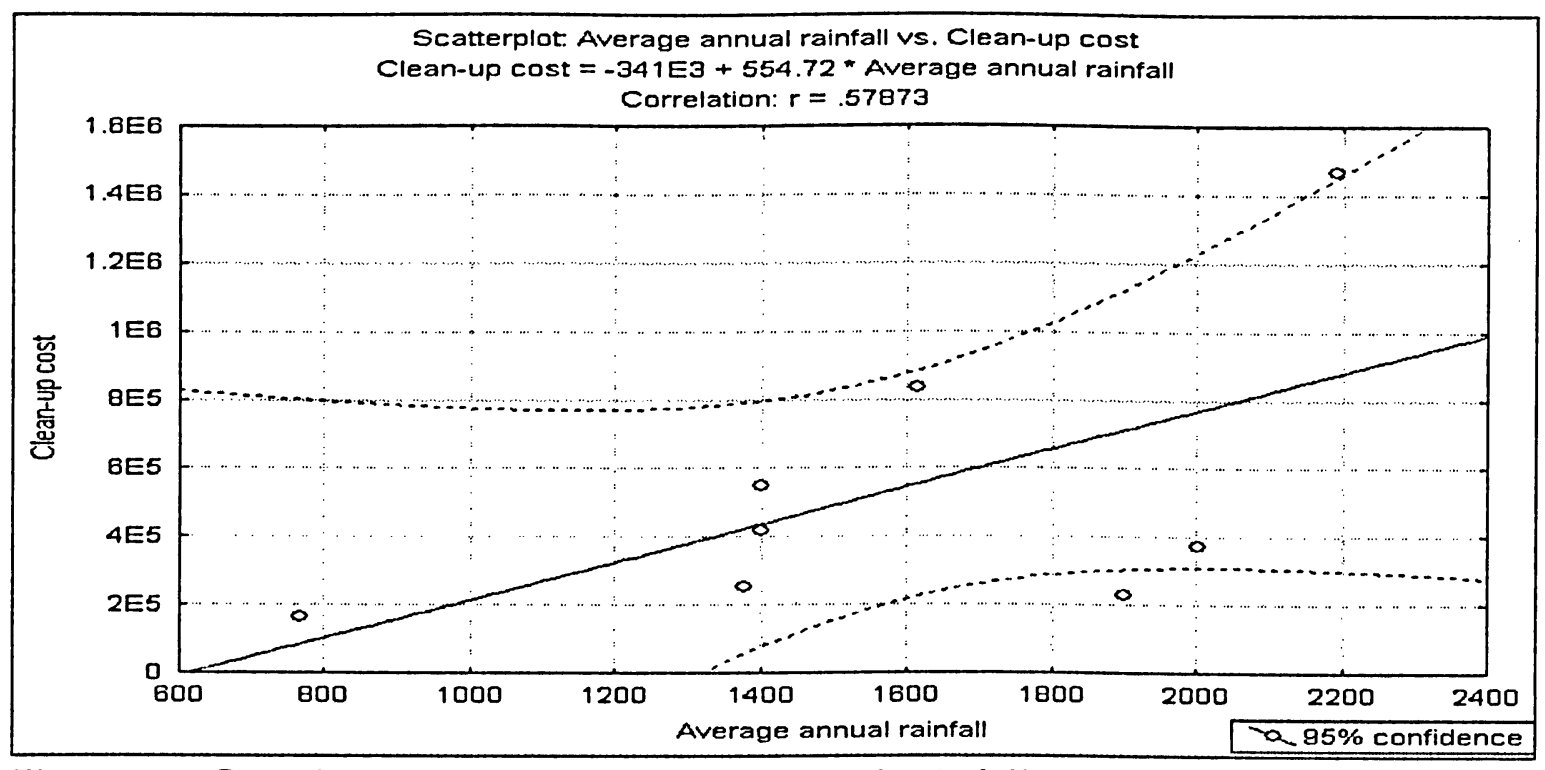

Figure 24: Correlation between average annual rainfall and clean-up cost 


\subsection{Analyses of oil spills at two oilfield districts}

Section 4.1 provided an overview of the volume, frequency and costs of oil spills as well as the factors that influence oil spill events at TTOil. The goal of this section is to take that information a step further, to examine oil spills at the oilfield district level. This is done by calculating the return period of the oil spill event volumes, the probability of oil spill clean-up costs, and the application of concepts from the "Flood Management Approach". The Flood Management Approach uses structural controls and nonstructural measures to mitigate or eliminate flood damage. A similar approach is used to demonstrate how oil spill costs, frequency and volume could also be potentially reduced. There are 34 oilfields at TTOil bounded by three districts. Oil spill data from two of the three districts are examined in this section.

The two oilfield datasets used in this chapter revealed that oil spill data were not collected and reported on an equal basis at TTOil. In fact, of the three oilfield districts, only one district comprised of 7 oilfields, demonstrated good oil spill data quality; this is referred to as District A. Another district with 10 oilfields and inconsistent/incomplete oil reports, is referred to as district B. Both districts are located near each other and display similar habitat types and land-use. They also both receive on average, similar rainfall volumes. District B however, is slightly larger in size. Districts A and B will be analyzed and compared to determine the efficacy of their oil data, in providing knowledge about oil spill dynamics, in order to apply appropriate oil spill management measures. 


\section{Calculation of the return period}

The return period is the likelihood of re-occurrences of oil spill event volumes. In sections 4.2.1 and 4.2.2, the return period for oil spill event volumes is calculated by the product of the probability of spill event volume per event, and the average annual number of spill events over the eight year study period. The return period of oil spill event volume is calculated using:

$$
\begin{aligned}
& P[S>s] / y r=P[S>s] / \text { event } *(\text { events } / y r) \\
& T_{r}=\frac{1}{P[S>s] / y r}
\end{aligned}
$$

$\mathrm{P}[\mathrm{S}>\mathrm{s}]=\quad$ is the probability of spill event volume equals or exceeds $\mathrm{s}$

$\mathrm{s}=$

$\mathrm{T}_{\mathrm{r}}=$ spill event volume, $\mathrm{L}$

(Li, 1991)

$$
\text { return period of spill event volume, year }
$$

\subsubsection{Frequency of oil spill events}

District $A$ : The most frequent oil spill events are medium in volume, measuring $57 \%$. Enormous oil spills account for 3\%, while large and small spills are $20 \%$ each. No catastrophic spills have been reported at this district. Given knowledge of the relative volume distribution of oil spills over eight years, it is equally important to understand the return period for these events. Figure 25 highlights the frequency of oil spill event volumes from 1995-2002 at two oilfield districts. For district A, the graph illustrates that oil spills less than 10,000 liters occur frequently, small to medium spills occur daily or at least a few times each month, while large oil spills occur a few times each year. Oil spills greater than 10,000 and less than 20,000 liters occur every year, but their frequency is limited to a few events per year. Oil spills greater than 20,000 liters are isolated events, and may occur once per year, or once every few years. The highest spill volume recorded at this district was 65,500 liters. It occurred once during the eight-year period. 
Oil spills greater than 20,000 liters are limited to the period 1995-1999, perhaps this is due to the introduction of ISO 14001 standard at the end of 1999 at District A. Overall, the return period of oil spills is highest for medium events followed by small and large spills. The lowest return periods are for spills classified as enormous or catastrophic.

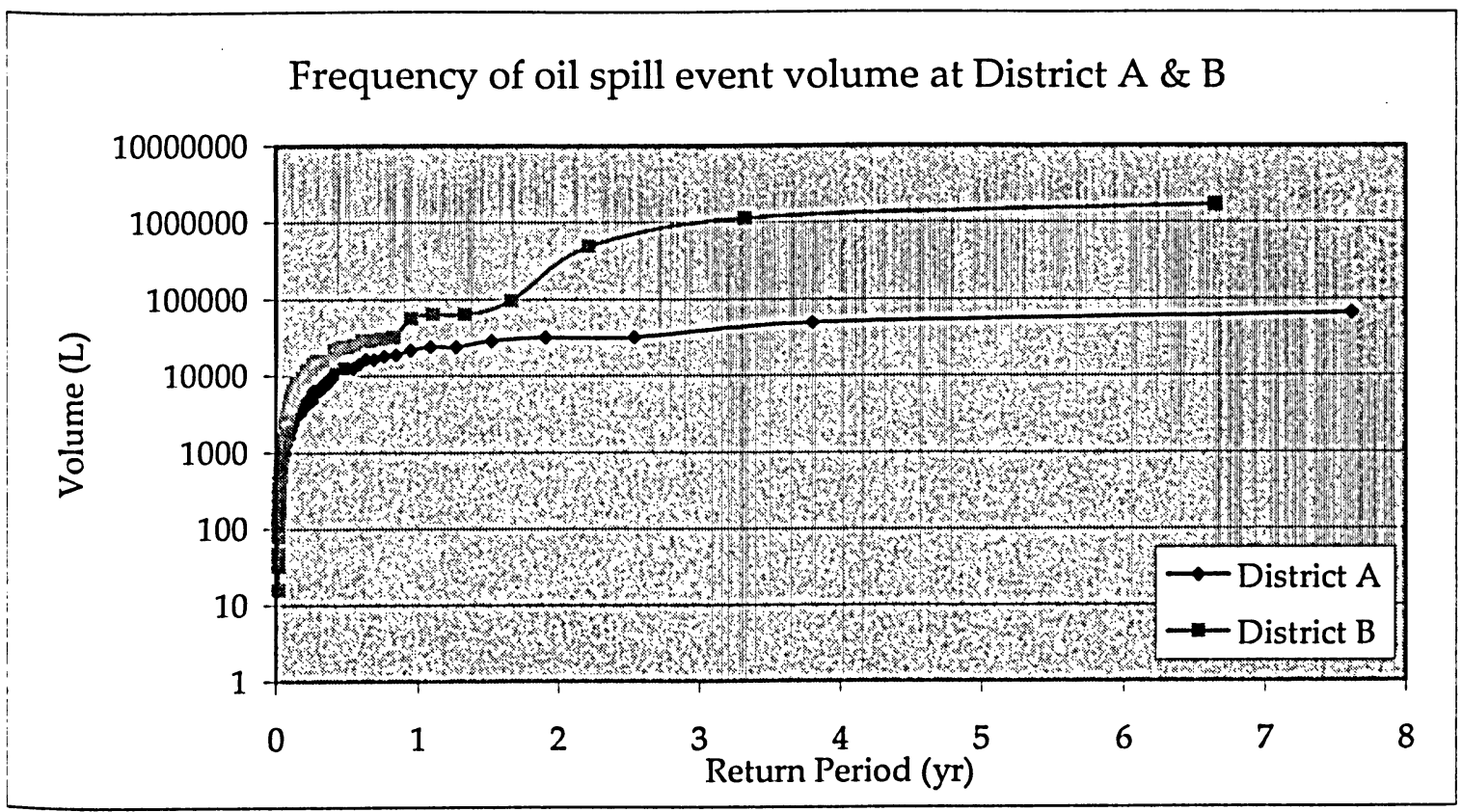

Figure 25: District A \& B: Frequency of oil spill event volume

District $B$ : The number of oilfields are greater in District $B$, but oil spill frequency is lower compared to district A. Oil spill events at district A represent $48 \%$ of total oil spill frequency at TTOil, almost half of all oil spills events while district $B$ represent $27 \%$. The remaining $25 \%$ exist at District $C$ which is not considered in the study. An examination of Figure 25 indicates that oil spill volume is higher in District B. This suggests that given the lower frequency and higher volume, single oil spill events generally involve higher volumes. In District B, small and medium oil spills make up $64 \%$ of all spills, while those that are large or greater account for $36 \%$. Compared to District A, $77 \%$ of oil spills are small and medium in size and only $23 \%$ are large or greater in volume, a substantial difference between the two districts. Therefore, given the higher frequency 
of oil spills at greater volumes at District $B$, the return period for oil spills is $13 \%$ higher for oil spills $>10,000$ liters compared to District A. Oil spills greater than 10,000 liters occur on average 4 times per year. The return period for catastrophic events is low. However, given the entire oil spill dataset, three catastrophic events occurred over the eight year period, two of which were in District $B$, each measuring over one million liters.

Two interesting observations between the two districts are, firstly, a full dataset is not available for District B as 1995 data are not available, and secondly, only in district A $43 \%$ of all spills occurred in the last four years of the eight year study period, therefore fewer oil spills occurred since the installment of improved environmental management practices. District B, 70\% of the total frequency of oil spill events actually occurred in the last fours years 1999-2002. Perhaps this percentage is skewed because 1995 data is unavailable, however, because the percentage is fairly high, it may be fair to say oil spills pose a greater pollution risk in recent years in District B, compared to previous years. While in District A, it may also be fair to say that oil spill events are less of a pollution risk in recent years, compared to previous years.

\subsubsection{Frequency of oil spill events due to leaks and corrosion}

District A: Corrosion and leaks account for $24 \%$ and $29 \%$ of all oil spill events respectively, $83 \%$ of which occurred as a result of pipeline disruptions. The frequency of oil spill events for these two reasons is significant, and therefore it is important to understand the relative oil spill volume contribution in order to prepare for future incidents. In Figure 26, oil spills from leaks appear to occur in higher volumes, however, the return period for oil spills from corrosion and leaks are highest for spills less than 1000 liters. These oil spills occur frequently in a single year. 
Medium oil spills significantly contribute to the cluster of oil spill events illustrated in Figure 26, they account for $56 \%$ of all spills at this district, and on average there are 31 medium oil spills each year from corrosion and leaks combined. Small oil spills represent 25\%; they occur on average 10 times per year. Large oil spills have an annual return period of on average 7 events per year. Two enormous oil spills occurred in eight years and no catastrophic spills have occurred. Thus, this district is more prone to receive small and medium oil spills, and a few large oil spills each year from corrosion and leaks.

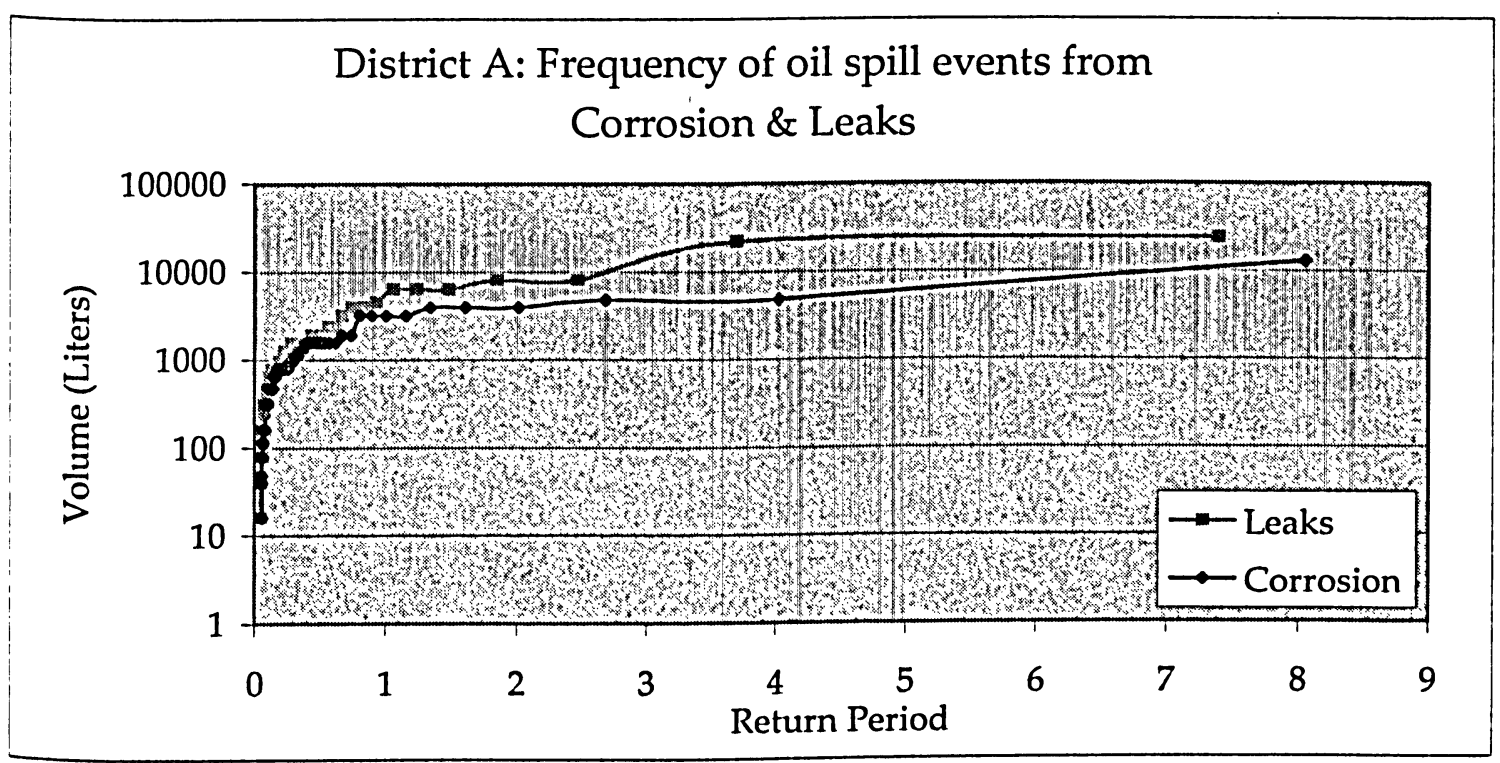

Figure 26: District A: Frequency of oil spill events - Corrosion \& Leaks

District B: Like district A, corrosion and leaks represent a significant portion of oil spill frequency and volume at District B, 36\% combined. Another major reason for oil spills are classified as "unknown". These events account for $29 \%$ of oil spill events at this district. This could be due to poor oil spill reporting, or at the time of the incident report, the actual reason for the event was unknown. Oil spills from leaks/corrosion and unknown reasons exhibit a similar frequency of oil spill volume as indicated in Figure 27. In terms of annual averages, the return period is approximately 3 small spills, 18 
medium, 8 large and 2 enormous oil spills every year from leak/corrosion and unknown reasons. An interesting point to note is that, $75 \%$ of oil spills from leaks and corrosion are from pipelines, suggesting that the pipeline infrastructure at district $B$ like district $A$, are both in need of immediate improved preventative maintenance. Given that medium and large oil spills have a higher return period in district $B$, and there is evidence of infrequent but skewed enormous and catastrophic oil spill events, further action in the form of structural and non structural controls are required at this district. These measures are discussed in the next section.

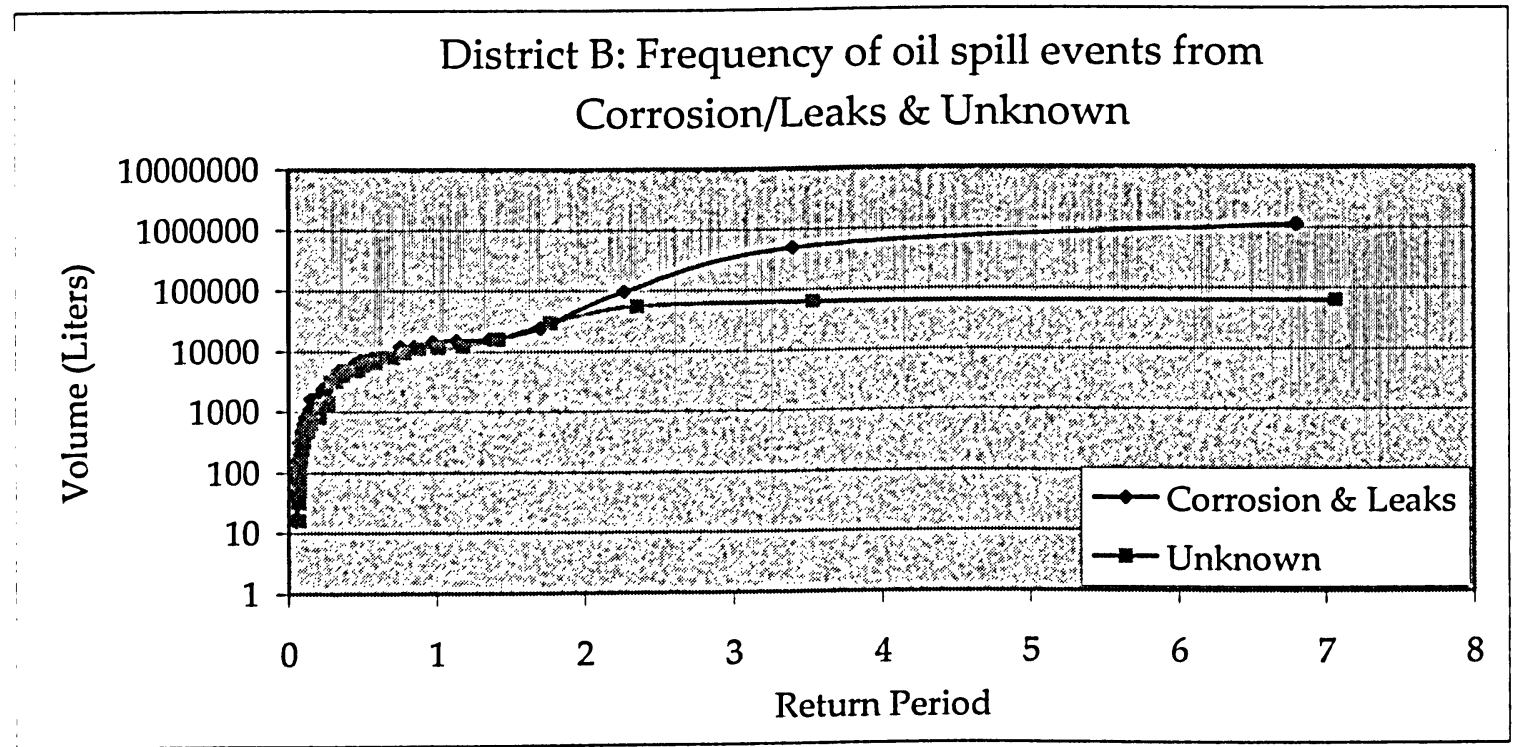

Figure 27: District B: Frequency of oil spill events - Corrosion\& Leaks/Unknown 


\subsubsection{Application of Ontario's "Flood Management Approach"}

During the period 1950-1985, severe flooding in Ontario resulted in hundreds of flood reports; the damage caused by some of the most severe floods resulted in more than $\$ 85$ million spent on floods, and in some instance lives lost. Hurricane Hazel for example took 86 lives and cost millions of dollars in damage. Conservation authorities responded with over $\$ 400$ million in floodplain management to minimize or eliminate the negative impacts of floods. As it turned out, as the population increased, there was a growing demand for houses, many of which were built or being built in flood prone areas. Development, therefore, was the major stimulus for flood damage. On March $31^{\text {st }}$ 1978, the Canada/Ontario Flood Damage Reduction Program Agreement was signed and enforced. The purpose of the agreement was to identify flood risk areas, reduce flood damage and risk of loss of life, by discouraging new developments in these areas, and finding feasible ways of reducing future flood damage to existing development (Environment Canada, 1998).

One method used to reduce flood damage of existing development is called floodproofing. "Floodproofing is any combination of structural or non-structural changes to buildings or utilities, to reduce or eliminate damage caused by floods" (Environment Canada, 1998). Structural measures are "flood damage reduction measures that attempt to keep flood waters away from people and property" (MorrisOswald et al, 1991). They include reservoirs, levees, dams, dikes, drainage systems or river channel improvements (Morris-Oswald et al, 15). Non-structural measures do not involve construction. They include flood insurance, development policy, zoning laws, floodplain regulations, building codes, flood-proofing activities, tax incentives, emergency preparedness, flood forecasting and post-flood recovery (Morris-Oswald et al, 1991). 
The idea of structural controls and non-structural measures used in flood management can be applied to oil spill management, as a method to mitigate oil spill costs, volume, frequency and environmental impacts. There are several structural and non-structural measures that can be applied to oil spills, a combination of the two are required as they work together to foster a mutual benefit. This is further reinforced by Morris-Oswald et al (1991), who states that because flood prevention and reduction are highly complex, it does not only deal with a technical or engineering component, but a multifaceted human dimension as well, hence the reliance on non-structural measures which rely on human values, cognition and behaviour.

The parallel between the flood problem and the oil spill pollution problem is that the concepts used in the flood management approach, can be just as effective for oil spill pollution. Both oil spills and floods are problematic. Floods and oil spills can potentially pose health risks and damage to personal property and the environment. In addition, they both result is significant costs. The concepts of structural and non-structural measures have proven to be effective in flood management. This concept therefore, is applied oil spills Districts A and B at TTOil to illustrate how oil spill clean-up cost can be reduced. Only clean-up cost is used in these analyses as it is available on an event basis. Compensation cost is only available on an annual basis therefore not considered. The next section provides and overview of the types of structural and non-structural controls that can be applied to oil spills at TTOil or similar petroleum industries. 


\subsubsection{Structural and non-structural controls suitable for petroleum industries}

\section{Structural controls (Cost elimination)}

Structural controls enable the elimination of oil spill costs by addressing pollution sources with the use of structural changes. Like floods, which involve structural changes to buildings or utilities to eliminate damage costs, oil spill costs can be similarly eliminated, using structural changes to petroleum facilities and mechanisms.

1. Tanks: Overflows account for a significant volume of oil spills. All tanks should therefore be outfitted with a built containment systems such as bond walls that can contain the maximum capacity of the tank, and the expected annual volume of rainfall. The installation of oil traps to contain the spilled oil within the containment system is useful, to ensure oil is not lost or become a pollution concern if the containment system is connected to a sewer system.

2. Wells: Simple pits can be constructed around wells to ensure spilled oil is caught within the confines of the containment system.

3. Pipelines (pumplines, flowlines, trunklines, gaslines and testline): Instead of temporary clamping which is conducted in many instances, patches can be welded unto broken lines or where feasible, sections of a broken or corroded pipeline should be replaced to reduce the volume and frequency of oil spill leaks.

\section{Non-structural measures (Cost reduction)}

Non-structural measures enable the reduction of oil spill costs by addressing the other sources of the pollution problem, some of which are indirect sources. These measures do not require construction.

1. Non-structural controls can be found in oil spill contingency plans which focus on emergency preparedness. The required resources, contacts, equipment and levels of expertise and response to address emergencies are identified in these 
plans. Many petroleum industries develop contingency plans for each of their facilities or operations.

2. Non-structural measures can also be the recognition of environmental legislation into in-house policies, programs and operations.

3. Non-structural measures are often implemented in employee work ethics, to ensure regular preventative maintenance of equipment and incorporate a culture of environmental stewardship into work practices.

4. At TTOil, oil spill statistics have revealed that a significant amount of oil is lost due to human error, equipment failure or defect. Proper education and training of staff on the importance of preventative maintenance is necessary. For example, to recognize when the equipment is not functioning they way it is intended, and the importance of double checking their work to ensure valves are not left open or closed when they should not be, or to ensure that smaller tanks such as test tanks do not exceed their capacity. This should be addressed in accountability for oil spills, a non-structural measure.

\subsubsection{Application non-structural controls to District A}

In flood damage reduction programs, non-structural measures have been effective in reducing the damage costs caused by floods. To reduce the clean-up costs of oil spills, a similar approach is used. A non-structural measure that may be useful in District A is described to illustrate the utility of this approach. One of the problems observed from year to year is that human error is responsible for many oil spill events. This represents $14 \%$ of the total volume of oil spills in this district over the 8 year study period. Probability is used to illustrate the likelihood of oil spill event clean-up costs, associated with the annual maximum oil spill event volumes. 


\section{Example of a non-structural control}

The recommended non-structural control to mitigate oil spills caused by human error is the implementation of a re-training program for field employees. The purpose of the program is to instill the importance of preventative maintenance of equipment and facilities, environmental liability and accountability for oil spills. A cost of $\$ 2500$ is estimated to provide two Health Safety and Environment (HSE) representatives and one field operations leader, to visit District $A$ to re-train field employees. Two workshops are required; the first session should address preventative maintenance to include an overview of proper field procedures, how to use certain equipment, the common triggers of oil spills, how to prepare and react to emergencies, etc. The second workshop should focus on the accountability for oil lost and damage to the environment. For example, tasks should be logged to ensure routine checks are conducted consistently, and the team leader or supervisor notified when operations are compromised, such as when equipment require repairs or replacements. A corrective action check should be addressed as well, to ensure that reported problems are addressed within a reasonable timeframe.

The following is a list of assumptions made. Similar to the flood management approach, the highest spill event volume caused by human error each year, and their associated clean-up costs at District A, are graphed against the associated probability as shown in Figure 28. The expected annual clean-up costs are determined by integrating the costfrequency curve in Figure 28, over the entire range of probability. To calculate the potential cost saving which is represented by the new cost-frequency curve after nonstructural measures are implemented, the area under the curve calculation is used. 
Calculation of the area under the curve

The area under the cost-frequency curve is calculated using the area of a trapezoid. The difference in area between the curves before and after non-structural or structural controls represents the control benefit.

Assumptions (\$TT)

1. Estimated cost of re-training program: $\$ 2500$

2. Clean-up cost of oil spills/largest spill volume/year: \$5387 (actual value)

3. Clean-up cost is reduced by $50 \%$ with the implementation of non-structural controls

Expected results based on assumptions (\$TT)

1. Expected clean-up cost of oil spills/largest spill volume/year after re-training program is estimated to be $\$ 1027$.

2. Expected clean-up cost savings (control benefit) after non-structural measures are implemented is estimated to be $\$ 1027$ per year. 


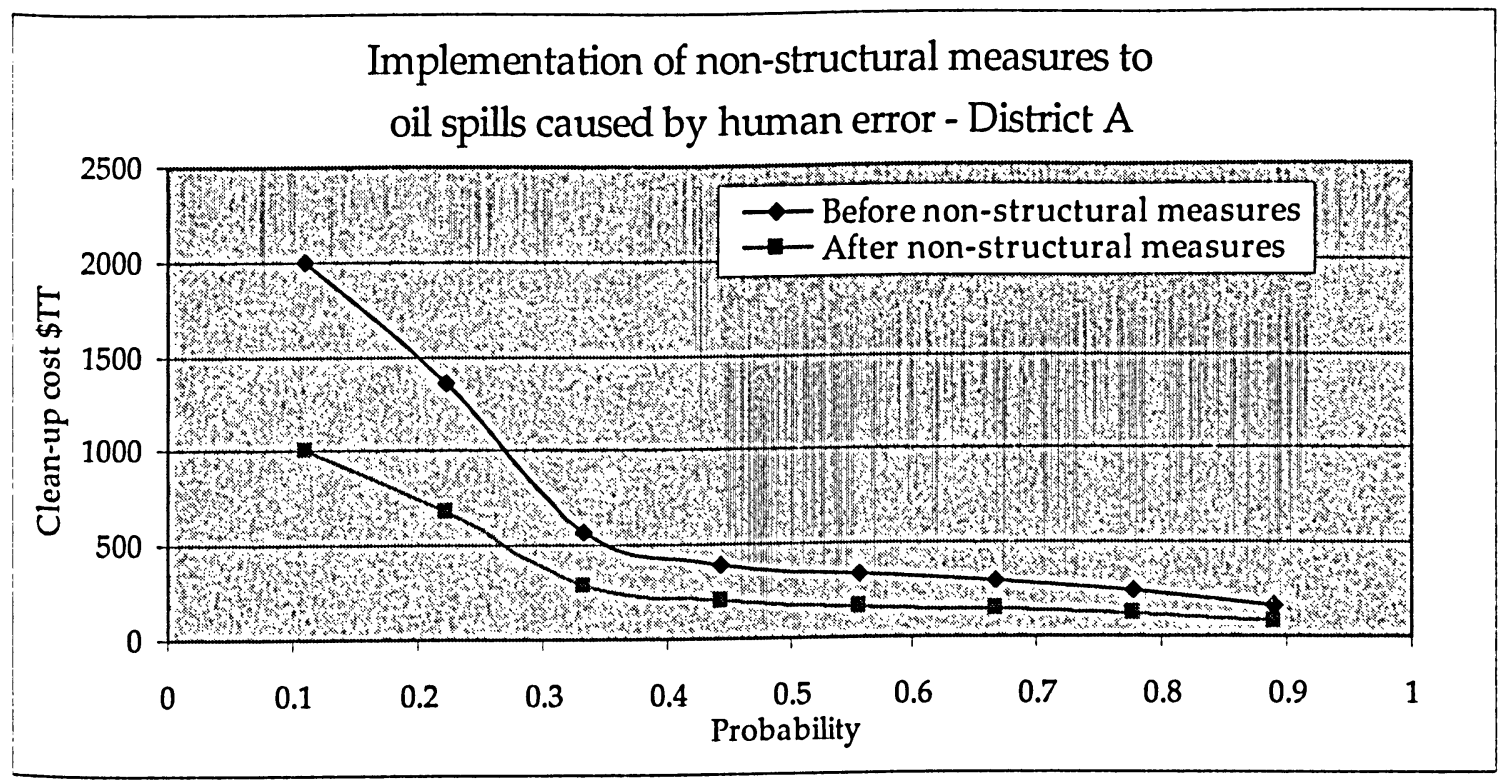

Figure 28. Implementation of non-structural measures to oil spills caused by human error-District A

The graph illustrates the cost of oil spills before the implementation of non-structural measures on the top line; the bottom line (a horizontal shift downwards), represents an assumption that after the re-training program, the oil spill event clean-up cost caused by human error is expected to be reduced by $50 \%$. The control benefit per year is $\$ 1027$ with the implementation of non-structural controls, by end of the second year, the retraining program of $\$ 2500$ would almost pay for itself. This reduction will at least facilitate the cost expended for the training program, thereby, the company benefits financially from the non-structural application, as the amount invested yields an equal saving on oil spill clean-up costs by the end of the second year. The benefit of this nonstructural measure can potentially go beyond mitigating oil spill costs, to also include reduced oil spill volumes, frequencies, and environmental impacts caused by human error. 


\subsubsection{Application structural controls -District $A$}

In flood damage reduction programs, structural measures have been effective in eliminating some or all of the damage costs caused by floods. To reduce the costs of oil spills, a similar approach is used. A structural measure that may be useful in District A is described in order to illustrate the utility of this approach. Given that much of the physical infrastructure of TTOil is aging, resulting in frequent oil spill events, a simple containment system around wells can eliminate future environmental impacts and clean-up cost of oil spills at well sites. In District A, $8 \%$ of oil spill frequency occurs at well sites as a result of leaks, equipment failure, blowout or pressure. Probability is used to illustrate the likelihood of oil spill event clean-up costs, associated with the annual maximum oil spill event volumes. The area under the curve is calculated to determine the control benefit.

\section{Example of a structural control}

To contain spilled oil at well sites, pits with a capacity to contain at least 1500 liters are implemented at all producing wells. These containment systems are necessary and should be implemented as most wells are located in highly rural and vegetative areas, most of which exhibit medium to high environmental sensitivity. The highest volume of oil spills at well sites and their associated costs are selected for each year. The probability of each event versus the event clean-up cost is illustrated in Figure 29, based on the following assumptions.

\section{Assumptions (\$TT)}

1. Estimated cost of building pits around wells: TT $\$ 20,000$.

2. Clean-up cost of oil spills/largest spill volume/year: $\$ 14,153$ (actual value).

3. Assumption that the capacity of the pit can hold 1500 liters of spilled oil. 
Expected results based on assumptions (\$TT)

1. Expected clean-up cost for an oil spills greater than 1500 liters after the oil containment pits are built is $\$ 5420$.

2. Expected clean-up cost savings after structural measures are implemented is $\$ 1200$ per year.

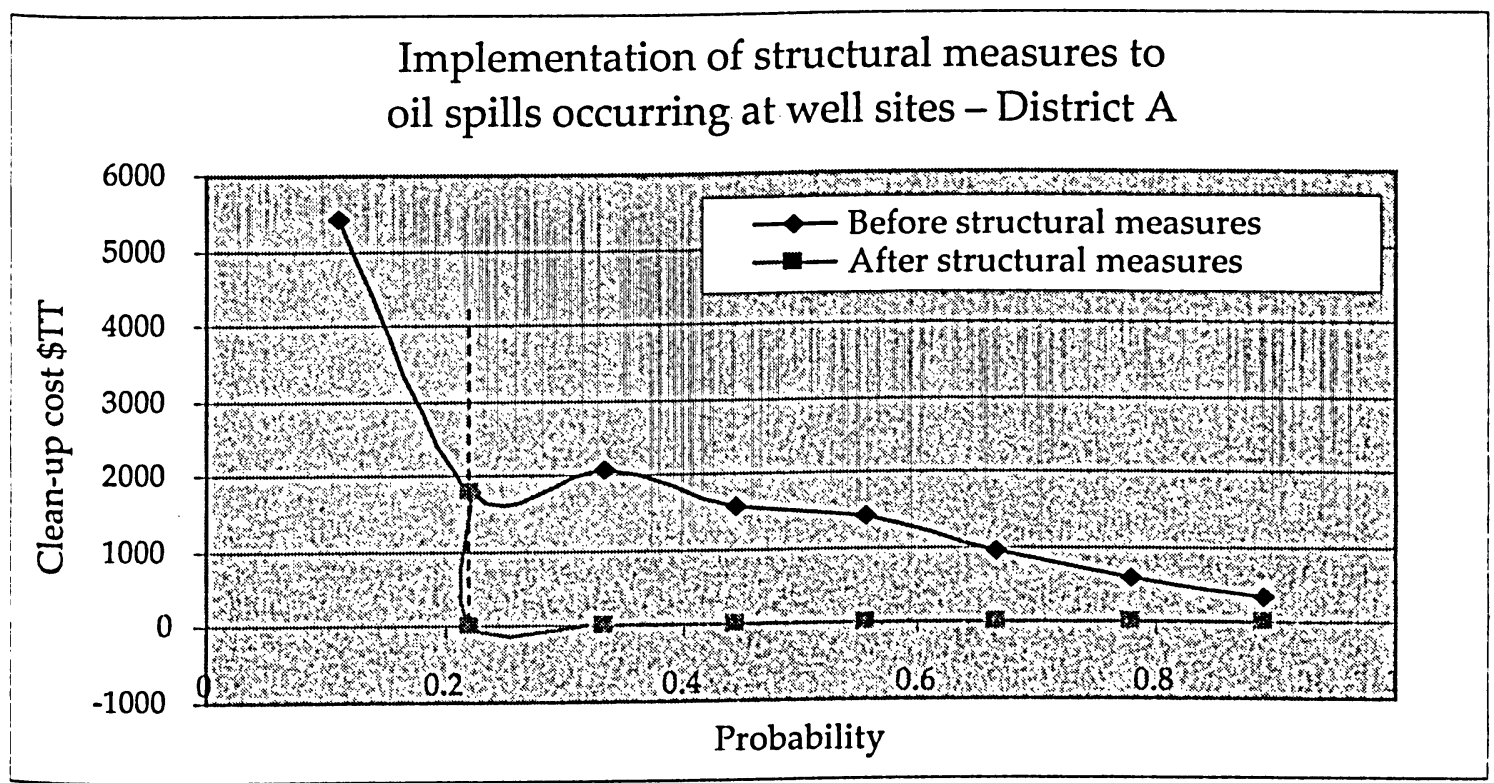

Figure 29: Implementation of structural measures to oil spills occurring at well sites District A

The first line illustrates the original oil spill clean-up cost from the largest oil spills at well sites each year. With the implementation of pits with a capacity to hold 1500 liters of oil, oil spill clean-up cost for spills less than 1500 liters are eliminated, as they are contained in the oil pit. This is highlighted by the vertical cut at a probability of approximately 0.23 . Oil spills greater than 1500 liters cannot be completely contained as their volume exceeds the capacity of containment system. Oil spill clean-up cost would begin to accumulate for oil spills greater than the capacity of the pit. The annual cost saving for oil spills at well sites is $\$ 1,200 /$ year. Given that the cost of constructing these pits is $\$ 20,000$, within approximately 17 years, the amount of money invested to build 
the containment systems will equal the clean-up cost saved. Within the $17^{\text {th }}$ year, the company will begin to see the financial benefit of the implementation of the oil pits beyond the amount invested to build them. Like non-structural measures, structural controls can also potentially reduce the environmental impacts of oil spills, as a portion of the oil spill volume is contained rather than dispersed or released into adjacent environments.

\subsubsection{Application non-structural controls - District B}

The structural and non-structural controls identified in District $\mathrm{A}$ can be equally applied to District B, as similar causes and reasons for oil spills exist in all three oilfield districts. However, upon review of oil spill statistics at district B in detail, additional structural and non-structural control measures will be suggested for district B. Graphs are not constructed in this section, as the financial benefit is apparent from Figures 28 and 29.

\section{Example of a non-structural control}

Since $29 \%$ of oil spills at district B are unknown, non-structural measures to promote improved environmental management should be introduced to incorporate oil spill accountability and reporting measures. These measures should facilitate employee training on how to define oil spill reasons, causes, estimate volume, and the clean-up cost of oil spills, in order to provide thorough oil spills reports. This initiative would not only foster improved and consistent oil spill reporting, but also provide more detailed information to allow for immediate and adequate clean-up and preventative measures. A GPS system would also be helpful to identify exact locations of oil spills, as vague information about the location of a spill site is provided in oil spill reports. 


\subsubsection{Application structural controls - District B}

Structural measures to mitigate pipeline oil spills are a necessity at TTOil as 60\% of 1440 records are a result of pipeline problems. In District $B$, approximately $50 \%$ of all oil spills are caused by pipelines. These statistics represent a significant problem at not only district B but also the entire pipeline operation of TTOil. The cost to repair or replace lines or sections of pipelines will be expensive, especially since corrosion is the primary problem. However, pipeline oil spills need to be addressed immediately in order to rectify the pollution problem, as it will only worsen with time.

\section{Example of a structural control}

Corroded pipelines lead to leaks therefore corrosion and leaks of pipelines refer in most instances to the same single problem. In most oil spill reports they are classified as two separate reasons, but leaks and corrosion with respect to pipelines are one and the same problem. Replacing or repairing corroded pipelines are expensive and to cover the cost of miles of pipelines is a significant undertaking, the cost cannot be accurately estimated. However, TTOil has recently developed a pipeline infrastructure program to replace old pipelines. Their plan occurs in installments, and covers a twenty-year period which began in 1999. Oil spill statistics since 1999 have revealed no distinct pattern in oil spill reduction from pipelines at district $B$ or any other district. The reduction in oil spills from pipelines appears to be very gradual as the proposed plan for pipeline infrastructure improvements occur over a large time frame. Future studies may be able to better detect the benefit of the pipeline infrastructure improvements. 


\subsection{Probability of Clean-up cost}

The probability of clean-up cost refers to the cost incurred for materials, equipment, labour and contractors to clean-up oil spills. The probability of this cost is examined in districts A and B. Eight data points are graphed, each data point represents the approximate highest spill event volume at that year, and its associated oil spill clean-up cost for the period 1995-2002. This information is useful because it provides a measure of the extent of clean-up cost that can be expected. The only limitation of these data is that the highest volume does not always correspond to the highest cost in all circumstances. Therefore, the clean-up costs illustrated in Figure 30, is not representative of the highest costs incurred in clean-up efforts. Nonetheless, the concept is illustrated and described to showcase the value and usefulness of this information in oil spill management. A stronger correlation does exist between clean-up costs and certain oil spill causes or reasons, but these costs are not considered in this section.

\subsubsection{Probability of clean-up cost at district A}

Clean-up costs in the range of $\$ 7,000-\$ 15,000$ have the highest probability. The medium range is $\$ 30,000-\$ 40,000$, but the probability is not significant. The highest cost of $\$ 175,791$ occurred in 1998 for an oil spill measuring 31,796 liters however, the probability of the company incurring this type of cost is very low. If a strong correlation existed between oil spill cost and volume it would be beneficial to know the range of cost associated with different sizes of oil spills in District A. This knowledge could foster increase planning and mobilization of resources to mitigate the negative impacts of oil spills, particularly those measuring very high volumes in an effort to reduce the clean-up and other associated costs. However, in summary it appears that the highest probability exists for oil spills measuring between TT\$7,000-15,000. 


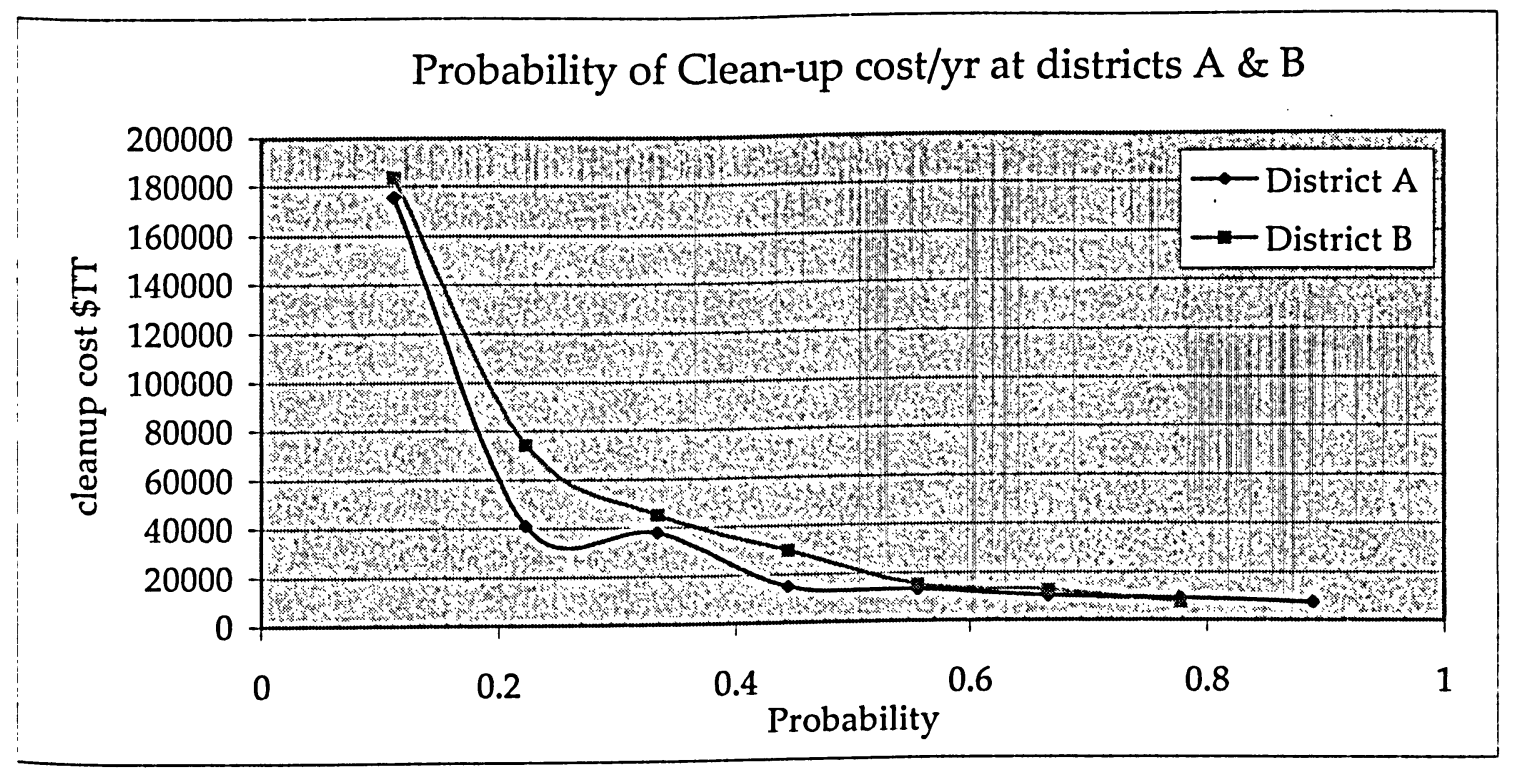

Figure 30. Probability of clean-up cost/yr at districts A \& B - Damage Frequency

\subsubsection{Probability of clean-up cost at district B}

The clean-up cost of oil spills in District B appears to be a little higher than in District A, as the medium probability applies to clean-up cost in the range of $\$ 30,000-\$ 75,000$. However, like district $A$, the highest probability exist for clean-up costs in the range of $\$ 7,000-\$ 15,000$. The lowest probability is also similar to that of District $A$, except that $\$ 183,888$ was spent for an oil spill just over 1 million liters which occurred in 1999. In summary, between the two districts, the general trend and expectation are for clean-up costs in range of $\$ 7,000-\$ 15,000$, as these costs have the highest probability. 


\subsection{CONCLUSIONS AND RECOMMENDATIONS}

The scope of the study outlined three specific tasks which were implemented to meet the study's objectives. The functions of each component of the proposed oil spill management planning framework were developed in the first task. In the second task, statistical analyses were performed using oil spill data from TTOil, to understand the factors that influence and characterize oil spill volume, frequency and cost. The third task focused on oil spills at the oilfield district level, to understand oil spill volume and expectations, and apply flood management concepts to reduce oil spill costs. These tasks were successfully performed, and the following conclusions are made. There are two conclusions, one based on the oil spill management planning framework, and the other based on the case study findings.

\section{CONCLUSIONS}

The proposed oil spill management planning framework

1. The proposed oil spill management planning framework is a new contribution to oil spill research as it has not been formally developed. The individual components of the framework are typically addressed individually, not collectively. They include an oil spill characterization, oil spill prevention, oil spill control, oil spill clean-up and an economic evaluation of oil spill costs.

2. The framework is a systematic approach to oil spill management. There are five consecutive steps. Each step relies on information from the previous one to make decisions and mobilize resources and activities for oil spill management.

3. The framework isn't geared towards all pollution concerns of petroleum industries. It focuses on oil spill pollution issues alone through a series of steps. 
4. The framework is designed to target two pollution control needs - oil spill management and oil spill mitigation or elimination

5. The application of the "Flood Management Approach" is a new dimension of oil spill management. This approach has not been previously utilized in oil spill management. It incorporates the use of probability of the frequency of cost, rather than the use of averages which are traditionally used in industries.

6. Although the oil spill management planning framework is designed for oil spills, it is versatile enough that the concepts can be easily adapted by other types of pollution, such as chemical spills.

7. The economic evaluation process in particular, is commonly addressed as a separate issue within the petroleum sector. However, the framework includes this component as a key feature in oil spill management planning. As efforts to reduce costs can directly relate to a subsequent reduction in oil spill volume, frequency and potential adverse environmental impacts.

8. The utility of two components of the framework are demonstrated in the case study, the oil spill characterization and economic evaluation. Using statistical analyses, useful information for future oil spill management was derived. For example, the primary cause and reasons for oil spills, the frequency, volume and costs of oil spills were all identified. This information in turn, can be used to develop solutions in the form of structural controls and non-structural controls, to improve oil spill management. 


\section{Case study}

\section{Oil spill characterization}

1. Oil spill reporting is not consistent and documentation of oil spill reports is generally poor. Oil spill reporting in District A is slightly better, but can be improved to include information about the environmental impacts, follow up action, final volume and final costs. Only initial estimates are documented.

2. Oil spills from Exploration and Production operations or upstream processes occur in significant volumes and frequencies. This operation is a major contributor to the oil spill pollution problem in the petroleum industry.

3. The five primary reasons for oil spills by frequency are: leaks, corrosion, unknown, human error and overflow. The five primary reasons for oil spills by volume are: overflows, leaks, corrosion, unknown and human error.

4. Pipeline oil spills account for $60 \%$ of the total oil spill frequency and $52 \%$ of the total oil spill volume. The aging pipeline infrastructure has resulted in significant corroded and leaking pipelines. Oil spills from this group represent the primary source of the oil spill pollution problem at TTOil.

5. Oil spills due to leaks and corrosion have resulted in $37 \%$ of oil spill volume and $53 \%$ of oil spill frequency. They are also closely related to the pipeline infrastructure problem; $75 \%$ of oil spill volume and $69 \%$ of oil spill frequency are from corroded or leaking pipelines

6. The five primary causes of oil spills in order of their frequency are flowlines, pumplines, tanks, valves and trunklines. In order of their volume are tanks, flowlines, pumplines, trunklines and valves.

7. Two groups of oil spills are predominant at TTOil, medium size oil spills in the range of 100-1000 liters are the most common occurrence; they account for $52 \%$. This is followed by large events measuring 1000-10000 liters, which account for $23 \%$ of oil spill events. 
8. Oil spill events under 16 liters are not reported. The reason in the researcher's opinion is that small oil spills are not considered important or harmful. However, if these spills occur in large numbers, they may be a pollution concern.

9. Many other factors apart from the causes and reasons mentioned earlier influence oil spills. An indirect factor is rainfall, whereby over $50 \%$ of oil spill volume and frequency occur in the wet season. As per appendix $C$, there is a very strong correlation between oil spill frequency and rainfall.

10. There is little or no correlation between oil spill volume/frequency with oil production. Oil spill volume and frequency data quality were the limiting factors. This was a negative finding in the study. If a correlation did exist, it would have been possible to estimate or forecast future oil spill volumes and frequencies with confidence. This information would be useful to not only TTOil, but also to polluters conducting similar upstream processes. Among the benefits, it would foster improved oil spill management and emergency preparedness.

11. The return period for oil spills at district $A$ is greatest for small and medium oil spills (77\%), while large oil spills have a lower return period, they occur a few times per year or less. The larger the event the lower the frequency. At district $B$, the return period for oil spills is also high for small and medium oil spill (64\%), however, large or bigger oil spills have a higher return period than district A. At District $B$, large or greater oil spills occur $36 \%$ of the times, this translates into on average, 20 events per year

12. Within the eight-year period, oil spill frequency is lower at district A from 19992002, while at district B, oil spill frequency is higher for the same period. The reduction in district $\mathrm{A}$ is most likely due to the improved environmental management practices of ISO 14001, which began in 1999. 


\section{Economic Evaluation}

1. The factors that significantly influence oil spill clean-up costs are oil spill frequency, the number of pollution claims filed, and rainfall.

2. The factors which influence compensation costs are oil spill volume and the number of pollution claims filed.

3. The factors that influence the total cost (clean-up + compensation costs) are oil spill frequency, and the number of pollution claims filed

4. Oil spill clean-up cost by reason in order of the highest cost are from corrosion, leaks, unknown, overflow and human error

5. Oil spill clean-up cost by cause in order of the highest cost are from pumplines, trunklines, flowlines, tanks and valves

6. The clean-up cost is not available for each oil spill event; this needs to be improved by all oilfield districts. In addition, the final clean-up cost is not provided for all oil spill events only initial estimates, this has resulted in underestimated costs for many oil spill events.

7. Compensation cost is not recorded for each oil spill event, nor is the oil spill database and compensation database connected. It would beneficial to the company to have this information combined, in order to fully understand the relationship between the oil spill event and the total cost incurred.

8. On an annual basis, oil spills clean-up costs are lower from 1999 to 2002 compared to the first four years 1995-1998. This could be attributed to the decrease of clean-up cost at District A from 1999-2002.

9. Application of the structural and non-structural concepts derived from the Flood Management Approach to the oil spill data of Districts A and B, has resulted in a reduction in oil spill clean-up costs.

10. Structural controls have the potential to eliminate oil spill costs. At District $A$, the oil spill clean-up cost benefit is $\$ 1200$ per year. 
11. Non-Structural controls have the potential to reduce oil spill costs. At District A, the oil spill clean-up cost benefit is estimated at $\$ 1027$ per year.

12. Non-structural controls combined with structural controls are necessary at TTOil, some of which have already begun at District A, particularly the nonstructural controls through oil spill contingency planning and the adoption of ISO 14001 international standard. A combination of the two types of controls is necessary to successfully reduce in oil spill volume, frequency and costs.

13. An examination of the probability of the clean-up costs at districts A and B, found that the highest probability exist for oil spills costing $\$ 7000-\$ 15000$ for oil spill clean-up at both districts. District B showed an overall higher probability for slightly higher oil spill clean-up costs. 


\section{RECOMMENDATIONS}

Upon completion of this study there are several recommendations that can be made to improve oil spill management within the petroleum sector and in particular, at TTOil.

1. The oil spill management framework should be adopted by petroleum industries, as it organizes and contains information pertinent to understanding oil spill characteristics and factors that influence and mitigate oil spill events and costs. This knowledge can be mobilized into appropriate resources that directly target the sources of the pollution. This could enable a reduction or elimination of oil spill events and costs.

2. Oil spill reporting must be significantly improved. It should also be more comprehensive to account for final reports rather than initial estimations, at all oilfield districts. All oil spills should be reported, regardless of its size. Details of environmental impacts must be recorded to contain information such as the exact location of an oil spill, the environmental medium/s affected, and the extent of the damage. Accurate and complete oil spill data is the key to improving oil spill management. For example, a variable that would have been extremely useful in this study is the environmental impacts of oil spills. However, this information was absent from oil spill reports.

3. The problem of an aging pipeline infrastructure for many petroleum industries require greater attention, as the environmental impacts from oil spills from these operations are largely unknown. The research at TTOil proves that this problem is serious and deserves immediate response. Corroded and leaking pipelines need to be replaced, repaired or regularly maintained, in order to mitigate or eliminate future oil spill events

4. Oil spill prevention efforts are necessary at all oilfield districts. The comparison between oilfield districts A \& B in chapter 4 has shown that although slight, the return period for oil spill events at District $A$, is highest for small to medium oil 
spills, rather than larger and more destructive events which are more common at District B. In addition, the cost of oil spills at District A appears to be slightly less that District B. Perhaps this can be attributed to the improved oil spill prevention efforts made to District A. Similar efforts are required in Districts B and C.

5. The applications of structural and non-structural controls are incredibly useful concepts, and should be employed throughout petroleum operations to include upstream and downstream operations. These concepts are shown to be effective in eliminating or mitigating oil spill costs in chapter 4, section 4.2.

6. A very effective tool for understanding oil spill spatial distribution and potential impacts is a Geographical Information System (GIS). It can map oil spill hot spots against various environmental layers to understand, deduce or infer the types of environmental impacts that have occurred, or could occur in the future. This information would add another dimension to oil spill management, that is, the environmental impacts of oil spills.

7. Should there be a stronger correlation between oil production and oil spill volume and frequency, it would be possible to forecast future oil spill events and costs. This information can be used develop oil spill management planning initiatives.

8. Oil spill controls are showed to be effective in reducing or eliminating oil spill costs, and can potentially reduce oil spill volume, frequency and environmental impacts. Therefore, they should be implemented at all petroleum facilities. At TTOil for example, not all facilities or mechanisms were equally outfitted with these controls, this needs to be improved.

9. An oil spill prevention suitability matrix should be developed by petroleum industries, to list the most appropriate and effective oil spill prevention efforts suitable for their facilities and operations. Prevention method selection should also focus on the environments in which their operations are based. 
10. A suitability matrix which defines the clean-up procedures best suited for the environment affected and circumstances at oil spill sites, is a useful tool. It ensures that oil spill clean-up is effective in minimizing adverse environmental impacts and costs, while maximizing oil spill recovery.

11. A suitability matrix which defines the procedures for oil spill control is a useful tool. It identifies the best control measures for various facilities and operations within the petroleum industry.

12. Oil spill costs reported should be a true reflection of the costs associated with the oil spill events. In many instances at TTOil, the costs of oil spill events were underestimated or not reported. It therefore becomes difficult to measure the true costs of oil spills without proper documentation.

13. Oil spill prevention efforts need to be improved for land-based oil spills within the petroleum industry. It sets out the policies and programs which facilitate the activities, roles, knowledge, work ethic and above all, the pollution needs of an organization. Fostering an environmentally conscious work ethic and culture in an organization, can minimize the oil spill pollution problem.

14. Selecting the appropriate technique or tool for the appropriate environment is extremely important, as the wrong tool or technique can worsen the environmental impact and inflate the costs associated with the spill.

15. A proactive approach to oil spill management planning should be a key function of petroleum industries. This would enable a reduction in oil spill frequency, volume and costs. Traditionally, their response has been reactionary. 


\section{LIST OF REFERENCES}

Breuel,A. ed. 1981. Oil Spill Clean-up and Protection Techniques for Shorelines and Marshlands. New Jersey: Noyes Data Corporation.

Canada. Environment Canada. 1998. Summary of Spill Events in Canada 1984-1995. Ottawa: Environmental Emergencies Program.

Canada. Canadian Petroleum Association. 1989. Oil Spill Preparedness in the Upstream Petroleum Industry. Calgary: IPAC.

Canada. Environment Canada. 1998. Floodproofing: Protect your home against flooding. Alberta: Canada-Alberta Flood Damage Reduction Program.

Etkin, Dragmar Schmidt, and Jeff Welch. eds. 1997. Oil Spill Intelligence Report, International Oil Spill Database: Trends in Oil Spill Volumes and Frequency. Proc. of 1977 International Oil Spill Conference. Massachusetts: USA.

Etkin, Dagmar Schmidt. Estimating cleanup costs for oil spills. Proc. of the 1999 International Oil Spill Conference. \#168. Arlington, Massachusetts: USA.

Lentz, Sally Ann, and Fred Felleman. eds. 2003. Oil spill prevention: A proactive Approach. Proc. of 2003 International Oil Spill Conference. API Publications and Materials. Washington: USA,

Fingas, Merv. 2001. The Basics of Oil Spill Clean-up. Second Ed. Lewis Publishers, Florida: USA.

Fingas, Mervin. et al. 1978. The Basics of Oil Spill Clean-up; with particular reference to Southern Canada. Environmental Emergency Branch or Environment Canada. Quebec: Canada.

International Tanker Owners Pollution Federation Limited. 2001. The Cost of Oil Spills. On-line. Internet. Available: http://www.itopf.com/costs.html

International Tanker Owners Pollution Federation Limited. 2001. Contingency Planning. On-line. Internet. Available: http://itopf.com/contplan.html 
International Petroleum Industry Environmental Conservation Association. 2000. $\underline{A}$ Guide to Contingency Planning for oil spills on Water. $2^{\text {nd }}$ ed. 2 March. London: United Kingdom

Li, James. 2002. Spill Management for the Toronto AOC: The City of Toronto Study. Ryerson University. Toronto: Ontario, Canada

Li, James. 1991. Comprehensive Urban Runoff Control Planning. PHD Thesis, University of Toronto.

Morris-Oswald, Slobodan, P. Simonovic and John. Sinclair. 1991. Efforts in Flood Damage Reduction in the red river basin - Practical Considerations. Natural Resource Institute, University of Manitoba. Winnipeg: Manitoba

Nansingh, Permanand., and Shari Jurawan. 1999. "Environmental Sensitivity of a Tropical Coastline (Trinidad, West Indies) to Oil Spills." Spill Science \& Technology Bulletin. 5.2: 161-172.

Olsson., Eric H. The Oil Spill Triangle: A Prevention Tool. Proc. of the 1997 International Oil Spill Conference. Seattle, Washington: USA.

Owens, E.H., E. Taylor, R, Marty and D.I. Little. An Inland oil spill response manual to minimize adverse environmental impacts. Proc. of the 1993 International Oil Spill Conference on Prevention, Preparedness and Response. Washington, DC: Woodward-Clyde Consultants.

TTOil. 2001. The ISO 14001 Project. On-line. Intranet: Available: http://corpweb/hseweb/ISO14001/MainISO1400.htm

TTOil. 2003. The ISO 14001 Environmental Management System for District A Exploration \& Production Division of TTOil. On-Line. Intranet: Available: http://corpweb/hseweb/ISO14001/MainISO1400.htm

Steen, Alexis., Robert. Pond, David. Salt, Michael. deBettencourt, Michael. Julian and Thomas Liebert. eds. 2003. Global Challenges To Preparedness and Response Regimes. Proc. of 2003 International Oil Spill Conference. Washington: USA. Washington: API Publications and Materials. 
Torling, Gustav, and Jonas, Fejes. 1995. Geographic Information System (GIS) For Impact Assessment, Ecology Sound Measures and Documentation of Oil Spills. Proc. of 2003 International Oil Spill Conference. Karlstad: Sweden.

Tourism and Industrial Development of Trinidad and Tobago (TIDCO). 2001. About Trindad and Tobago - Georgraphy On-Line. Available: http://www.visittnt.com/General/about/geography.html

Trinidad. TTOil. 1993. Guidelines for the Clean-up of Oil Spills in Exploration and Production Operational Areas. Port of Spain

Trinidad. TTOil. 2002. Legal Registry. Environmental Management System. Legal Department.

Trinidad. TTOil. 2003. The ISO 14001 Environmental Management System for District A Exploration and Production Division of TTOil. Department of Health, Safety, Environment and Quality.

Trindad. TTOil. 2003. Oil Spill Contingency Plan for District A - Exploration and Production. Department of Health, Safety, Environment and Quality.

Trindad. TTOil. 2003. Oil Spill Contingency Plan for District B - Exploration and Production. Department of Health, Safety, Environment and Quality.

Trinidad. 2001. Ministry of Energy and Energy Industries. National Oil Spill Contingency Plan - First Draft. Port-of-Spain

Trinidad. TTOil. 2003. Oil spill pollution dataset 1995-2002. Department of Health, Safety, Environment and Quality.

Trinidad. 2003. Water and Sewage Authority. Daily Rainfall Data 1995-2002: Rain Gauges 3.9, 4.01, 5.9, 7.1, 8.25. Port-of-Spain.

Trindad. TTOil. 2003. Oil production reports. Exploration and Production Department

Shell Canada. 2002. ISO 14001. On-line. Internet. Available: http://www.shellcanada.ca/code/values/ISO14001.html 
United States. U.S. Environmental Protection Agency. 2001. Oil Program: Types of Refined Petroleum Products. On-line. Internet. Available: http://www.epa.gov/oilspill/refined.htm

United States Environmental Protection Agency. 2001. Oil Program: Response Techniques. On-line. Internet. Available: www.epa.gov./cgi-bin/epaprintonly.cgi.

United States Environmental Protection Agency. 1999. Understanding oil spills and oil spill response. Washington: Oil Program Center.

United States Coast Guard. 2001. Risk Assessment for the Coast Guard's Oil Spill Prevention, Preparedness, And Response Program (OSPPR) Phase I: Concept Development, Risk Characterization, and Issue Identification. Potomac Management Group (PMG).

United States Environmental Protection Agency. 1997. Oil Pollution Prevention: NonTransportation Related Onshore Facilities Rule. 40 CFR Part 112.

United States. National Ocean Service. 1999. Oil Spill Response Options in Tropical Areas. New York: Office of Response \& Restoration. National Ocean Service, United States Coast Guard.

Zhen, Qiaohua. 1998. Evaluation of Oil Water Separators in Removing Hydrocarbon Contaminants in Stormwater. (Undergraduate Thesis, Ryerson University. Toronto, Ontario. 


\section{Oleophilic surface skimmers}

Also known as sorbent surface skimmers, these uses a surface such as a disc, drum, belt, brush or rope to which oil can adhere to and be removed from the water surface.

Disc

Works best with light crude oil and suited to working with waves and among weeds or debris. Disadvantage is the recovery rate is slow, not very useful in the removal of light fuels or heavy oils

\section{Drum}

Works well with fuels and light crude, but ineffective with removing heavy oils. Drums are made from steel or proprietary polymer

\section{Belt}

Works best with heavier crudes, tar balls and heavy oils. These function by lifting oil up from the water surface to a recovery well. An inverted belt skimmer carries the oil under the water and is subsequently removed from the belt by scrapers and rollers after the belt returns to a selected position at the bottom of the skimmer.

\section{Brush}

Works well with heavier oils but not effective for fuels and light crudes. Use tufts of plastic attached to drums or chains to recover the oil from the water. The oil is then removed from the brushes by wedge-shaped scrapers.

Rope

Works best with medium viscosity oils and useful for picking up debris and working in ice-laden waters. Oil is removed from the water surface with an oleophilic rope made of polymer or polypropylene. The skimmers, depending on the size, have an either long or short rope that hangs down to the water surface from a suspended skimmer body 


\section{Weir skimmers}

Weir skimmers are a major group of skimmers that use gravity to drain the oil from the surface of the water into submerged holding tank. Weir skimmers consist of a weir or dam, a holding tank and a connection to an external or internal pump to remove the oil. It works best in clam, protected water.

Disadvantages: Tendency to rock back and forth in choppy water, sucking in air above the slick and water below, thus reducing the amount of oil recovered. Do not work well in ice and debris or in rough waters. Not useful in collecting very heavy oils or tar balls.

Advantages: Economical, Larger capacities. Can be built into booms to recover lighter crudes, this has been proven to moderately improve the success of oil recovery

\section{Suction or vacuum skimmers}

This oil recovery technique uses a vacuum or slight differential in pressure to remove oil from water surface. The skimmer is a small floating head connected to an external vacuum truck. This skimmer sits on the water and uses an external vacuum truck for oil intake/suction into a holding tank. This system works best in calm waters with thick slicks and no debris.

Disadvantages: Easily clogged with debris that stops the oil flow, which can also damage the pump. Also experience rocking in choppy waters allowing water and air intake rather than oil. Works only with light to medium oils

Advantages: Most economical of all skimmers. Compact and shallow draft enables good oil recovery performance in shallow waters and confined spaces.

\section{Elevating skimmers}

Elevating skimmers use conveyors to lift oil from the water surface into a recovery area. A conveyor belt with ridges is adjusted to the top of the water layer and the oil is moved up the recovery device on a moving belt. The oil is removed from the conveyor by gravity.

Advantage: This technique is ideal for the removal of medium to heavy oils in calm waters

Disadvantage: This technique is not applicable in rough waters or in waters with large pieces of debris

5. Submersion skimmers 
Submersion skimmer uses a belt or inclined plate to force the oil beneath the surface. The belt or plane forces the oil downward toward a collection well where it is removed from the belt by a scraper or by gravity.

Advantages: This skimmer moves faster than other skimmers, thus can cover a larger area making it more useful for larger spills. Suitable for the removal of light oils with low viscosity and thin oil slicks. Larger than other types of skimmers and are usually mounted on a powered vessel

Disadvantage: Not suitable for spill sites with debris. Not suitable for use in shallow waters

\section{Vortex or centrifugal skimmers}

Vortex or Centrifugal skimmers make use of the density between the oil and water to separate them. This is followed by the removal of the oil. A water vortex is created to draw the oil into a collection area where it is rotated in a centrifuge, using either the force of the water itself or an external power source. The oil is therefore forces to the center by heavier water and pumped from the chamber.

Disadvantage: Not suitable for spill sites with debris. They take in a lot of water (Fingas, 2001) 
Appendix B: Types of habitats in Trinidad

Table 8: Habitat Descriptions

\begin{tabular}{ll}
\hline Habitat & Description \\
\hline Agricultural & Land habitat under crop cultivation, usually one plant \\
Fields & species (primarily sugarcane) or livestock production \\
\hline Rice Fields & Rice plantings together with various species of freshwater \\
& plants, which trap sediments and stabilize fields from \\
& erosion. They are productive wetlands ecosystems, important \\
to migrating waterfowl and diverse resident fauna.
\end{tabular}


grasses, which trap sediments and stabilize the mash from erosion. Marshes usually range from areas that are completely exposed to areas that are forested and/or shoreline areas. The distribution of plants and animals in coastal salt marshes is associated with the tide levels. Plants are salt tolerant

Freshwater Highly productive ecosystems that provide habitat for a wide Swamps mosaic of plant and animal species. They consist of ridges and depressions (lagoons), the ridges are colonized with stands of mixed swamps wood and the depressions with herbaceous vegetation which trap sediments and stabilize the marsh from erosion

Source: TTOil, 1993 
Appendix C: Additional graphs and charts

C-1: Annual oil spill distribution

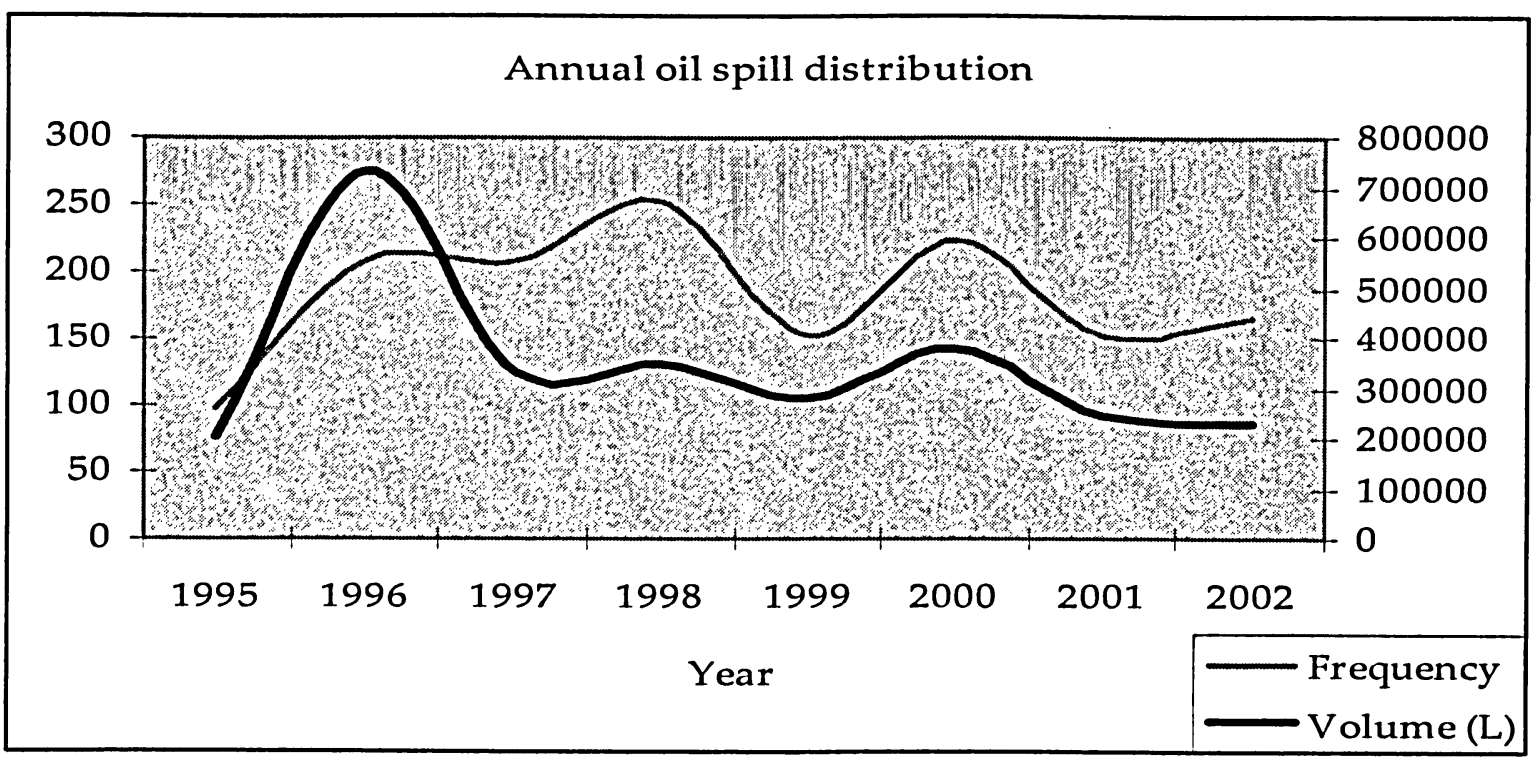

C-2: Environmental mediums impacts by oil spills (1995-2002)

Environmental mediums impacted by oil spills (1995-2002)

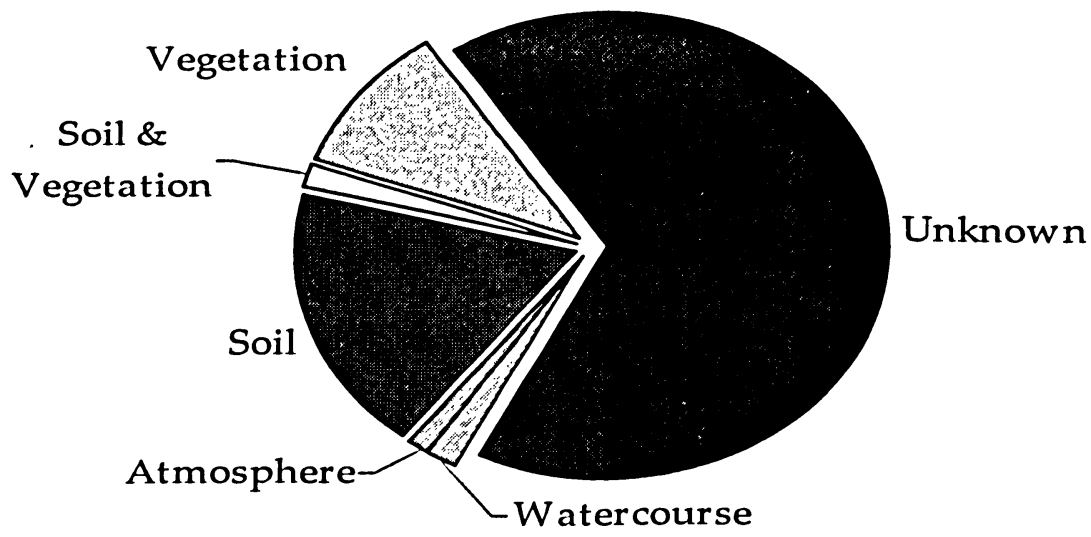


Appendix D: Correlation results from 3 regression models

Pearson r-value: The most widely used type of correlation coefficient is Pearson $r$ also called linear or product-moment correlation. Correlation coefficients can range from 1.00 to +1.00 . The value of -1.00 represents a perfect negative correlation while a value of +1.00 represents a perfect positive correlation. A value of 0.00 represents a lack of correlation.

\begin{tabular}{|c|c|c|c|c|}
\hline \multirow[t]{2}{*}{$\begin{array}{l}\text { Dependent } \\
\text { Variables }\end{array}$} & $\begin{array}{c}\text { Model } 1 \\
\text { Multiple } \\
\text { Linear Form }\end{array}$ & $\begin{array}{c}\text { Model } 2 \\
\text { Semi-Log } \\
\text { Transform } \\
\text { Form }\end{array}$ & $\begin{array}{c}\text { Model } 3 \\
\text { Log-Log } \\
\text { Transform } \\
\text { Form }\end{array}$ & \multirow[t]{2}{*}{$\begin{array}{l}\text { Best } \\
\text { Model } \\
\text { (Predicting } \\
\text { Dependent } \\
\text { Variable) }\end{array}$} \\
\hline & $\begin{array}{c}\text { Strong } \\
\text { Predictors } \\
\end{array}$ & $\begin{array}{c}\text { Strong } \\
\text { Predictors } \\
\end{array}$ & $\begin{array}{c}\text { Strong } \\
\text { Predictors } \\
\end{array}$ & \\
\hline Yr - Volume & $\begin{array}{l}\text { \#Claims: } 0.76 \\
\text { Frequency: } 0.52 \\
\text { Production:0.39 }\end{array}$ & $\begin{array}{l}\text { \# Claims: } 0.58 \\
\text { Frequency: } \\
0.53 \\
\text { No correlation } \\
\text { with } \\
\text { production }\end{array}$ & $\begin{array}{l}\text { Frequency: } \\
0.67 \\
\text { Total Cost: } \\
0.63 \\
\text { No correlation } \\
\text { with } \\
\text { production }\end{array}$ & 1 \\
\hline $\mathrm{Yr}$ - Frequency & $\begin{array}{l}\text { \#Claims: } 0.84 \\
\text { Avg Rain: } 0.80 \\
\text { Avg Wet: } 0.75 \\
\text { No correlation } \\
\text { with } \\
\text { production }\end{array}$ & $\begin{array}{l}\text { \# Claims: } 0.84 \\
\text { Avg Rain: } 0.80 \\
\text { Avg wet: } 0.74 \\
\text { No correlation } \\
\text { with } \\
\text { production }\end{array}$ & $\begin{array}{l}\text { \# Claims: } 0.90 \\
\text { Avg Rain: } 0.84 \\
\text { Avg wet: } 0.81 \\
\text { No correlation } \\
\text { with } \\
\text { production }\end{array}$ & 3 or 1 \\
\hline $\begin{array}{l}\mathrm{Yr}-\text { Cost A } \\
\text { (Clean-up) }\end{array}$ & $\begin{array}{l}\text { Frequency: } 0.74 \\
\text { \# Claims: } 0.62 \\
\text { Avg Rain: } 0.58 \\
\text { Avg wet: } 0.47 \\
\text { No correlation } \\
\text { with volume }\end{array}$ & $\begin{array}{l}\text { Frequency: } \\
0.69 \\
\text { \# Claims: } 0.54 \\
\text { Avg Rain: } 0.54 \\
\text { Avg wet: } 0.43 \\
\text { No correlation } \\
\text { with volume }\end{array}$ & $\begin{array}{l}\text { Frequency: } \\
0.81 \\
\# \text { Claims: } 0.71 \\
\text { Avg Rain: } 0.60 \\
\text { Avg wet: } 0.55 \\
\text { No correlation } \\
\text { with volume }\end{array}$ & 3 \\
\hline $\begin{array}{l}\mathrm{Yr}-\text { Cost } \mathrm{B} \\
\text { (Compensation) }\end{array}$ & $\begin{array}{l}\text { Volume: } 0.88 \\
\text { \#Claims: } 0.57 \\
\text { No correlation }\end{array}$ & $\begin{array}{l}\text { Volume: } 0.81 \\
\text { \# Claims: } 0.40 \\
\text { No correlation }\end{array}$ & $\begin{array}{l}\text { Volume: } 0.74 \\
\text { No correlation } \\
\text { with } \\
\end{array}$ & 1 \\
\hline
\end{tabular}




\begin{tabular}{|c|c|c|c|c|}
\hline - & with frequency & $\begin{array}{l}\text { with } \\
\text { frequency }\end{array}$ & frequency & \\
\hline $\begin{array}{l}\text { Yr - Total Cost } \\
(\text { Cost } A+B)\end{array}$ & $\begin{array}{l}\text { Cost A: } 0.89 \\
\text { \#Claims: } 0.87 \\
\text { Frequency: } 0.85 \\
\text { Avg Rain: } 0.57 \\
\text { Volume: } 0.50\end{array}$ & $\begin{array}{l}\text { Cost A: } 0.92 \\
\text { Frequency: } \\
0.82 \\
\text { \# Claims: } 0.74 \\
\text { Volume: } 0.58 \\
\text { Avg Rain: } 0.56\end{array}$ & $\begin{array}{l}\text { Cost A: } 0.91 \\
\text { Frequency: } \\
0.86 \\
\text { \# Claims: } 0.80 \\
\text { Volume: } 0.60 \\
\text { Avg Rain: } 0.60\end{array}$ & 3 \\
\hline $\mathrm{Yr}-\#$ Claims & $\begin{array}{l}\text { Frequency: } 0.84 \\
\text { Volume: } 0.76 \\
\text { Avg wet: } 0.66 \\
\text { Avg Rain: } 0.53\end{array}$ & $\begin{array}{l}\text { Frequency: } \\
0.86 \\
\text { Volume: } 0.82 \\
\text { Avg wet: } 0.68 \\
\text { Avg Rain: } 0.60\end{array}$ & $\begin{array}{l}\text { Frequency: } \\
0.90 \\
\text { Avg wet: } 0.88 \\
\text { Avg Rain: } 0.79 \\
\text { Volume: } 0.67\end{array}$ & 1 \\
\hline Mo - Volume & Frequency: 0.51 & $\begin{array}{l}\text { Frequency: } \\
0.45\end{array}$ & $\begin{array}{l}\text { Frequency: } \\
0.57\end{array}$ & 1 or 3 \\
\hline Mo-Frequency & Avg Rain: 0.33 & Cost A: 0.55 & Cost A: 0.54 & 2 or 3 \\
\hline Mo-Cost A & None & None & $\begin{array}{l}\text { Frequency: } \\
0.54 \\
\text { Volume: } 0.38\end{array}$ & 3 \\
\hline
\end{tabular}

Best "overall" regression model for predicting the dependant variables is MODEL 1 or 3 


\begin{tabular}{l|l}
\hline BOPD & Barrels of oil per day \\
\hline Flowlines & $\begin{array}{l}\text { Refers to pipelines, usually 2" or 3". Its function is to } \\
\text { transport crude oil from the wellhead (pumping jacks at } \\
\text { oilfields) to the Gathering Station. }\end{array}$ \\
\hline Gaslines & $\begin{array}{l}\text { Refers to the pipeline that transfers gas from the Separator } \\
\text { in the Gathering Stations to the Gas Compressors, and from } \\
\text { the compressors to the sales (external) or to be reused for } \\
\text { injection in wells for secondary recovery. The gas line only } \\
\text { transports gas. }\end{array}$ \\
\hline Leaks & $\begin{array}{l}\text { Central area in the field where there are tanks for collecting } \\
\text { the crude oil produced by the wells. From here the crude oil } \\
\text { is pumped to the Tank Farm (storage tanks) }\end{array}$ \\
\hline Manifold & $\begin{array}{l}\text { When oil spills are reported, if a description about a leak is } \\
\text { provided but no reason why the leak occurred, that reason } \\
\text { is categorized as a leak. It could be that the leak occurred } \\
\text { because a line was corroded, therefore the term "leaks", } \\
\text { could also in some instances overlap with corrosion as the } \\
\text { reason for an oil spill event. }\end{array}$ \\
\hline Oilfields & $\begin{array}{l}\text { This is the structure where all wells flow into at the } \\
\text { gathering station. There is a test manifold as well as a bulk } \\
\text { manifold. All wells would normally go the bulk manifold } \\
\text { and then to the bulk tanks to be pumped away. Wells } \\
\text { would be put to the test manifold only when it needs to be } \\
\text { tested to determine its production for the day. Then it } \\
\text { would flow through the testline to the test tank. }\end{array}$ \\
\hline $\begin{array}{l}\text { A region comprised of several wells and other upstream } \\
\text { processes. One or more towns can combine to form one } \\
\text { oilfield. Some oilfields are larger or more productive. }\end{array}$ \\
$\begin{array}{l}\text { An oil field district is comprised of several oilfields. No one } \\
\text { oilfield district is equal, each vary in the number of oilfield } \\
\text { and size of geographic area. Oilfield districts are grouped } \\
\text { according to the geographic region in which they are } \\
\text { located. Three oil field districts exist at TTOil. } \\
1 . \text { District A: 7 oilfields }\end{array}$ \\
\hline 2. District B: 10 oilfields
\end{tabular}




\begin{tabular}{|c|c|}
\hline & 3. District C: 7 oilfields \\
\hline Other (Cause) & $\begin{array}{l}\text { Is a group of spills I grouped into a single category, it } \\
\text { includes repairs along pipelines were lines are changed, } \\
\text { cleaning of the pits or pumps, problems at the site of a well } \\
\text { related to the union or casing mechanisms for example, or } \\
\text { when a vague description is provided that cannot } \\
\text { definitively place the event it in a well defined category }\end{array}$ \\
\hline Other (Reason) & $\begin{array}{l}\text { Refers to fires, repairs, power outages, natural disasters, } \\
\text { cleaning of containment systems, or debris hindering } \\
\text { equipment from working }\end{array}$ \\
\hline Pearson r-value & $\begin{array}{l}\text { The most widely used type of correlation coefficient is } \\
\text { Pearson } r \text { also called linear or product-moment correlation. } \\
\text { Correlation coefficients can range from }-1.00 \text { to }+1.00 \text {. The } \\
\text { value of }-1.00 \text { represents a perfect negative correlation } \\
\text { while a value of }+1.00 \text { represents a perfect positive } \\
\text { correlation. A value of } 0.00 \text { represents a lack of correlation }\end{array}$ \\
\hline Pipelines & $\begin{array}{l}\text { Refers to any size of circular metal lines used for } \\
\text { transporting crude oil, water or any other type of liquid or } \\
\text { gas. Types of pipelines are pumplines, flowlines, trunklines, } \\
\text { gaslines and testlines }\end{array}$ \\
\hline Pumplines & $\begin{array}{l}\text { Refers to pipelines, usually } 4^{\prime \prime} \text { to } 6^{\prime \prime} \text { or bigger in } \\
\text { circumference. Its function is to transport crude oil from the } \\
\text { Gathering Station to the Tank Farm }\end{array}$ \\
\hline Separator & $\begin{array}{l}\text { Vessel that is found in the Gathering Station. This vessel } \\
\text { separates the oil from the gas. Only used for wells that are } \\
\text { flowing naturally, or being produced by gas lifting } \\
\text { methods. Not used for pumping wells. }\end{array}$ \\
\hline Stuffing Box & $\begin{array}{l}\text { This is a cylindrical shaped part that is found where the } \\
\text { sucker rods enter a wellhead that has a pumping jack. This } \\
\text { is really a lubricating box that keeps the sucker rods moist } \\
\text { to prevent damage to the rod itself. Inside the box are } \\
\text { rubbers that cling to the rods, to prevent leakage to the } \\
\text { environment. The in and out movement of the rods into the } \\
\text { well brings crude droplets to the rubbers to keep them } \\
\text { moist and lubricated }\end{array}$ \\
\hline Testlines & $\begin{array}{l}\text { The flowline transports crude from the wellhead to the } \\
\text { manifold at the gathering station. From the manifold are } \\
\text { two lines that can be used to transport oil to the tanks. One } \\
\text { is the bulk line and the other is the testline. The testline is }\end{array}$ \\
\hline
\end{tabular}




\begin{tabular}{l|l}
\hline & $\begin{array}{l}\text { used to test each individual well to a tank to determine } \\
\text { what it produces for the day. }\end{array}$ \\
\hline Trunklines & $\begin{array}{l}\text { Refers to the pipeline, usually } 8^{\prime \prime}, 10^{\prime \prime} 12^{\prime \prime} \text { or bigger in } \\
\text { circumference. Its function is to transport crude oil from the } \\
\text { Tank Farm to the refinery. }\end{array}$ \\
\hline TT\$ & $\begin{array}{l}\text { Trinidad and Tobago dollar. On average the exchange rate } \\
\text { is TT } \$ 5 \text { for } \$ 1 C D N\end{array}$ \\
\hline Unknown & $\begin{array}{l}\text { Refers to reports that do not define the reason for an oil } \\
\text { spill event or the description is too vague to discern a } \\
\text { definitive reason }\end{array}$ \\
\hline Upstream & $\begin{array}{l}\text { The exploration and production activities of a petroleum } \\
\text { company. It includes field operations such as drilling and } \\
\text { pumping oil or transporting oil from its source to storage } \\
\text { areas such as tank farms. It does not include any refinery } \\
\text { processes. }\end{array}$ \\
\hline
\end{tabular}


Appendix F: Description of oil spill data

The oil spill data set used in this research is from a variety of sources and have resulted in inconsistent units of data. Inadequacies in oil spill reporting at some oilfields have resulted in incoherent reported data leading to inferior data quality at some districts. These two limitations in data quality have resulted in some instances inconclusive results as many initial assumptions could not be proven. The following table illustrates the units of data that were available for the oil spill analyses conducted in the case study.

Units of available oil spill data

\begin{tabular}{|c|c|c|}
\hline $\begin{array}{l}\text { Daily, Monthly } \& \mathrm{j} \\
\text { Annually }\end{array}$ & $\begin{array}{l}\text { Monthly \& } \\
\text { Annually }\end{array}$ & 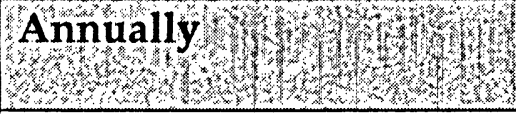 \\
\hline $\begin{array}{l}\text {-Volume } \\
\text {-Frequency } \\
\text {-Cause } \\
\text {-Reason } \\
\text {-Clean-up cost } \\
\text {-Rainfall } \\
\text {-Oilfields }\end{array}$ & $\begin{array}{l}\text {-Oil Production } \\
\text {-Average rainfall } \\
\text {-Average rainfall in wet } \\
\text { season } \\
\text {-Average rainfall in dry } \\
\text { season }\end{array}$ & $\begin{array}{l}\text {-Compensation (Cost } \\
\text { paid to external parties) } \\
\text {-Claims (Number of } \\
\text { pollution claims filed) } \\
\text {-Total Cost }\end{array}$ \\
\hline
\end{tabular}

Volume: Is the volume of oil spilled in liters and is available per oil spill event. The volume of spilled oil reported is the final estimated volume. Limitation: Upon completion of final clean-up efforts the actual volume could be higher or lower, final reports are not documented or required therefore, the true volume may not be known for all oil spill events. Secondly, oil spills reports from one oilfield to the next remain inconsistent. 
Frequency: The frequency is number of times an oil spill event occurs. Daily oil spill event data is available in most instances. Limitation: All oil spills are not reported as some oilfield districts report significantly higher numbers of oil spills although they have fewer oilfields. Since most oil spills are influenced by an aging pipeline infrastructure, the number of oil spills at two of the three oil field districts in particular should be higher. This may be attributed to poor oil spill reporting.

Cause: The cause of an oil spill is one of the factors that directly influence or instigate an oil spill events. There are 12 causes: Leaks, Corrosion, Overflows, Human Error, Equipment failure or defect, Pressure, Tampering, Sand, Blowout, Vandalism, Other and Unknown Causes. Limitation: The unknown cause's represent 23\% of the volume of oil spills and $18 \%$ of the frequency therefore, the cause of these oil spills cannot be determined.

Reason: The reason for an oil spill incident is the medium that defaulted to constitute one of the causes above. There are 14 reasons: Pumplines, Flowlines, Trunklines, Gaslines, Testlines, Valves, Stuffing Box, Well Feature, Manifold, Gathering Station, Separator, Tanks, Other and Unknown reasons. Limitation: No apparent limitation is obvious however inferior oil spill reporting remains a concern.

Clean-up cost: Clean-up cost as the name suggests is the cost to clean-up oil spills and remediate a contaminated site. It includes the cost of labour, contractors, materials and equipment. Limitation: The initial clean-up cost of an oil spill events is provided, follow-up clean-up activities and remediation efforts are not recorded in the oil spill reports in all instances, therefore some clean-up costs may be underestimated as the final cost is not reported. 
Rainfall: Rainfall events are incorporated to determine if clean-up and compensation costs are influenced by rainfall on a per spill event basis during the dry and wet season. Correlation between these costs and rainfall can provide insightful information about whether costs are inflated during wet weather events. Knowing this information in advance could foster improved oil spill prevention efforts. Limitation: The smallest unit of data available is on a daily basis using the "tipping bucket" rainfall measuring gauge.

Oilfields: Three oil field districts house 35 oilfields. Within each oilfield there are a number of wells, each well site with their own capacity of oil reserve. An oil spill event that occurs at or near a well is reported and documented by the oilfield name. Limitation: It has been noted from observation of the oil spill dataset that district $\mathrm{A}$ exhibits the most complete and consistent oil spill reports compared to the other two districts.

Oil Production: Oil production as the name states refers to the volume of oil pumped from a well site. The volume of oil pumped varies at each oilfield depending on the capacity of oil reserve at that well site and the required quantity needed for that day. Limitation: Daily production data is not available for each oilfield only the monthly data is available.

Compensation: Compensation represents the cost incurred from paying external parties for oil spilled into their property. Many well sites for example are located near farmland or urban areas, large oil spills or spills mobilized by the transport of water during rainfall events can negatively impact adjacent crops, livestock or watercourses. Limitation: This data is best available on an annual basis. Pollution claims as they are called, when filed are not payable on the same day therefore, it could take a few days to a few months for a financial assessment to occur. Once the assessment is made and 
external parties are paid, the payment does not correspond to the oil spill event, instead it is filed under the name of the external party and recorded in financial statements on the day the compensation was paid rather than the oil spill event date. This limits the use of the data to only an annual cost as inconsistencies in documentation limit its use on a daily or monthly basis

Pollution claims: Pollution claims refer to the number of claims filed per day by external parties. Limitation: The same limitation described under compensation.

Total cost: The total cost refers to the clean-up costs plus compensation. Limitation: This information is only available on an annual basis. Although clean-up cost is available for each event compensation cost is not, therefore only annual values are available for analysis.

Legal penalties: Legal penalties issued for oil spill pollution events are not available therefore not considered in this study. Thus the cost represented in this study refers primarily to clean-up cost in most instances as this information is available on a per event basis and to a lesser extent, compensation costs. 